\title{
THERMAL PERFORMANCE OF POLY ALPHA OLEFIN NANOFLUID WITH SPHERICAL AND NON-SPHERICAL NANOPARTICLES
}

\author{
A Thesis \\ by \\ CHAN HYUN PARK
}

\begin{abstract}
Submitted to the Office of Graduate Studies of
Texas A\&M University

in partial fulfillment of the requirements for the degree of

MASTER OF SCIENCE
\end{abstract}

May 2011

Major Subject: Mechanical Engineering 


\title{
THERMAL PERFORMANCE OF POLY ALPHA OLEFIN NANOFLUID WITH SPHERICAL AND NON-SPHERICAL NANOPARTICLES
}

\author{
A Thesis \\ by \\ CHAN HYUN PARK
}

\begin{abstract}
Submitted to the Office of Graduate Studies of Texas A\&M University in partial fulfillment of the requirements for the degree of

MASTER OF SCIENCE
\end{abstract}

Approved by:

Chair of Committee, Jorge L. Alvarado

Committee Members, Kalyan Annamalai Karen Vierow

Head of Department, Dennis O’Neal

May 2011

Major Subject: Mechanical Engineering 


\begin{abstract}
Thermal Performance of Poly Alpha Olefin Nanofluid with Spherical and Non-spherical Nanoparticles. (May 2011)

Chan Hyun Park, B.S., Hanyang University, Korea

Chair of Advisory Committee: Dr. Jorge L. Alvarado
\end{abstract}

Research on nanofluids has been undertaken for several years because of the reported enhancements of thermal properties such as thermal conductivity and enhanced heat transfer performance in laminar flow. Nanofluid is the fluid where nanoparticles are dispersed in a base fluid. Thermal conductivity and viscosity are considered to be the most prominent factors in the efficient use of nanofluids. A change in thermal conductivity and viscosity also changes the convective heat transfer coefficient. Nanoparticles can be metallic or non-metallic and also can have different shapes. In this study, Poly-Alpha-Olefin (PAO) has been used as a base fluid with Alumina $\left(\mathrm{Al}_{2} \mathrm{O}_{3}\right)$ nanoparticles. Poly-Alpha-Olefin is commonly used for engine lubrication in military applications and cooling in electronic and industrial devices. Several nanofluid samples were made by METSS Corp. in Ohio, USA using different dispersants, different base fluids and different morphology of alumina nanoparticles. The mass fraction of nanoparticles is from 2.5 to $20 \%$. The thermal properties of each sample such as thermal conductivity and viscosity have been measured. Thermal conductivity of nanofluids and pure base fluids were both measured and the thermal conductivity enhancement has 
been calculated. Also, the heat transfer coefficient has been determined for laminar flow under constant heat flux conditions.

Results indicate that all the tested nanofluids and base fluid samples show a Newtonian behavior. Among the nanofluid samples, NF-048, which contains nonspherical Alumina nanoparticles exhibits the greatest thermal conductivity enhancement when compared to pure PAO. Heat transfer tests were conducted with pure PAO and NF-048, and an enhancement in convective heat transfer coefficient was observed. The thermal conductivity of NF-048 increases with temperature, which is consistent with heat transfer results. Furthermore, the percentage enhancement in convective heat transfer coefficient was shown to increase non-linearly with the axial distance in the heat transfer section. NF-048 exhibits a lower Re (Reynolds number)*Ra (Rayleigh number) than pure PAO under laminar flow constant heat flux conditions indicating that nanoparticle morphology and composition are the two main factors responsible for convective heat transfer enhancement at low Reynolds number. 
TO MY PARENTS:

FOR THE LOVE, SUPPORT AND SACRIFICE TO MAKE MY DREAM COME TRUE 


\section{ACKNOWLEDGEMENTS}

I would like to thank my committee chair, Dr. Jorge L. Alvarado for his guidance. He has been always cooperative and tried to share his knowledge with me and helped me proceed in the right direction. I also would like to thank my committee members, Dr. Kalyan Annamalai and Dr. Karen Vierow for their support for this thesis.

In addition, I would like to express my gratitude to Dr. Hansoo Lee and other members in Microscopy center at Texas A\&M University for allowing me to use TEM and to Dr. Daniel Shantz in the chemical engineering department for providing a chance to use the Dynamic Light Scattering device. I also would like to thank other research team members: Dr. Hessam Taherian and Guillermo Soriano for helping in the experimental work.

Finally, thanks to my mother and father for their encouragement and love. They have always trusted me and encouraged me to study for higher education. 


\section{NOMENCLATURE}

A

$c_{p}$

$c_{b f}$

$D_{i}$

$D_{t}$

F

$g$

$h(x)$

$i$

$k$

$L$

$\dot{m}$

$N$

$P$

$\dot{q}$

$q_{s}^{\prime \prime}$

$q$

$R$

$R_{c}$
Inner surface area of the copper tube

Specific heat of the fluid

Specific heat of basefluid

Inside diameter of copper tube of heat transfer section

Translational diffusion coefficient

Fraction of D.C. power used to heat fluid in the test section

Gravitational acceleration

Convective heat transfer coefficient at a distance, $x$ from the inlet

Current through the coil

Thermal conductivity of the medium

Effective length of the spindle

Mass flow rate of the fluid in the test section

Rotational speed of the spindle

Perimeter of the copper tube

Rate of heat dissipation

Heat flux applied to the fluid

Magnitude of the scattering wave vector

Total resistance of the coil

Radius of the sample container 


$\begin{array}{ll}R_{s p} & \text { Radius of the spindle } \\ T_{s}(x) & \text { Time } \\ T_{b}(x) & \text { Surface or wall temperature at a distance, } x \text { from the inlet } \\ \Delta T & \text { Temperature difference }\left(=T_{s}(x)-T_{b}(x)\right) \\ T_{b, i} & \text { Fluid bulk temperature at the inlet } \\ T_{b, o} & \text { Fluid bulk temperature at the outlet } \\ \theta & \text { Scattering angle } \\ k_{B} & \text { Boltzmann's constant } \\ x & \text { Axial distance from the inlet of the test section }\end{array}$

\section{Greek symbols}

$\alpha$

$\beta$

$\mu_{n f}$

$\phi$

$\mu_{b}$

$\tau$

$\dot{\gamma}$

$\tau^{\prime}$

$\omega$
Thermal diffusivity of the medium

Thermal expansion coefficient

Effective viscosity of the nanofluid

Particle volume fraction in the dispersion

Viscosity of the base fluid

Decay time

Shear rate

Yield shear stress

Angular speed of the spindle 


$\begin{array}{ll}\mu & \text { Dynamic viscosity } \\ v & \text { Kinematic viscosity } \\ \rho & \text { Density of nanofluid } \\ \rho_{p} & \text { Density of nanoparticle } \\ \rho_{b f} & \text { Density of basefluid }\end{array}$

\section{Dimensionless group}

$\begin{array}{ll}\mathrm{Z}^{+} & \text {Dimensionless axial distance }=x / D_{i} \cdot \operatorname{Re} \cdot \operatorname{Pr} \\ \mathrm{Gr} & \text { Grashof number }=g \beta D_{i}^{3} \Delta T / v^{2} \\ \mathrm{Nu} & \text { Nusselt number }=h \cdot D_{i} / k \\ \mathrm{Pr} & \text { Prandtl number }=\mu \cdot c_{p} / k \\ \mathrm{Re} & \text { Reynolds number }=\rho \cdot v \cdot D_{i} / \mu \\ \mathrm{Pe} & \text { Peclet number }=\operatorname{Re} \cdot \operatorname{Pr} \\ \mathrm{Ra} & \text { Rayleigh number }=G r \cdot \operatorname{Pr}\end{array}$

\section{Subscripts}

$b$

$c$

$f$

$i$

$O$
Bulk

Container

Fluid

Inlet

Outlet 


$\begin{array}{lc}p & \text { Particle } \\ s p & \text { Spindle } \\ s & \text { Surface }\end{array}$

\section{Acronyms}

$\begin{array}{ll}\text { CNT } & \text { Carbon nanotube } \\ \text { DLS } & \text { Dynamic light scattering } \\ \text { MWCNT } & \text { Multi-walled carbon nanotube } \\ \text { NNLS } & \text { Nonnegative least squares method } \\ \text { PAO } & \text { Poly-Alpha-Olefin } \\ \text { SWCNT } & \text { Single-walled carbon nanotube } \\ \text { TEM } & \text { Transmission electron microscopy }\end{array}$




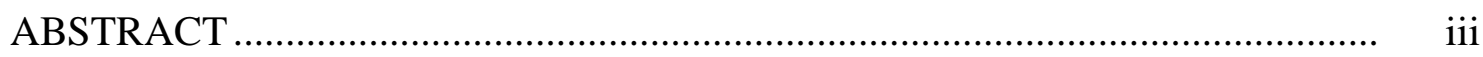

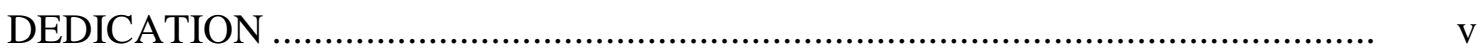

ACKNOWLEDGEMENTS ………………………................................... vi

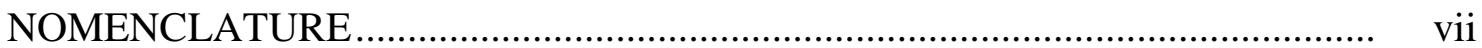

TABLE OF CONTENTS …….......................................................................... xi

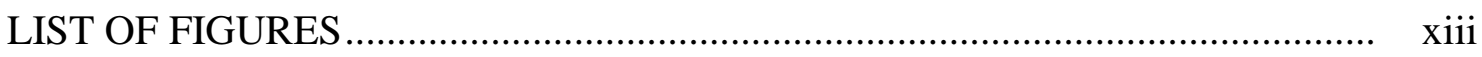

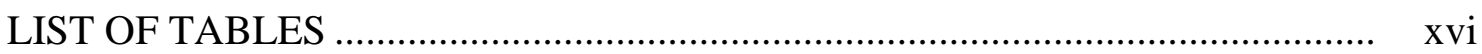

CHAPTER

I INTRODUCTION ....................................................................

II LITERATURE REVIEW .........................................................

2.1 Nanofluids containing $\mathrm{Al}_{2} \mathrm{O}_{3}$ nanoparticles in $\mathrm{PAO}$................ 4

2.2 Nanofluids containing $\mathrm{Al}_{2} \mathrm{O}_{3}$ nanoparticles in different base

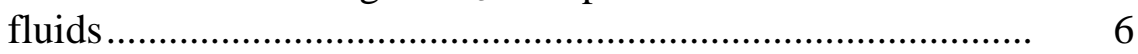

2.3 PAO nanofluids with different nanoparticles........................... 10

2.4 Past research on viscosity of $\mathrm{Al}_{2} \mathrm{O}_{3}$ based PAO nanofluids..... 14

2.5 Past research on thermal conductivity of $\mathrm{Al}_{2} \mathrm{O}_{3}$ based PAO nanofluids ............................................................................ 16

2.6 Past research on convective heat transfer of $\mathrm{Al}_{2} \mathrm{O}_{3}$ based

PAO nanofluid.................................................................... 18

III EXPERIMENTAL DESIGN …………………....................... 20

3.1 Objectives and methodology ……………………………....... 20

3.2 Set-up description................................................................ 22

3.2.1 TEM ……............................................................... 22

3.2.2 Dynamic Light Scattering (DLS)................................... 24

3.2.3 Viscometer .................................................................... 25 
CHAPTER

Page

3.2.4 Thermal conductivity analyzer ................................. 26

3.2.5 Convective heat transfer section ................................ 31

3.2.6 Sample preparation ................................................... 36

3.3 Summary of experiments ........................................... 37

IV RESULTS AND DISCUSSION ............................................ 39

4.1 Imaging data.................................................................. 39

4.1.1 TEM image of NF-046 and NF-048 _......................... 39

4.1.2 Dynamic Light Scattering data of NF-007, 013 and

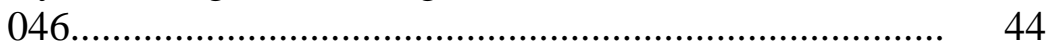

4.2 Viscosity data .......................................................... 62

4.3 Thermal conductivity data............................................... 67

4.4 Convective heat transfer data .......................................... $\quad 70$

V CONCLUSIONS ............................................................. 85

5.1 Imaging conclusions..................................................... 85

5.2 Viscosity conclusions .................................................... 85

5.3 Thermal conductivity conclusions .................................... 86

5.4 Convective heat transfer conclusions ................................. 87

5.5 Recommendations for future work ...................................... 88

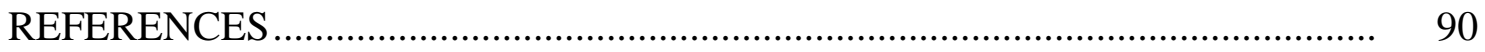

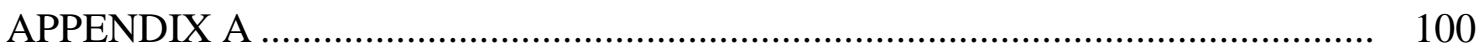

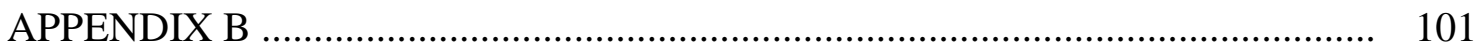

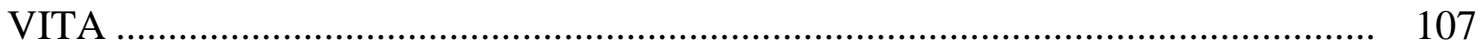




\section{LIST OF FIGURES}

FIGURE $\quad$ Page

1 FEI TECNAI G2 F20 FE-TEM................................. 23

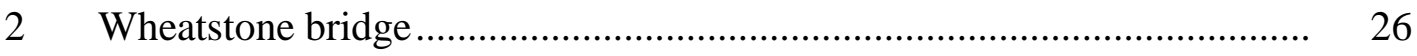

3 Transient Hot Wire (THW) system............................ 29

$4 \quad$ Transient Hot Wire (THW) apparatus............................ 30

$5 \quad$ The trend between supplied voltage and time..................... 31

6 Schematic for convective heat transfer measurement experimental set-up.................................................. 32

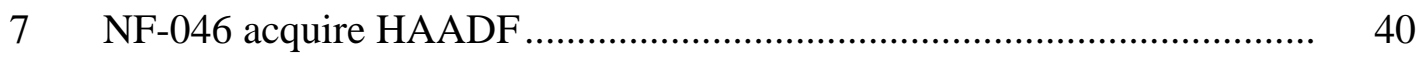

$8 \quad$ NF-048 acquire HAADF .............................................................. 40

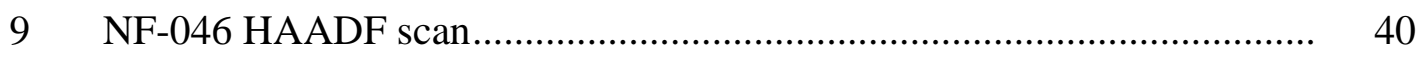

10 NF-048 HAADF scan ................................................................ 41

11 NF-046 drift corrected spectrum profile .......................................... 42

12 NF-048 drift corrected spectrum profile ............................................ 42

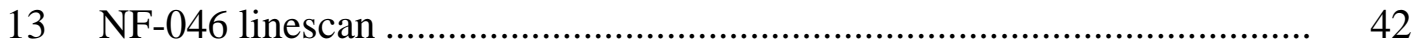

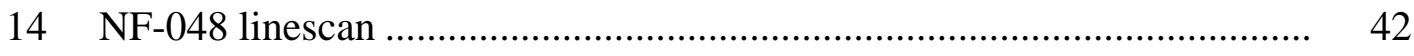

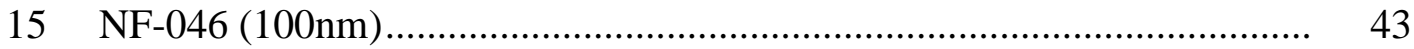

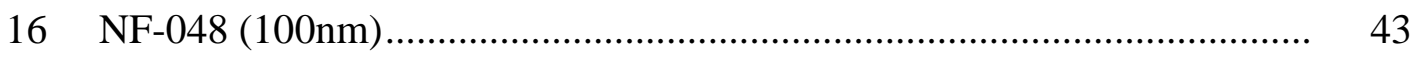

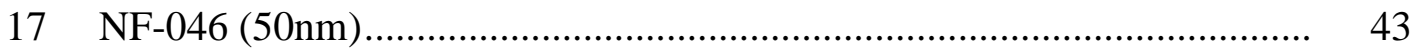

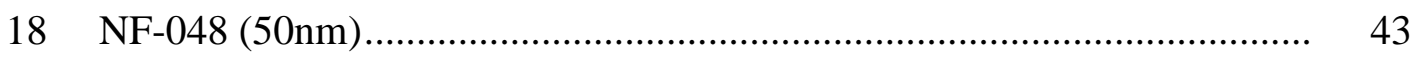

19 DLS test 1 results for NF-007 ........................................................ 45 
FIGURE $\quad$ Page

20 DLS test 2 results for NF-007 ........................................................ 46

21 DLS test 3 results for NF-007 ...................................................... 47

22 DLS test 4 results for NF-007................................ 48

23 DLS test 1 results for NF-013 …................................................. $\quad 50$

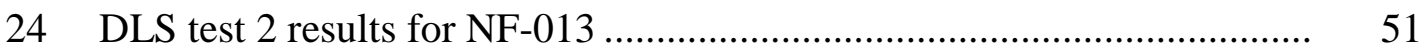

25 DLS test 3 results for NF-013 _......................................................... 52

26 DLS test 1 results for NF-046................................... 54

27 DLS test 2 results for NF-046 ...................................................... 55

28 DLS test 3 results for NF-046 ....................................................... 56

29 DLS test 4 results for NF-046 ......................................................... 57

30 Scattering intensity vs delay time................................................... 59

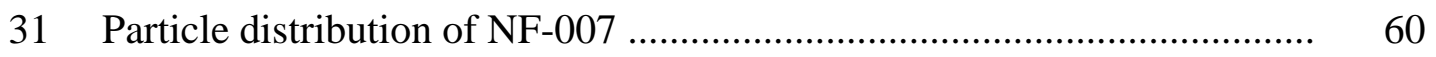

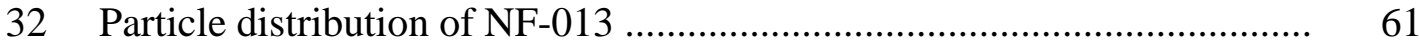

33 Particle distribution of NF-046 ..................................................... 61

34 Dynamic viscosity with shear rate for all fluids at $25{ }^{\circ} \mathrm{C} \ldots \ldots \ldots \ldots \ldots \ldots \ldots . . . . . . . . . . . . .63$

35 Dynamic viscosity with shear rate for all fluids at $45{ }^{\circ} \mathrm{C} \ldots \ldots \ldots \ldots \ldots \ldots \ldots \ldots . . . . . . . . . . . . . . . .63$

36 Dynamic viscosity of nanofluids and Royco 602 at $25^{\circ} \mathrm{C} \ldots \ldots \ldots \ldots \ldots \ldots \ldots . . . . . . . . . .64$

37 Dynamic viscosity of nanofluids and Royco 602 at $45{ }^{\circ} \mathrm{C} \mathrm{\ldots .....................} 64$

38 The comparison of viscosity with Einstein model ............................... 66

39 The surface and bulk temperature difference of pure PAO and NF-048_. 72

40 The variation of heat transfer coefficient of pure PAO ........................... 72 
FIGURE $\quad$ Page

41 The variation of heat transfer coefficient of NF-048 ............................. 73

42 The comparison of heat transfer coefficient of pure PAO and NF-048

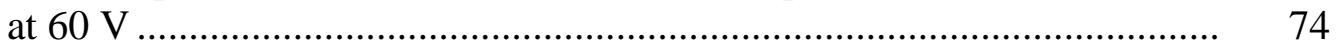

43 The comparison of heat transfer coefficient of pure PAO and NF-048

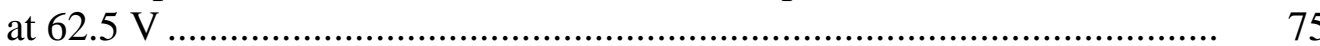

44 The comparison of heat transfer coefficient of pure PAO and NF-048

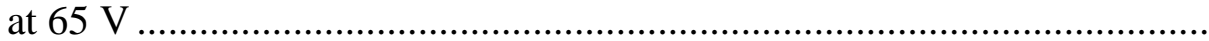

45 The percentage enhancement of heat transfer coefficient of NF-048 with axial distance

46 The percentage enhancement of heat transfer coefficient of NF-048

47 The variation of relative Peclet number with axial distance ................... $\quad 79$

48 The variation of Nusselt number depending on Peclet number........... 80

49 The variation of Nusselt number depending on axial distance ................ 81

50 The variation of Nusselt number along heat transfer section ............ 82

51 The variation of ReRa with axial distance for pure PAO and NF-048..... 84 


\section{LIST OF TABLES}

TABLE Page

1 Comparison of published thermal conductivity data of nanofluids (at room temperature)

$2 \quad$ PAO nanofluids formulation ........................................................ 36

$3 \quad$ Summary of experiments .......................................................... 37

$4 \quad$ Effective diameter of NF-007..................................... 49

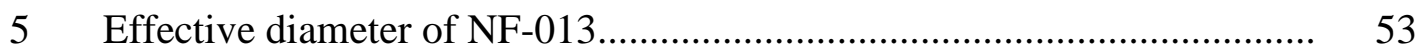

$6 \quad$ Effective diameter of NF-046......................................................... 58

7 The enhancement in thermal conductivity of nanofluids ...................... 68

8 The comparison of enhancement in thermal conductivity of NF-048 measured at different time period............................... 70 


\section{CHAPTER I}

\section{INTRODUCTION}

High thermal performance of heat transfer fluids is required in heat transfer applications such as in automobiles, electronic equipment, and space and military equipment. As the heat load in those technological applications continues to grow, the importance of cooling is emphasized even more. Depending on the size of the system and its specific needs, different cooling schemes should be applied accordingly. In small heat transfer systems, higher cooling efficiency is needed to manage considerable dense thermal loads. Among the physical limitations encountered in those systems include small heat transfer surface area and limited volume of coolant to dissipate considerable high heat loads. Such conditions make the development of nanofluids even more important. Several ideas have been proposed to resolve this issue. One of the ideas is to use nanoparticles and disperse it into a base fluid. Nanoparticles can be metallic or nonmetallic and they can be spherical or non-spherical. Carbon nanotube, copper oxide and Alumina nanoparticles are the most obvious examples. Mostly, nanoparticles should be highly thermally conductive to ensure higher thermal conductivity of nanofluids.

In this study, the thermal properties of several nanofluids samples were measured. Nanofluid samples containing Alumina nanoparticles with different shapes and sizes were used to determine their effects on thermal conductivity and viscosity. Different

This thesis follows the style of ASME Journal of Heat Transfer. 
kinds of dispersant were used with different concentration of nanoparticles. It is expected that the thermal properties of each sample would be different. Few publications have addressed the thermal enhancement of Poly-Alpha-Olefin (PAO) using nanoparticles. This study can be beneficial for providing ideas when developing new nanofluids using Poly-Alpha-Olefin. Through the analysis of the results, the mechanisms responsible for enhancing thermal conductivity in PAO-based nanofluids can be exposed clearly by taking into account the effects of nanoparticle size, shape and concentration. By comparing different PAO-based nanofluids that use different types of Alumina nanoparticles, it is possible to understand what it takes to make a highly efficient PAObased nanofluid. The dispersant is another factor that controls the reliability and stability of nanofluids. Even if nanofluids exhibit high thermal conductivity, they must be stable and nanoparticles must remain suspended for a considerable amount of time. Furthermore, thermal properties should not be considered separately since each property has a significant influence on other properties.

Most of research group working in nanofluids have used spherical-type nanoparticles. There are still few studies about the different type nanoparticles that can be used to make PAO-based nanofluids. It has been reported that different spherical shape alumina nanoparticles dispersed in PAO showed comparatively similar enhancement in thermal conductivity. A recent study looks into the effects of Alumina nanoparticle on PAO for different concentration, shape of nanoparticles and different kinds of thermal conductivity measuring devices [1]. The current work is helpful in providing new data obtained through the use of an optimized thermal conductivity 
device, which shows good agreement with the results from the benchmark study [1]. In addition, nanofluid samples used in this work have been found to be stable for a long period of time, which exhibit minimal agglomeration problems. This study could help in determining optimum conditions for efficient heat transfer behavior by taking into account not just concentration of Alumina nanoparticles, but also their morphology and size. Furthermore, limited experimental data is available for the convective heat transfer behavior of PAO-based nanofluid in laminar flow since most research groups have usually focused on measuring viscosity or thermal conductivity alone. The effects of nanoparticle morphology on laminar flow heat transfer needs to be understood to accurately predict their behavior in other heat transfer applications. Combined with other measurements such as viscosity and thermal conductivity, investigating convective heat transfer behavior could make it possible to understand the effects of using of Alumina PAO nanofluids in real heat transfer application.

The thesis comprises of six chapters. The first chapter presents introduction and the motive of the research. The second chapter is the literature review and explains what has been done in the area of nanofluids and its relevance to the current study. The third chapter describes the experimental plan and experimental set-up, and the fourth chapter includes the results obtained from the TEM, DLS imaging, viscosity, thermal conductivity and convective heat transfer coefficient measurements. The last chapter consists of concluding remarks and suggestion for future work. 


\section{CHAPTER II}

\section{LITERATURE REVIEW}

There are not many studies which dealt with aluminum oxide nanoparticles in PAO. Therefore, other studies which dealt with aluminum oxide in different base fluids or different nanoparticles in PAO were also surveyed to compare and clarify the thermal properties of aluminum oxide in PAO. Then, especially for nanofluid containing aluminum oxide in PAO, some of its properties such as thermal conductivity, viscosity, and convective heat transfer behavior have been measured and compared to conventional models. Additionally, the mechanisms behind these behaviors have been explained by each research group.

\subsection{Nanofluids containing $\mathrm{Al}_{2} \mathrm{O}_{3}$ nanoparticles in PAO}

Buongiorno et al. [1] performed a series of studies on the thermal conductivity of several nanofluids samples. Identical samples were distributed to several research groups as part of a benchmark study to determine the thermal conductivity of Aluminabased PAO nanofluids. Alumina nanoparticles with different concentration and shapes were suspended in PAO and water, and the data from each group was compared, respectively. Each group used different thermal conductivity measuring device such as the KD2 Pro, THW (Transient hot wire method), parallel hot plate, and hot disk. The result showed that the thermal conductivity increased the most at a higher concentration 
of non-spherical nanoparticles. Also, it became evident that nanoparticle concentration should be over a certain limit to exhibit a significant thermal conductivity enhancement. The enhancement rate was higher for PAO nanofluid than water.

Schmidt et al. [2] measured the shear and longitudinal viscosity of alumina nanoparticles in $\mathrm{C}_{10} \mathrm{H}_{22}$ (decane) and PAO (Synfluid 4cSt) as a function of volume fraction. They used impulsive stimulated thermal scattering (ISTS), which made it possible to measure both viscosity and thermal conductivity concurrently. According to their results, viscosity of their nanofluid exceeded the values predicted by the Einstein model. It was concluded that particle aggregation was not the cause for the discrepancy between Einstein model and experimental data since the both fluids were highly diluted. Brownian motion was proposed as a possible mechanism which could explain the difference in thermal conductivity enhancement. Schmidt et al. [3] conducted a similar study by using different methods to measure thermal conductivity. They used the transient hot-wire method and optical grating. The results from both methods were well matched and they found that 1 vol. $\% \mathrm{Al}_{2} \mathrm{O}_{3}$-decane nanofluid exhibited a $10.5 \%$ enhancement in thermal conductivity while 1 vol. $\% \mathrm{Al}_{2} \mathrm{O}_{3}-\mathrm{PAO}$ showed only a $5 \%$ enhancement, which is above the estimated enhancement of $3 \%$ according to the continuum theory [4]. Chiesa et al. [5] also showed that thermal conductivity enhancement of $\mathrm{Al}_{2} \mathrm{O}_{3}-\mathrm{PAO}$ fluid was greater than expected by the effective medium theory.

Zhou et al. [6] examined the effect of shear rate and temperature on viscosity of nanofluids consisting of alumina nanospheres and nanorods in PAO fluid. Nanofluids 
with 1 vol. $\%$ and 3 vol. $\%$ samples were used. For each concentration, two different shapes of nanoparticles were used including nanospheres and nanorods. They found that 3 vol. \% of Alumina nanorods in PAO fluid resulted in a non-Newtonian shear thinning viscosity behavior. Moreover, the relative viscosity of the nanofluid decreased as temperature increased. It became obvious that relative viscosity is temperature independent only at low volume fraction and low aspect ratio of the nanoparticles.

\subsection{Nanofluids containing $\mathrm{Al}_{2} \mathrm{O}_{3}$ nanoparticles in different base fluids}

Heris et al. [7] measured the convective heat transfer of $\mathrm{Al}_{2} \mathrm{O}_{3}$-water nanofluid and it was shown that heat transfer coefficient of nanofluid increased with particle concentration. They explained that the enhanced heat transfer coefficient could not only be attributed to enhanced thermal conductivity but also to the role of Brownian motion and particle agglomeration. Fischer et al. [8] also studied the convective heat transfer of $\mathrm{Al}_{2} \mathrm{O}_{3}$-water nanofluid, and they found that surface tension worsens the thermal performance at low Reynolds number. However, the effect of nanoparticles in microchannels was not significant since the thermal performance was enhanced only $3 \sim 5 \%$. The low heat transfer enhancement was attributed to the effective low interfacial tension induced by nanoparticles. They suggested using bubble flow for efficient heat transfer.

Li et al. [9] investigated the effect of temperature and volume fraction on the effective thermal conductivity of $\mathrm{CuO}$-water and $\mathrm{Al}_{2} \mathrm{O}_{3}$-water nanofluids. $6 \% \mathrm{CuO}$ 
nanofluid showed a 50\% increase in the thermal conductivity of distilled water, while $10 \% \mathrm{Al}_{2} \mathrm{O}_{3}$ nanofluid showed only a $30 \%$ time enhancement. It was shown that the effective thermal conductivity was affected by both temperature and volume fraction; however, the effect of volume fraction was stronger than that of temperature. They also explained the two main effects of nanoparticles in nanofluids, the high thermal conductivity of nanoparticles and their Brownian motion.

Zhang et al. [10] studied the effect of different nanoparticle shapes. They measured the effective thermal conductivity and thermal diffusivity of Au-toluene, $\mathrm{Al}_{2} \mathrm{O}_{3}$-water, $\mathrm{TiO}_{2}$-water, $\mathrm{CuO}$-water and CNT-water nanofluids. They found that there was no anomalous enhancement in thermal conductivity and the values followed the Hamilton-Crosser model at lower volume fraction well for spherical nanoparticles. $\mathrm{Al}_{2} \mathrm{O}_{3}$-water nanofluid showed lower thermal conductivity than that from $\mathrm{H}-\mathrm{C}$ model above 5 vol. \%. They argued that it was due to the settling of particles at high volume fractions. They also indicated that the changes in thermal conductivity with temperature depends more on the thermal conductivity of the base fluid than other nanoparticles.

Nguyen et al. [11] studied the effect of temperature and volume fraction on viscosity of $\mathrm{Al}_{2} \mathrm{O}_{3}$-water nanofluid with two different particle sizes. They found that viscosity was affected by temperature, volume fraction and particle size. Particle size was found to affect the viscosity significantly at higher volume fraction. It was concluded that classical model like Einstein's equation can be applied to nanofluids with low volume fraction.

Tavman et al. [12] measured thermal conductivity and viscosity of $\mathrm{SiO}_{2}$-water, 
$\mathrm{TiO}_{2}$-water and $\mathrm{Al}_{2} \mathrm{O}_{3}$-water nanofluids. The thermal conductivity was measured by 3- $\omega$ method and it is relatively in good agreement with the Hamilton-Crosser model. The increase was independent of temperature. They also noted that thermal conductivity of $\mathrm{Al}_{2} \mathrm{O}_{3}$-water nanofluid was higher than that of $\mathrm{TiO}_{2}$-water nanofluid even though $\mathrm{TiO}_{2}$ nanoparticles are more thermally conductive that $\mathrm{Al}_{2} \mathrm{O}_{3}$ nanoparticles. It is concluded that not only nanoparticles but also other factors can affect overall thermal conductivity. The viscosity results agreed well with Einstein law of viscosity at lower volume fraction only.

Chandrasekar et al. [13] examined the effective thermal conductivity and viscosity of $\mathrm{Al}_{2} \mathrm{O}_{3}$-water nanofluid, and it was shown that thermal conductivity increased linearly depending on volume fraction; however viscosity increased in a non-linear fashion. They attributed this behavior to the interaction between particles and fluid at higher concentration.

Beck et al. [14] measured thermal conductivity of $\mathrm{Al}_{2} \mathrm{O}_{3}$-water, ethylene glycol with particle ranging from 8 to $282 \mathrm{~nm}$ in diameter. It was shown that the thermal conductivity enhancement decreased as the particle size decreased below about $50 \mathrm{~nm}$. The enhancement was independent of size over $50 \mathrm{~nm}$, but decreased considerably for nanoparticles less than $50 \mathrm{~nm}$ in diameter. The effect of smaller nanoparticles $(<50 \mathrm{~nm})$ on thermal conductivity was attributed to an increase in phonon scattering at the solidliquid interface. Yu et al. [15] used a modified Maxwell model, which includes an interfacial layer effect and found that the effect of nanolayer on thermal conductivity becomes larger when the particle diameter is less than $10 \mathrm{~nm}$. Thermal conductivity enhancement decreased as particle size approached to $10 \mathrm{~nm}$ and was almost constant 
after $10 \mathrm{~nm}$. Their results contradict the results of the previous study [14].

Timofeeva et al. [16] found that the thermal conductivity enhancement was independent of the temperature. They noted that the agglomeration state changed as time passed. They also estimated that the effect of Brownian motion was less than that of heat diffusion between particles and fluid. Non-spherical nanoparticles caused higher thermal conductivity enhancement than spherical particles. They concluded that surface (Kapitza) resistance is the main factor that results in lower thermal conductivity than the parameters accounted by the effective medium theory. The geometry and agglomeration states were also thought as the critical factors that affect thermal conductivity.

Kumar et al. [17] found that thermal conductivity enhancement is inversely proportional to the particle radius. Chon et al. [18] concluded that Brownian motion is the key factor that affects thermal conductivity enhancement with increasing temperature and decreasing particle size. Prasher et al. [19] also chose Brownian motion as the main reason for thermal conductivity enhancement.

Xie et al. [20] argued that thermal conductivity enhancement increased as interfacial nanolayer thickness increased and particle size decreased. Conversely, Xue et al. [21] concluded that the liquid layering had negligible effect on thermal properties. They used a simple (monoatomic) liquid for molecular dynamic simulation to justify their observation but did not take into account complex fluids such as water might to explain their different behavior. Das et al. [22] indicated that thermal conductivity enhancement matched well the Hamilton-Crosser model only at room temperature, and as temperature increased, the enhancement increased. 
Wen et al. [23] investigated the convective heat transfer of $\mathrm{Al}_{2} \mathrm{O}_{3}$-water nanofluid. The enhancement in convective heat transfer was especially significant in the entrance region and decreased as axial distance increased. Not only thermal conductivity but also particle migration resulted in a decreased thermal boundary layer thickness, which was used to explain the enhancement. Thermal developing length was greater than that of pure base fluid and increased with increasing particle loading.

\subsection{PAO nanofluids with different nanoparticles}

Shaikh et al. [24] used carbon nanotubes (CNTs), exfoliated graphite (EXG), and heat treated nanofibers (HTT) and treated with PAO fluid. For thermal conductivity and thermal diffusivity measurement, they used the laser flash method. CNTs in PAO fluid showed the highest enhancement in thermal conductivity, which was about $161 \%$ at 1 vol. \%. Hong et al. [25] also studied PAO nanofluids using high concentration carbon nanotubes (CNTs). They tested multi-wall CNTs and single-wall CNTs without surfactant. A $11 \mathrm{wt} \%$ (7 vol. \%) of single-wall CNTs showed a 60 70\% thermal conductivity enhancement. It became obvious that different lengths and diameters of nanotubes did not affect the properties in carbon nanotubes grease. CNTs were also mixed with $\mathrm{Fe}_{2} \mathrm{O}_{3}$ to see if there was a time-dependent magnetic field effect on CNTs grease. For different $\mathrm{Fe}_{2} \mathrm{O}_{3}$ concentration, thermal conductivity remained constant as time passed. They concluded that $\mathrm{CNTs}$ and $\mathrm{Fe}_{2} \mathrm{O}_{3}$ movement is constrained by the three-dimensional network arrangement of CNT. 
Hwang et al. [26] used multi-walled carbon nanotube (MWCNT), fullerene, copper oxide, silicon dioxide and silver in several base fluids including PAO. Thermal conductivity was measured by the transient hot-wire method. It was concluded that the thermal conductivity enhancement depends on the thermal conductivity of particles. Fullerenes were able to suspend well in oil due to their non-polar nature. However, pressure drop increased by $225 \%$.

Choi et al. [27] reported a non-linear trend of thermal conductivity enhancement for MWCNT in PAO contrary to classical model. Thermal conductivity was measured by THW method and showed $150 \%$ enhancement at 1 vol. $\%$, which is similar to the study done by Shaikh et al. [24]. The assumed ballistic conduction was due to the large phonon mean free path present in nanotubes. Other factors such as liquid layering around particles and particle interactions from high aspect ratio have been suggested to facilitate energy transport. Yang et al. [28] investigated CNT-PAO nanofluid thermal conductivity and viscosity and concluded that among the many mechanisms, nanoparticle clustering affect heat transfer the most. 
Table 1. Comparison of published thermal conductivity data of nanofluids (at room temperature)

\begin{tabular}{|c|c|c|c|c|c|c|}
\hline $\begin{array}{l}\text { Nanofluid } \\
\text { composition }\end{array}$ & $\begin{array}{c}\text { Particle } \\
\text { description }\end{array}$ & $\begin{array}{c}\text { Particle } \\
\text { size } \\
\text { (diameter } \\
, \mathrm{nm})\end{array}$ & $\begin{array}{c}\text { Particle } \\
\text { concentration }\end{array}$ & $\begin{array}{c}\% \\
\text { Enhanceme } \\
\text { nt in } \\
\text { thermal } \\
\text { conductivit } \\
\text { y over the } \\
\text { base fluid } \\
\text { (measured) }\end{array}$ & $\begin{array}{c}\text { Exceeds } \\
\text { Maxwell } \\
\text { or } \\
\text { Hamilton } \\
\text { Crosser } \\
\text { model }\end{array}$ & Ref. \\
\hline \multirow{6}{*}{$\begin{array}{c}\mathrm{Al}_{2} \mathrm{O}_{3}+ \\
\text { PAO }\end{array}$} & Spherical & 10 & 1 vol. $\%$ & 3.9 & $\begin{array}{c}\text { No } \\
\text { (agree) }\end{array}$ & [1] \\
\hline & Spherical & 10 & 3 vol. $\%$ & 12.1 & $\begin{array}{c}\text { No } \\
\text { (agree) }\end{array}$ & [1] \\
\hline & Cylindrical & $80 \times 10$ & 1 vol. \% & 5.1 & $\begin{array}{c}\text { No } \\
\text { (agree) }\end{array}$ & [1] \\
\hline & Cylindrical & $80 \times 10$ & 3 vol. $\%$ & 17.6 & $\begin{array}{c}\text { No } \\
\text { (agree) }\end{array}$ & [1] \\
\hline & Spherical & 20 & 1 vol.\% & 5 & Yes & [3] \\
\hline & Spherical & $<80$ & 1 vol.\% & 5 & Yes & [5] \\
\hline \multirow{11}{*}{$\begin{array}{c}\mathrm{Al}_{2} \mathrm{O}_{3}+ \\
\text { water }\end{array}$} & Spherical & 36 & 10 vol.\% & 30 & Yes & [9] \\
\hline & Spherical & 20 & 5 vol. $\%$ & 15 & $\begin{array}{c}\text { No } \\
\text { (agree) }\end{array}$ & [10] \\
\hline & Spherical & 20 & 15 vol. $\%$ & 20 & No (less) & [10] \\
\hline & Spherical & 30 & 1 vol.\% & 1.5 & No (less) & [12] \\
\hline & Spherical & 43 & 1 vol.\% & 3 & N/A & [13] \\
\hline & Spherical & 11 & 1 vol.\% & 7 & N/A & [18] \\
\hline & Spherical & 47 & 1 vol.\% & 3 & N/A & [18] \\
\hline & Spherical & 47 & 4 vol. $\%$ & 10 & N/A & [18] \\
\hline & Spherical & 150 & 1 vol.\% & 2 & N/A & [18] \\
\hline & Spherical & 38.4 & 0.04 vol.\% & 7 & Yes & [19] \\
\hline & Spherical & 13 & 0.04 vol. $\%$ & 28 & Yes & [20] \\
\hline
\end{tabular}


Table 1. Continued

\begin{tabular}{|c|c|c|c|c|c|c|}
\hline $\begin{array}{l}\text { Nanofluid } \\
\text { composition }\end{array}$ & $\begin{array}{c}\text { Particle } \\
\text { description }\end{array}$ & $\begin{array}{c}\text { Particle } \\
\text { size } \\
\text { (diameter, } \\
\text { nm) }\end{array}$ & $\begin{array}{c}\text { Particle } \\
\text { concentration }\end{array}$ & $\begin{array}{c}\% \\
\text { Enhancement } \\
\text { in thermal } \\
\text { conductivity } \\
\text { over the base } \\
\text { fluid } \\
\text { (measured) }\end{array}$ & $\begin{array}{c}\text { Exceeds } \\
\text { Maxwell } \\
\text { or } \\
\text { Hamilton } \\
\text { Crosser } \\
\text { model }\end{array}$ & Ref. \\
\hline \multirow{8}{*}{$\begin{array}{c}\mathrm{Al}_{2} \mathrm{O}_{3}+ \\
\text { water }\end{array}$} & Spherical & 38.4 & 1 vol. $\%$ & 2 & $\begin{array}{c}\text { No } \\
\text { (agree) }\end{array}$ & [22] \\
\hline & Spherical & 38.4 & 4 vol. \% & 9.4 & $\begin{array}{c}\text { No } \\
\text { (agree) }\end{array}$ & [22] \\
\hline & Spherical & $27 \sim 56$ & 0.01 vol.\% & 6.5 & Yes & [23] \\
\hline & Spherical & 38 & 0.04 vol. $\%$ & 9 & $\begin{array}{c}\text { No } \\
\text { (agree) }\end{array}$ & [41] \\
\hline & Spherical & 80 & 1 vol.\% & 4.5 & Yes & [55] \\
\hline & Spherical & 150 & 1 vol.\% & 3 & Yes & [55] \\
\hline & Spherical & 80 & 0.5 vol. $\%$ & 4 & Yes & [55] \\
\hline & Spherical & 80 & 1 vol.\% & 7 & Yes & [55] \\
\hline \multirow{4}{*}{$\begin{array}{c}\mathrm{Al}_{2} \mathrm{O}_{3}+ \\
\text { Ethylene } \\
\text { glycol }\end{array}$} & Spherical & 38.4 & 0.04 vol. $\%$ & 12 & Yes & [19] \\
\hline & Cylindrical & $10 \sim 15$ & 1 vol. $\%$ & 161 & Yes & [24] \\
\hline & Spherical & 10 & 5 wt. $\%$ & 10 & Yes & [35] \\
\hline & Spherical & 38 & 0.04 vol. $\%$ & 13 & $\begin{array}{c}\text { No } \\
\text { (agree) }\end{array}$ & [41] \\
\hline $\begin{array}{l}\mathrm{Al}_{2} \mathrm{O}_{3}+ \\
\text { propanol }\end{array}$ & Cylindrical & $1 \sim 2$ & 7 vol.\% & $60 \sim 70$ & N/A & [25] \\
\hline \multirow{3}{*}{$\begin{array}{c}\mathrm{CNT}+ \\
\mathrm{PAO}\end{array}$} & Cylindrical & $10 \sim 30$ & 0.5 vol. $\%$ & 8.5 & N/A & [26] \\
\hline & Cylindrical & 25 & 1 vol. $\%$ & 150 & Yes & [27] \\
\hline & Cylindrical & N/A & 0.1 vol. $\%$ & 20 & N/A & [28] \\
\hline
\end{tabular}

As seen in Table 1 above, the reported enhancement in thermal conductivity was 
not perfectly matched with theoretical model. Nevertheless, PAO nanofluids consisting of alumina nanoparticles show less deviation in thermal conductivity enhancement compared to other nanofluids. However, a full understanding of PAO-based nanofluids still is lacking. A study of alumina-based PAO nanofluids is needed to understand the effects of nanoparticle shape and concentration on thermal conductivity, viscosity and heat transfer performance.

\subsection{Past research on viscosity of $\mathrm{Al}_{2} \mathrm{O}_{3}$ based $\mathrm{PAO}$ nanofluids}

Viscosity is one of the most important thermal properties of any nanofluid. It is correlated with convective heat transfer and is regarded as one of the most important factors that affect heat transfer performance since the pumping power can increase

greatly as viscosity increases. In the analysis of heat transfer, viscosity play an important role in deciding channel specification such as how much fluid should flow and what condition should be given in a flow. For example, higher thermal performance is required and it might need higher concentration of nanofluid which might come at the expense of higher viscosity as well as more pumping power. Therefore, some adjustments are required to increase heat transfer effectiveness. Viscosity is measured with other parameters such as particle volume fraction, shear rate mostly and in some cases, with temperature. Viscosity studies about Alumina nanofluid have been performed by many different research groups but limited for PAO base fluid. Many viscosity data have been compared with conventional model including the Einstein 
viscosity model as shown below

$$
\mu_{n f}=(1+2.5 \phi) \mu_{b}
$$

where $\mu_{n f}, \phi$ and $\mu_{b}$ are effective viscosity of the nanofluid, particle volume fraction, and viscosity of the base fluid, respectively. However, some papers argue that the Einstein viscosity model does not explain the viscosity trend in some cases. It is indicated that Einstein equation is only applicable for spherical particle in volume loading less than 5\% [7]. Several other models for viscosity of nanofluids are described in [8], [13]. Schmidt et al. [2] measured the shear and longitudinal viscosity of Alumina dispersed in PAO (Synfluid 4cSt) as a function of volume fraction. It was found that the viscosity enhancement values exceeded the Einstein model values. Brownian motion might have affected the viscosity trend due to the low possibility of particle aggregation. Zhou et al. [6] investigated the effect of shear rate and temperature on viscosity of Alumina dispersed in PAO fluid. At 1\% and 3\% volume concentration, nanosphere and nanorod shapes were used and those samples were the same used for the benchmark study [1]. It was shown that for the same volume concentration, the viscosity of nanofluid with nanorod is higher than that of nanosphere due to the larger aspect ratio of rods. As the volume fraction increased, the viscosity increased which is consistent with previous studies [1]. Compared to nanofluid with nanosphere, nanorods showed clear non-Newtonian behavior. Particle aggregation was the main reason for the nonNewtonian behavior. At high shear rate, the disruption of might have cause a shear thinning behavior. It can be concluded that higher aspect ratio of nanorods cause higher 
viscosity as well as much more aggregation. Nanofluid with $3 \%$ nanorod particles showed non-Newtonian behavior and the viscosity decreased as the temperature increased. It was also found that the viscosity was independent of temperatureindependent at low volume fraction. Even nanofluids with nanorods were not affected by temperature at low volume fraction.

In this study, different viscosity data has been gathered from base fluids and nanofluids samples. Viscosity-Shear rate and Viscosity-temperature data has been compared each other.

\subsection{Past research on thermal conductivity of $\mathrm{Al}_{2} \mathrm{O}_{3}$ based PAO nanofluids}

Heat transfer performance is evaluated using mainly the heat transfer coefficient or Nusselt number. Those factors are correlated with thermal conductivity. Thus, for judging the heat transfer behavior of nanofluids, thermal conductivity should be measured first. Most of studies about nanofluids focus on thermal conductivity measurement only. Thermal conductivity enhancement has been studied taking into account the effect of volume concentration, particle size, particle shape, base fluid and temperature. Different kinds of conventional models of effective thermal conductivity of nanofluids are described in [19], [27], [29], and [30].

The benchmark study [1] showed that the data gathered from 34 organizations was similar regardless of measuring technique and was well-matched with the effective medium theory developed by Maxwell and generalized by Nan et al. [31]. The effect of 
particle geometry and finite interfacial resistance was taken into account. The thermal conductivity increased as the particle loading and aspect ratio increased. No anomalous thermal conductivity enhancement was found in this study so other mechanisms such as Brownian motion, liquid layering and aggregation were somewhat disqualified to explain the thermal conductivity enhancement. Other studies [3,5] observed a 5\% thermal conductivity enhancement at $1 \%$ volume fraction independent of particle size. Schmidt et al. [3] investigated that 1 vol. $\% \mathrm{Al}_{2} \mathrm{O}_{3}-\mathrm{PAO}$ showed a 5\% enhancement, which is above the estimated enhancement of $3 \%$ according to the continuum theory. Brownian motion or other mechanisms are suspected to be involved in thermal conductivity which bring about discrepancies with the effective medium model. Chiesa et al. [5] used THW method and determined that a thermal conductivity enhancement of 5\% was higher than that predicted by the effective medium theory. They also performed non-destructive breakdown tests to figure out what conditions the nanofluid losses it insulating properties as a dielectric fluid. The dielectric strength of nanofluid was also found to be dependent on particle loading. For $\mathrm{Al}_{2} \mathrm{O}_{3}-\mathrm{PAO}$ nanofluid, the minimum time-to breakdown for all tested voltages was found at $0.5 \%$ volume loading. At higher volume loading, the time-to-breakdown was shorter. It was concluded that generally, the addition of particles in base fluids worsens the overall dielectric strength.

The mechanism behind thermal conductivity enhancement in Alumina nanofluid has not been completely verified yet. There are many explanations about the enhancement of thermal conductivity in nanofluids such as Brownian motion, interfacial layering, ballistic heat transport, interfacial thermal resistance and particle clustering. 
Keblinski et al. [32] chose the ballistic heat transport and clustering effect as the main factors to determine thermal properties. Ozerinç et al. [33] reported in the review paper that the effect of particle size on the thermal conductivity of nanofluids is not clear since there are some disagreeable results among several research groups. It shows the conflicting concept between Brownian motion and particle clustering. It is also said that clustering can be correlated with the kind and quantity of additives, and the $\mathrm{pH}$ value of nanofluid. Not all the experimental data from each group is well matched with theoretical data from classical model for thermal conductivity. Prasher et al. [34] found that aggregation can increase thermal conductivity only if aggregation is well dispersed before large aggregates are formed. It indicates that there is some optimum extent of aggregates for effective heat transport. They also noted the importance of other factors such as the Hamaker constant, the $\zeta$ potential, $\mathrm{pH}$, and ion concentration.

\subsection{Past research on convective heat transfer of $\mathrm{Al}_{2} \mathrm{O}_{3}$ based $\mathrm{PAO}$ nanofluids}

Compared to thermal conductivity, there are few papers that discuss convective heat transfer behavior of Alumina nanofluid. Sommers et al. [35] studied $\mathrm{Al}_{2} \mathrm{O}_{3}$ nanoparticles suspended in propanol. Propanol was chosen because it has a low thermal conductivity similar to that of PAO so that similar results could be assumed for PAO. Measurements of density, specific heat, thermal conductivity, and viscosity were obtained. All other factors except viscosity showed a linearly increasing behavior as the particle loading increased. Heat transfer coefficient was also measured for both propanol 
base fluid and nanofluid after adding nanoparticles. It was indicated that a significant heat transfer coefficient enhancement was found at $1 \mathrm{wt} . \%$, but its thermal performance worsened at $3 \mathrm{wt} . \%$. Recycled fluid at high flow rate and increased temperature was discolored and nanoparticle abrasion was found to cause those changes. They concluded that increasing surface area and reducing the thermal boundary layer might be better than using nanoparticles. Still, the use of nanofluid is required to verify the enhanced thermal performance at low mass fraction.

Fischer et al. [8] measured the convective heat transfer of $\mathrm{Al}_{2} \mathrm{O}_{3}$-water and $\mathrm{Al}_{2} \mathrm{O}_{3}$-PAO nanofluid, and they concluded that bubble flow in microchannel could provide more efficient heat transfer than single phase flow. It was revealed that suspended particles in single liquid flow of PAO increased the Nusselt number by $12 \%$ even though pressure drop increases up by $44 \%$. Using nanoparticles of higher viscosity is regarded as an efficient way to improve thermal performance. 


\section{CHAPTER III}

\section{EXPERIMENTAL DESIGN}

This chapter includes the experimental objectives, the description of the experimental set-up for measuring viscosity, thermal conductivity, and convective heat transfer coefficient of samples as well as particle size data.

\subsection{Objectives and methodology}

The objective of this study was to analyze the thermal properties of nanofluids containing alumina nanoparticles, which have different morphology and study the specific thermal phenomena of Alumina nanofluids. There are many mechanisms that have been proposed for explaining the thermal property changes of nanofluids including the effects of particle size, particle shape and temperature. Past results have revealed that even for the same nanofluid, some research group has obtained different results. There have been many studies for $\mathrm{Al}_{2} \mathrm{O}_{3}$-water nanofluids but very few for $\mathrm{Al}_{2} \mathrm{O}_{3}$-PAO nanofluid. Using different shape and size of nanoparticles, and temperature, thermal properties have been measured and analyzed. To meet the overall objectives, several tasks were undertaken and are summarized below:

1. Analysis of nanoparticles in nanofluids

a. Nanoparticles in samples have been characterized using transmission electron 
microscopy (TEM) and dynamic light scattering (DLS).

b. The information about different size and shape of nanoparticles has been recorded and analyzed.

2. Viscosity measurement of nanofluids

a. Viscosity of base fluids and nanofluids using a rotating spindle Brookfield viscometer has been measured to determine the relative change in viscosity caused by addition of nanoparticles.

b. The temperature has been varied between at 25 and $45^{\circ} \mathrm{C}$.

c. The experimental data was compared with the theoretical viscosity model to understand the effect of nanoparticles on viscosity.

3. Thermal conductivity measurement of nanofluids

a. Transient hot-wire (THW) was used to measure thermal conductivity.

b. THW has been calibrated using pure PAO to find out the optimum condition under which thermal conductivity can be found accurately.

c. The temperature was set at 25 and $45^{\circ} \mathrm{C}$.

d. The experimental values were compared with that of pure PAO to investigate the relative enhancement in thermal conductivity.

4. Investigation of convective heat transfer behavior of nanofluids

a. Laminar heat transfer loop has been calibrated and the surface temperature under constant heat flux condition has been recorded.

b. Flow rate was controlled using two syringes. 
c. Convective heat transfer enhancement values were compared with that of pure PAO to find out the relative enhancement as a function of axial distance and temperature.

\subsection{Set-up description}

This part explains about the details of the experimental set-up used for measuring nanoparticle size, viscosity, thermal conductivity, and convective heat transfer enhancement of PAO-based nanofluids.

\subsubsection{TEM}

In the study, a FEI TECNAI G2 F20 FE-TEM located in microscopy center at Texas A\&M University was used to characterize the nanoparticles (See Figure 1). With most liquid samples, the test sample are usually dried and exposed to vacuum before they can be imaged; however, this could affect the level of agglomeration and clustering of nanoparticles present in nanofluids. Using PAO-based nanofluids, the samples did not have to be dried or diluted completely to be able to image them using TEM. The TEM cell was constructed by holding the fluid on a copper membrane window with TEM grids. The instrument was used with a $200 \mathrm{kV}$ source. High angle annular dark field (HAADF) scanning transmission electron microscopy (STEM) was used first to determine the presence of alumina particles, and their relative concentration. HAADF 
STEM uses z-contrast instead of BF (Bright Field) contrast which is non monotonic with thickness [36]. HAADF images show almost no diffraction effects so the intensity is proportional to $\mathrm{z}^{2}$ and provides strong contrast. Due to the strong contrast, it is useful for tomography reconstruction. From HAADF image, line scan could be performed. Line scans were used to measure the elemental distribution along a certain line across the interface of two layers or of the matrix and a precipitate. TEM images for all the Alumina-based nanofluids can be seen in the results section.

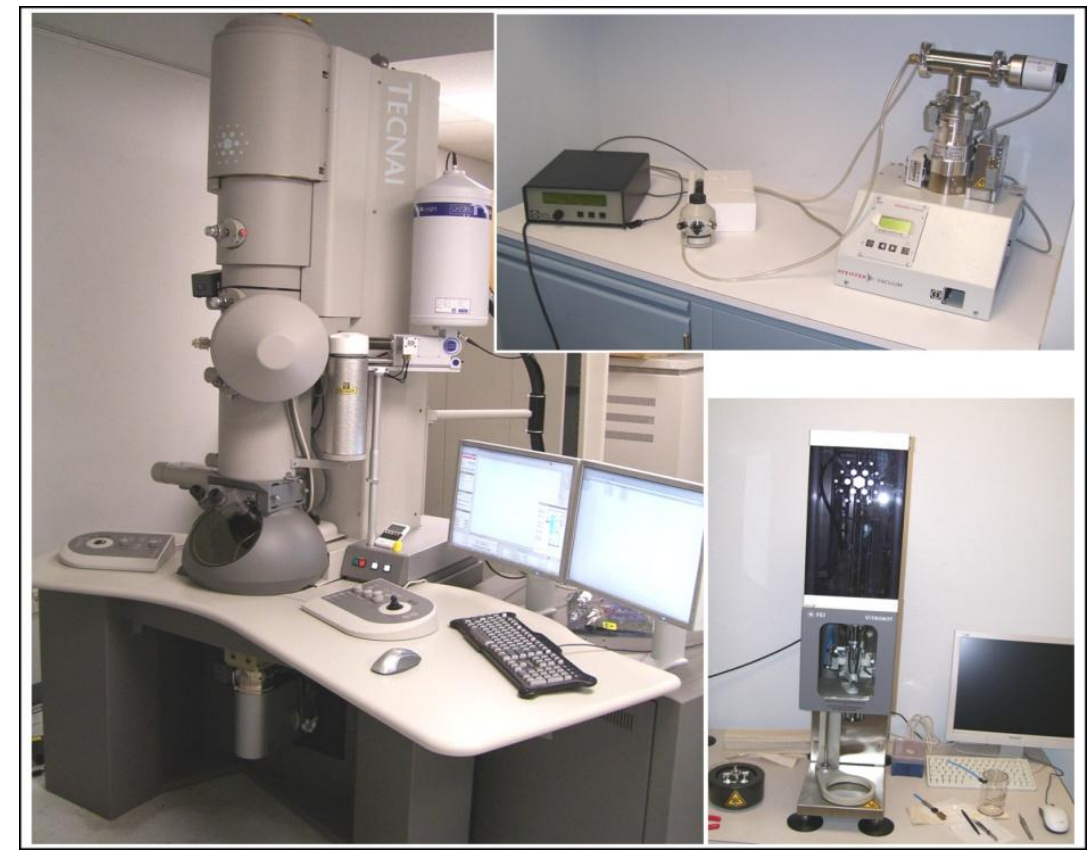

Fig. 1 FEI TECNAI G2 F20 FE-TEM (Microscopy center, Texas A\&M University) 


\subsubsection{Dynamic Light Scattering (DLS)}

Dynamic light scattering (DLS) is a technique used to determine particle size in suspensions [37]. The DLS experiments were performed using a BIC ZetaPALS with a BI-9000AT correlator. The wavelength of the incident laser beam $(\lambda)$ was $660 \mathrm{~nm}$, and the detector angle $(\theta)$ was $90^{\circ}$. For each sample, three or four measurements were performed and the elapsed time was $2 \mathrm{~min}$ or $5 \mathrm{~min}$ to ensure good signal-to-noise signal. The sampling and analysis were carried out in the self-beating mode. The delay time increased from $2 \mu s$ to $100 \mathrm{~ms}$, and the measurement was taken at room temperature. The intensity autocorrelation functions were analyzed with nonnegative constrained least-squares method (NNLS) [38]. For dilute system where the decay is generally due to translational, diffusive motion of the center of mass of the scatterer, it can be shown that:

$$
D_{t}=\frac{1}{\tau q^{2}}
$$

where $\mathrm{D}_{\mathrm{t}}$ is the translational diffusion coefficient, $q$ is the magnitude of the scattering wave vector , and $\tau$ is called the decay or relaxation time. The magnitude is expressed as follows:

$$
q=\frac{4 \pi n_{0}}{\lambda_{0}} \cdot \sin (\theta / 2)
$$

where $\mathrm{n}_{0}$ is the refractive index of the liquid, $\lambda_{0}$ is the wavelength of the laser in a vacuum, and $\theta$ is the scattering angle. The refractive index $(n)$ of the solution was taken 
to be 1.33. Given the dilute nature of the samples (Maximum 1 vol. $\% \mathrm{Al}_{2} \mathrm{O}_{3}$ ), particle particle interactions can be reasonably neglected and $D_{t}$ approaches to $D_{0}$ where $D_{0}$ is given by the Stokes-Einstein equation [39]:

$$
D_{0}=\frac{k_{B} T}{3 \pi \eta \cdot d_{h}}
$$

where $\mathrm{k}_{\mathrm{B}}$ is Boltzmann's constant, $1.3807 \times 10^{-16} \mathrm{ergs} / \mathrm{deg}$, $\mathrm{T}$ is the absolute temperature in Kelvin, $\eta$ is the bulk viscosity of the liquid in which the particle moves, and $d_{h}$ is the hydrodynamic diameter of the assumed sphere.

\subsubsection{Viscometer}

A Brookfield viscometer was used to measure viscosity. A UL Adaptor was used to measure viscosity at low values. The viscometer was able to measure viscosity from 1 to $10 \mathrm{cP}$ and up to $73.4 \mathrm{sec}^{-1}$ of shear rate (at $60 \mathrm{rpm}$ ). The UL Adaptor consists of a coaxial-cylinder like spindle and a polyethylene end cap for the outer cylinder. When all components were set up, the adaptor could hold $16 \mathrm{ml}$ of liquid. The viscometer converts the torque required to rotate an immersed element (the spindle) in a fluid to viscosity. With Brookfield viscometer, the viscosity of all nanofluids was measured at different temperatures and shear rates. In the result section, viscosity results are presented. 


\subsubsection{Thermal conductivity analyzer}

The thermal conductivity was measured by using a THW (Transient hotwire) apparatus. Nagasaka and Nagashima [40] first devised the system, which consisted of a platinum wire coated with a polyester insulation layer that was used as a heating element and a resistance thermometer. Some research teams have measured thermal conductivity using THW using bare wires. In the study, a platinum wire coated with a Teflon insulation layer was used to prevent from electric conduction. THW apparatus was connected to a Wheatstone bridge including four different resistances including one resistance for the platinum wire itself.

In the THW, $R_{1}$ and $R_{2}$ are standard $100 \Omega$ resistors, $R_{3}$ is the adjustable resistor (potentiometer) and $R_{x}$ is the platinum wire resistor.

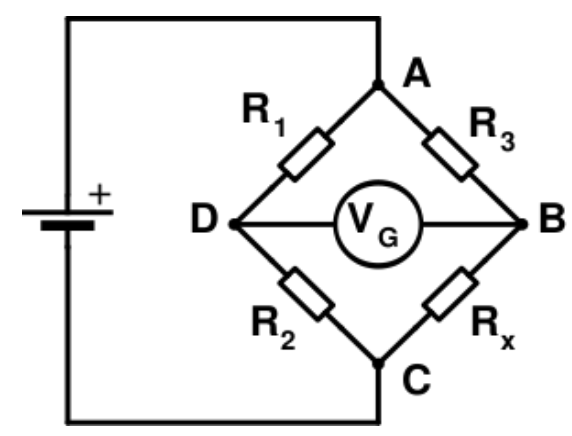

Fig. 2 Wheatstone bridge

$$
\frac{R_{2}}{R_{1}}=\frac{R_{x}}{R_{3}}
$$


The following is the theoretical equation used to determine thermal conductivity when using transient hot wire method [40]. A detailed explanation can be found in [40].

$$
\Delta \bar{T}=\frac{q}{4 \pi k}\left[\ln t+A+\frac{1}{t}(B \ln t+C)\right]
$$

The third term in the brackets can be neglected because the magnitude of the third term is below $5 \%$ of temperature rise, yielding the following equation:

$$
\Delta \bar{T}=\frac{q}{4 \pi k}[\ln t+A]
$$

To determine thermal conductivity, the wire voltage that appears in Eq. 3.11 should be used instead of $\Delta T$. Therefore, the wire voltage is correlated with $R_{x}$ and the relationship between $R_{x}$ and $\Delta T$ is needed to be able to find thermal conductivity. $R_{x}$ can be found using the following expression:

$$
R_{x}=R_{x o}(1+\beta \Delta T)
$$

$\beta$ : Temperature coefficient $\left[\mathrm{K}^{-1}\right]$ of platinum $(0.00392)$

$$
d R_{x}=R_{x o} \beta d \Delta T
$$

From (Eq. 3.6), we can take the derivative of each term, obtaining the following expression:

$$
d \Delta T=\frac{q}{4 \pi k} d \ln T
$$


(Eq. 3.9) is applied to (Eq. 3.8) and it follows that:

$$
d R_{x}=\frac{q \beta R_{x o}}{4 \pi k} d \ln T
$$

From the Wheatstone bridge shown above, the voltage across the bridge $\left(\mathrm{V}_{\mathrm{g}}\right)$ can be found using the supply voltage $(\mathrm{Vs})$ and three resistor values, $R_{1}, R_{2}$ and $R_{x}$.

$$
V_{g}=\left(\frac{R_{x}}{R_{3}+R_{x}}-\frac{R_{2}}{R_{1}+R_{2}}\right) V_{s}
$$

Taking the derivative of (Eq. 3.11), it follows that:

$$
d V_{g}=\frac{R_{x}^{\prime}\left(R_{3}+R_{x}\right)-R_{x}\left(R_{3}+R_{x}\right)^{\prime}}{\left(R_{3}+R_{x}\right)^{2}} V_{s}
$$

It is expressed as:

$$
d V_{g}=\frac{R_{3} V_{s}}{\left(R_{3}+R_{x}\right)^{2}} d R_{x}
$$

By substituting $d_{R_{x}}$ in (Eq. 3.13) using (Eq. 3.10), it follows that:

$$
d V_{g}=\frac{q \beta R_{x o} R_{3} V_{s}}{4 \pi k\left(R_{3}+R_{x}\right)^{2}} d \ln t
$$

Integrating each term again, (Eq. 3.14) becomes:

$$
V_{g}=A \ln t+B
$$


where,

$$
A=\frac{\beta R_{3} R_{x o} V_{s}}{\left(R_{x}+R_{3}\right)^{2}} \frac{q}{4 \pi k}=\frac{X}{Y} \frac{q}{4 \pi k}
$$

$\beta, R_{3}, R_{x o}, V_{s}, R_{x}$, and $q$ is known or can be measured. Using the LabView Signal Express software, $\mathrm{V}_{\mathrm{g}}$ versus $\ln (t)$ was plotted. From the slope of the graph of $\mathrm{V}_{\mathrm{g}}-\ln (t)$, $\boldsymbol{A}$ can be determined. From the value of $\boldsymbol{A}$, the thermal conductivity $\boldsymbol{k}$ of the liquid can be estimated.

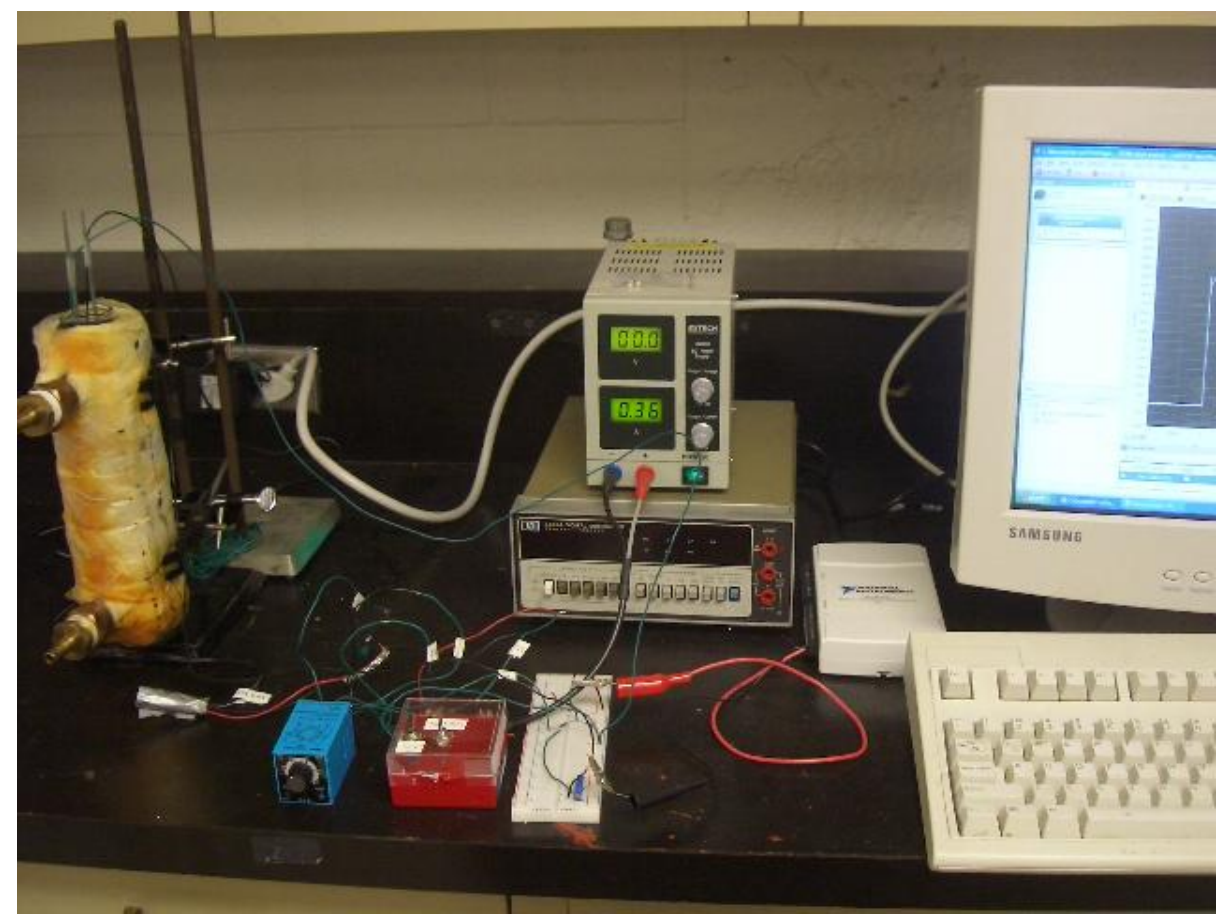

Fig. 3 Transient Hot Wire (THW) system 


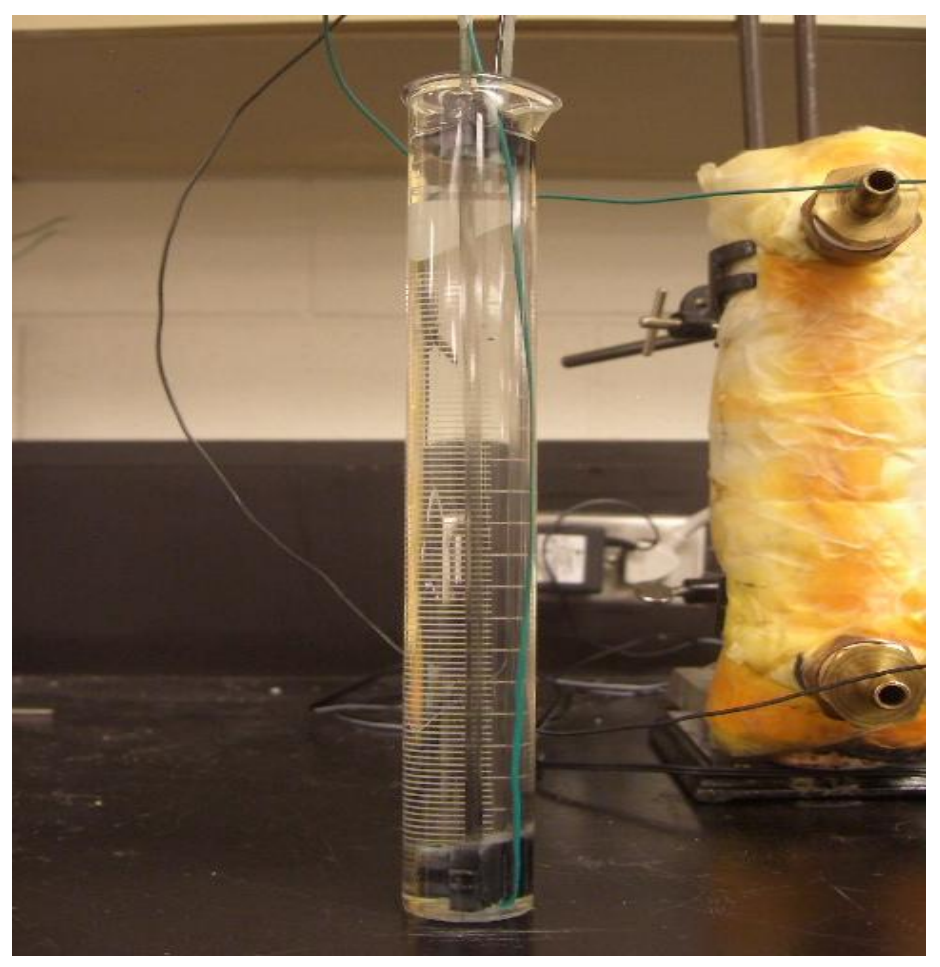

Fig. 4 Transient Hot Wire (THW) apparatus

A power supply, digital, switch, circuit board and computer were connected to the hotwire as shown in Figure 3. The hotwire itself was calibrated first in air to adjust the variable resistor, $R_{3}$, and then it was immersed in pure PAO (Royco 602) for calibration in fluid. The thermal conductivity value of pure PAO was obtained and compared with the values provided by the supplier and other sources [41]. A voltage of 4 V was used; data was collected for about 4 seconds. It was found that the optimum condition in which accurate thermal conductivity data could be gathered was between 1.6 to 2.6 seconds when the voltage was supplied from 1 to 5 seconds. Data were gathered only if the screen showed a smooth curve which depicted a clear relationship between $\mathrm{V}_{\mathrm{g}}$ and $\ln (t)$. A chiller was used to control temperature of the fluid. The 
following graph shows a smooth curve with raw voltage and time data after supplying voltage to the THW for 5 seconds.

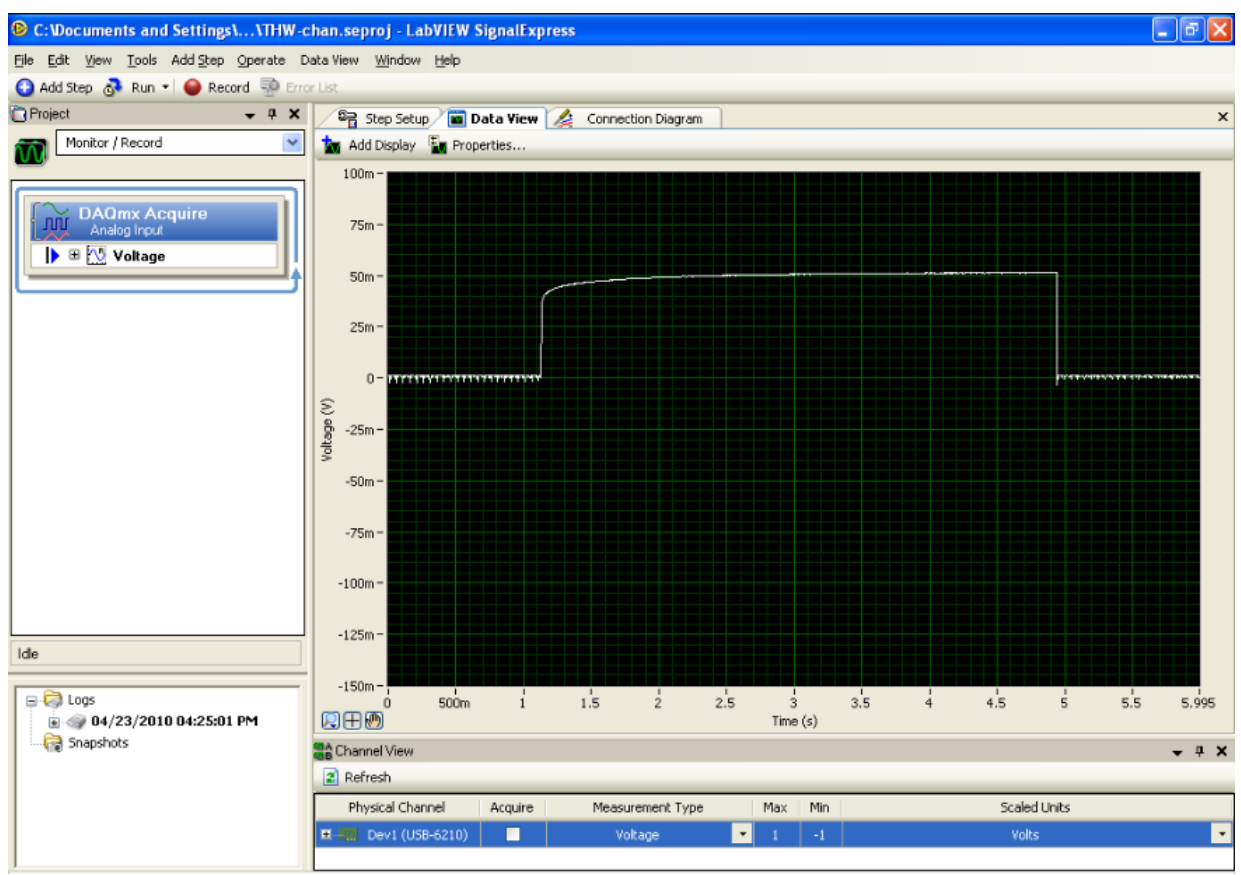

Fig. 5 The trend between supplied voltage and time

\subsubsection{Convective heat transfer section}

The experimental set up consisted of a copper heat transfer section, an Agilent data acquisition system, a D.C. power supply, two syringes and a computer as depicted in Figure 6. The test section was made of copper tubing $914.4 \mathrm{~mm}$ in length, with a 1.55 mm inner diameter and $3.175 \mathrm{~mm}$ outer diameter. 


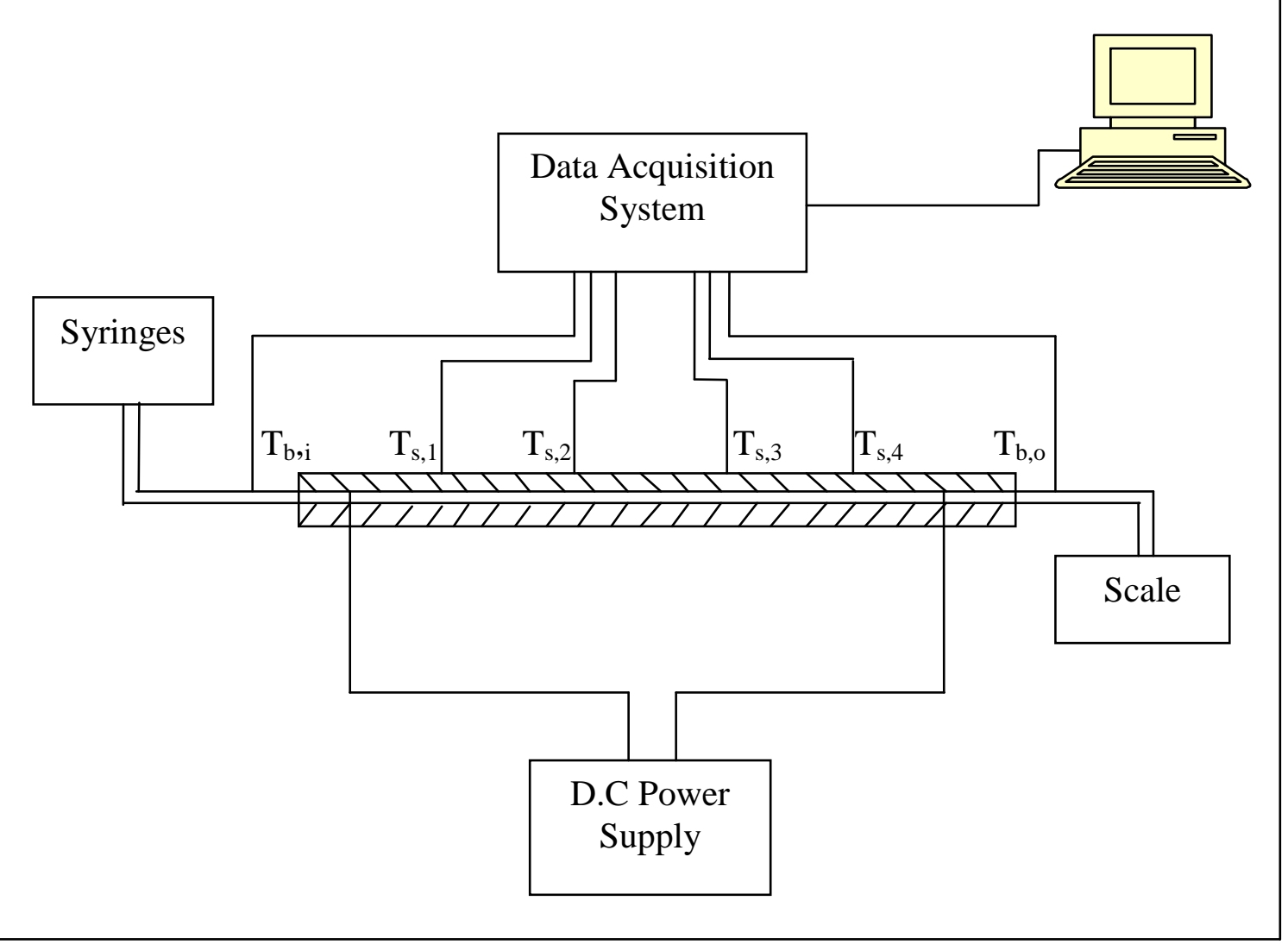

Fig. 6 Schematic for convective heat transfer measurement experimental set-up

The overall section was heated using AWG 30 nichrome 80 wire (MWS wire industries, USA) coiled around the tube and connected to a $1500 \mathrm{~W}, 0-300 \mathrm{~V}, 0-5 \mathrm{~A}$ D.C power supply (Lambda, USA). The experiments were performed under constant heat flux conditions using voltages of $60,62.5$ and $65 \mathrm{~V}$. The corresponding heat fluxes were 920, 999 and $1080.4 \mathrm{~W} / \mathrm{m}^{2}$. The tube was insulated with fiberglass to prevent heat loss to or from the surrounding. Four surface thermocouples were located on the test section at $19 \mathrm{~cm}\left(\mathrm{~T}_{\mathrm{s}, 1}\right), 39.5 \mathrm{~cm}\left(\mathrm{~T}_{\mathrm{s}, 2}\right), 59 \mathrm{~cm}\left(\mathrm{~T}_{\mathrm{s}, 3}\right), 79 \mathrm{~cm}\left(\mathrm{~T}_{\mathrm{s}, 4}\right)$ from the inlet section and were 
used to measure surface temperatures. Also, two other thermocouples were mounted at both inlet and outlet to measure the bulk temperature of the fluid at inlet and outlet. Two syringes were used to provide laminar fluid flow using dead weights on top of the syringes. The end of the loop was connected to a weight-scale to measure the mass of liquid flowing out of the loop as a function of time. Therefore, the mass flow rate was measured by measuring the weight of the fluid at various time intervals with a Denver Instrument APX-200 scale. The flow of the fluids was always laminar and the corresponding Reynolds number is within the range of $5 \sim 20$ and is shown in the Results section. All the thermocouples and the output from the D.C. power supply were connected to a Data Acquisition system (Agilent 34970A), which was connected to a computer. The experimental set-up was calibrated under isothermal and constant heat flux operating conditions. The calibration procedure is explained in Appendix B. The convective heat transfer coefficient at an axial distance ' $\mathrm{x}$ ' from inlet is described as:

$$
h(x)=\frac{q_{s}^{\prime \prime}}{T_{s}(x)-T_{b}(x)}
$$

where $q_{s}^{\prime \prime}, T_{s}(x)$ and $T_{b}(x)$ are heat flux applied to the fluid, surface or wall temperature at a distance ' $\mathrm{x}$ ' from the inlet, and the bulk temperature of fluid at a distance ' $\mathrm{x}$ ' from the inlet, respectively.

The specific heat of pure PAO (Royco 602) was obtained from [8]. The density and specific heat of Alumina nanofluid were calculated based on the following equations from [42] as follows: 


$$
\begin{aligned}
& \rho=\phi \rho_{p}+(1-\phi) \rho_{b f} \\
& c=\phi c_{p}+(1-\phi) c_{b f}
\end{aligned}
$$

where $p$ and $b f$ refer to the nanoparticles and base fluid, respectively. The specific heat of $\mathrm{Al}_{2} \mathrm{O}_{3}, c_{p}$ was obtained from [43] and the specific heat, $c_{p, b f}$ and density of pure PAO (Royco 602), $\rho_{b f}$ were also obtained from [44]. The density of PAO was also calculated from the measured volume and mass at room temperature, and matched well the values reported in [44]. It was assumed that the specific heat and density of $\mathrm{Al}_{2} \mathrm{O}_{3}$ were constant. The density of nanofluids at room temperature was found to be the same way and thus the density of $\mathrm{Al}_{2} \mathrm{O}_{3}$ was calculated using (Eq. 3.18). Conversely, the density of nanofluids was calculated at $45^{\circ} \mathrm{C}$ the same way. The specific heat of nanofluid was also obtained by (Eq. 3.19).

The heat flux through the copper tube is describes as:

$$
q_{s}^{\prime \prime}=\frac{\dot{m} c_{p}\left(T_{b, o}-T_{b, i}\right)}{A}
$$

Which is also expressed as

$$
q_{s}^{\prime \prime}=\frac{F\left(i^{2} R\right)}{A}
$$


where $T_{b, o}, A, F, i$ and $R$ are fluid bulk temperature at the outlet, inner surface area of the copper tube, fraction of DC power used to heat fluid, current through the coil, and the total resistance of the coil, respectively. ' $F$ ' was found from (Eq. 3.20) and (Eq. 3.21) and was found to be around 0.82 for the experiments. The heat capacity correction factor takes into account the net amount of heat flowing to the fluid.

From energy balance equation, the bulk temperature of the fluid at any point can be determined as follows:

$$
T_{b}(x)=T_{b, i}+\frac{q_{s}^{\prime \prime} P}{\dot{m} c_{p}} x
$$

where $T_{b, i}, P, x, \dot{m}$ and $c_{p}$ are the bulk temperature of fluid at inlet, perimeter of the copper tube, axial distance from the inlet section, mass flow rate of the fluid, and specific heat of the fluid, respectively.

The temperature data needed to be gathered in constant flow rate and the flow rate was controlled only by syringes and dead weights so both surface and bulk temperatures were recorded only after a quasi-steady flow was reached. After dead weights were put on top of the syringes, power was supplied to heat transfer section and it took around 11 12 min to reach a quasi-steady flow. Then the data was recorded for 50 scans and it took 1.5 1.7 min to complete recording. The quasi-steady state was sustained for several minutes but only the data for 50 scans was selected for analysis. 


\subsubsection{Sample preparation}

Different Alumina nanoparticles of different shapes, sizes and concentrations were suspended in PAO (Poly-Alpha-Olefin) and tested in the experiments. The nanofluid samples were made by METSS Corp., and were provided as proprietary liquids. The nanofluids have different characteristics depending as shown in Table 2. 'Synfluid2' is another kind of pure PAO and some additives were added for making nanofluids.

Table 2. PAO nanofluids formulation

\begin{tabular}{|c|c|c|c|c|}
\hline Name & Base fluid & $\begin{array}{c}\text { Morphology of } \\
\text { Alumina }\end{array}$ & $\begin{array}{c}\text { Volume } \% \text { of } \\
\text { particle }\end{array}$ & $\begin{array}{c}\text { Weight } \% \text { of } \\
\text { particle }\end{array}$ \\
\hline NF-007 & PAO (Royco 602) & platelet/spherical & $1 \% \mathrm{v} / \mathrm{v}$ & $5 \% \mathrm{w} / \mathrm{w}$ \\
\hline NF-013 & Additized PAO & platelet/spherical & $4 \% \mathrm{v} / \mathrm{v}$ & $20 \% \mathrm{w} / \mathrm{w}$ \\
\hline NF-046 & $\begin{array}{c}\text { Additized } \\
\text { SynFluid2 }\end{array}$ & platelet/spherical & $1 \% \mathrm{v} / \mathrm{v}$ & $5 \% \mathrm{w} / \mathrm{W}$ \\
\hline NF-048 & $\begin{array}{c}\text { Additized } \\
\text { SynFluid2 }\end{array}$ & needle & $0.5 \% \mathrm{v} / \mathrm{v}$ & $2.5 \% \mathrm{w} / \mathrm{w}$ \\
\hline NF-049 & Additized PAO & needle & $0.5 \% \mathrm{v} / \mathrm{v}$ & $5 \% \mathrm{w} / \mathrm{w}$ \\
\hline
\end{tabular}

Each sample was characterized using dynamic light scattering (DLS) and transmission electron microscopy (TEM) to verify the morphology claimed by the nanofluid supplier. Descriptions of the nanofluid characterization are included in the 
following chapter.

\subsection{Summary of experiments}

The following table provides a summary of experiments conducted in the study.

Table 3. Summary of experiments

\begin{tabular}{|c|c|c|c|c|}
\hline Fluid Type & $\begin{array}{c}\text { Imaging } \\
\text { analysis }\end{array}$ & $\begin{array}{c}\text { Viscosity } \\
\text { measurement }\end{array}$ & $\begin{array}{c}\text { Thermal } \\
\text { conductivity } \\
\text { measurement }\end{array}$ & $\begin{array}{c}\text { Convective } \\
\text { heat transfer } \\
\text { measurement }\end{array}$ \\
\hline Pure PAO & & $\begin{array}{c}\text { At } 25^{\circ} \text { and } \\
45^{\circ} \mathrm{C}\end{array}$ & $\begin{array}{c}\text { At } 25^{\circ} \text { and } \\
45^{\circ} \mathrm{C}\end{array}$ & $\begin{array}{c}\text { Under laminar } \\
\text { and constant } \\
\text { heat flux } \\
\text { condition }\end{array}$ \\
\hline NF-007 & DLS & $\begin{array}{c}\text { At } 25^{\circ} \text { and } \\
45^{\circ} \mathrm{C}\end{array}$ & $\begin{array}{c}\text { At } 25^{\circ} \text { and } \\
45^{\circ} \mathrm{C}\end{array}$ & \\
\hline NF-013 & DLS & $\begin{array}{c}\text { At } 25^{\circ} \text { and } \\
45^{\circ} \mathrm{C}\end{array}$ & $\begin{array}{c}\text { At } 25^{\circ} \text { and } \\
45^{\circ} \mathrm{C}\end{array}$ & \\
\hline NF-046 & TEM, DLS & $\begin{array}{c}\text { At } 25^{\circ} \text { and } \\
45^{\circ} \mathrm{C}\end{array}$ & $\begin{array}{c}\text { At } 25^{\circ} \text { and } \\
45^{\circ} \mathrm{C}\end{array}$ & \\
\hline NF-048 & TEM & $\begin{array}{c}\text { At } 25^{\circ} \text { and } \\
45^{\circ} \mathrm{C}\end{array}$ & $\begin{array}{c}\text { At } 25^{\circ} \text { and } \\
45^{\circ} \mathrm{C}\end{array}$ & $\begin{array}{c}\text { Under laminar } \\
\text { and constant } \\
\text { heat flux } \\
\text { condition }\end{array}$ \\
\hline NF-049 & & At $25^{\circ}$ and \\
$45^{\circ} \mathrm{C}$ & $\begin{array}{c}\text { At } 25^{\circ} \text { and } \\
45^{\circ} \mathrm{C}\end{array}$ & \\
\hline
\end{tabular}

For DLS imaging, NF-007, NF-013 and NF-046 were chosen which contain spherical nanoparticles because DLS imaging is based on the assumption that all nanoparticles are spherical. NF-046 and NF-048 were selected for TEM imaging since 
those two nanofluids consisted of needle type nanoparticles. The viscosity and thermal conductivity were measured at 25 and $45{ }^{\circ} \mathrm{C}$ for all nanofluids. For convective heat transfer measurement, only the fluids that exhibited the best thermal performance were selected for heat transfer testing. NF-048 was chosen and used for heat transfer testing, and the data were compared to that of pure PAO (Royco 602). 


\section{CHAPTER IV}

\section{RESULTS AND DISCUSSION}

This chapter describes the experimental data obtained from viscosity thermal conductivity, and convective heat transfer measurements. Analysis of the results was undertaken taking into account existing theories and past published research work.

\subsection{Imaging data}

\subsubsection{TEM image of NF-046 and NF-048}

A variety of scan methods were used for size analysis of NF-046 and NF-048. Figures 7 and 8 show the acquired images using HAADF-STEM, which were used to determine the presence and indirect concentration of Alumina nanoparticles [45]. Figures 9 and 10 show the raw trend of counts vs. energy put in the sample. HAADFSTEM based images confirmed the presence of aluminum atoms in the samples. It was found that the density of Alumina nanoparticles in NF-048 was higher than in NF-046 based on the bigger number of counts. The grid at the bottom of nanofluid was made of copper so that's why copper counts also show up in the figure. 


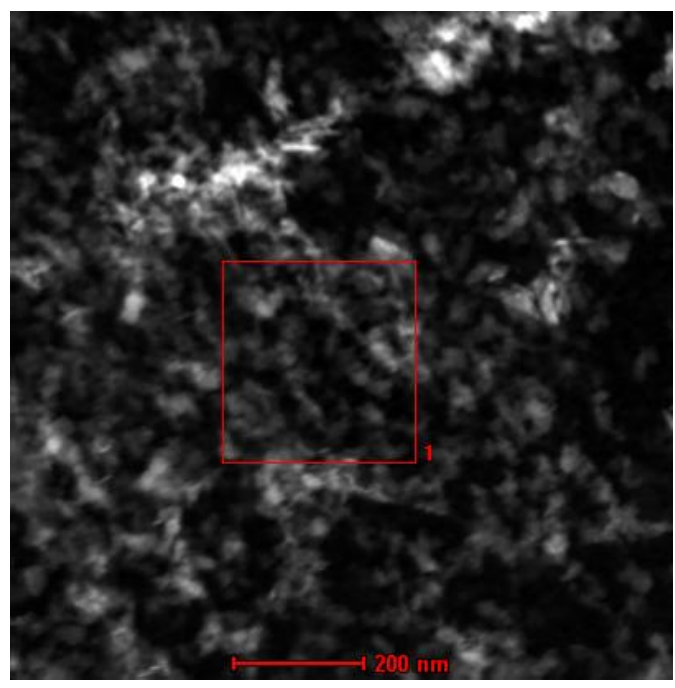

Fig. 7 NF-046 acquire HAADF

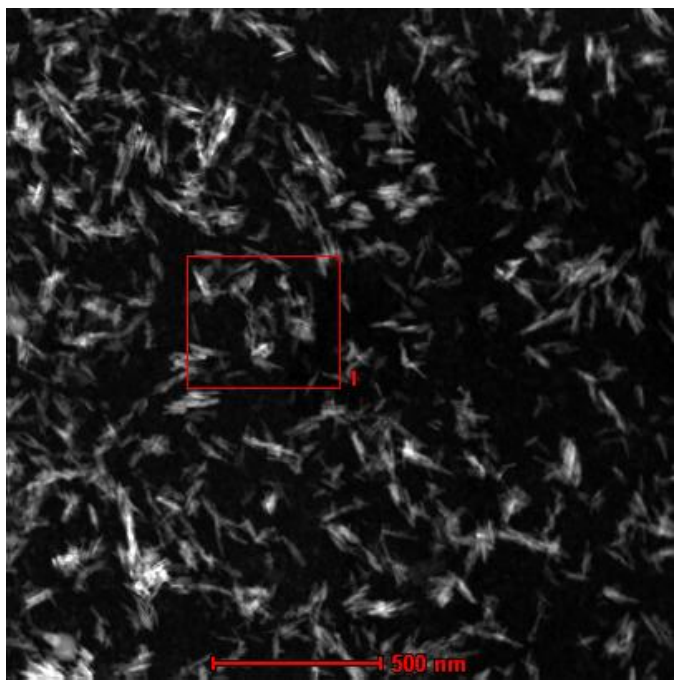

Fig. 8 NF-048 acquire HAADF

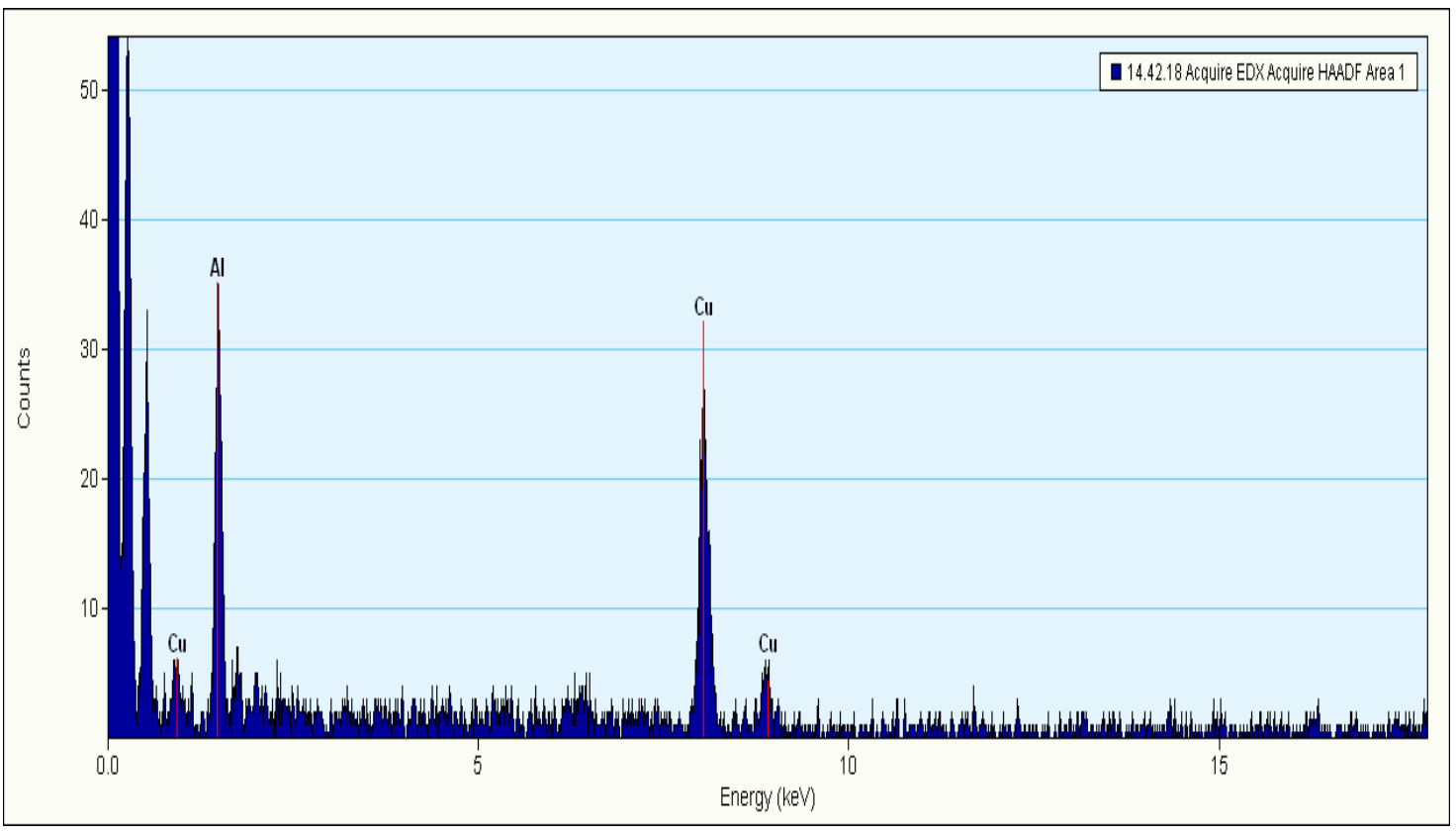

Fig. 9 NF-046 HAADF scan 


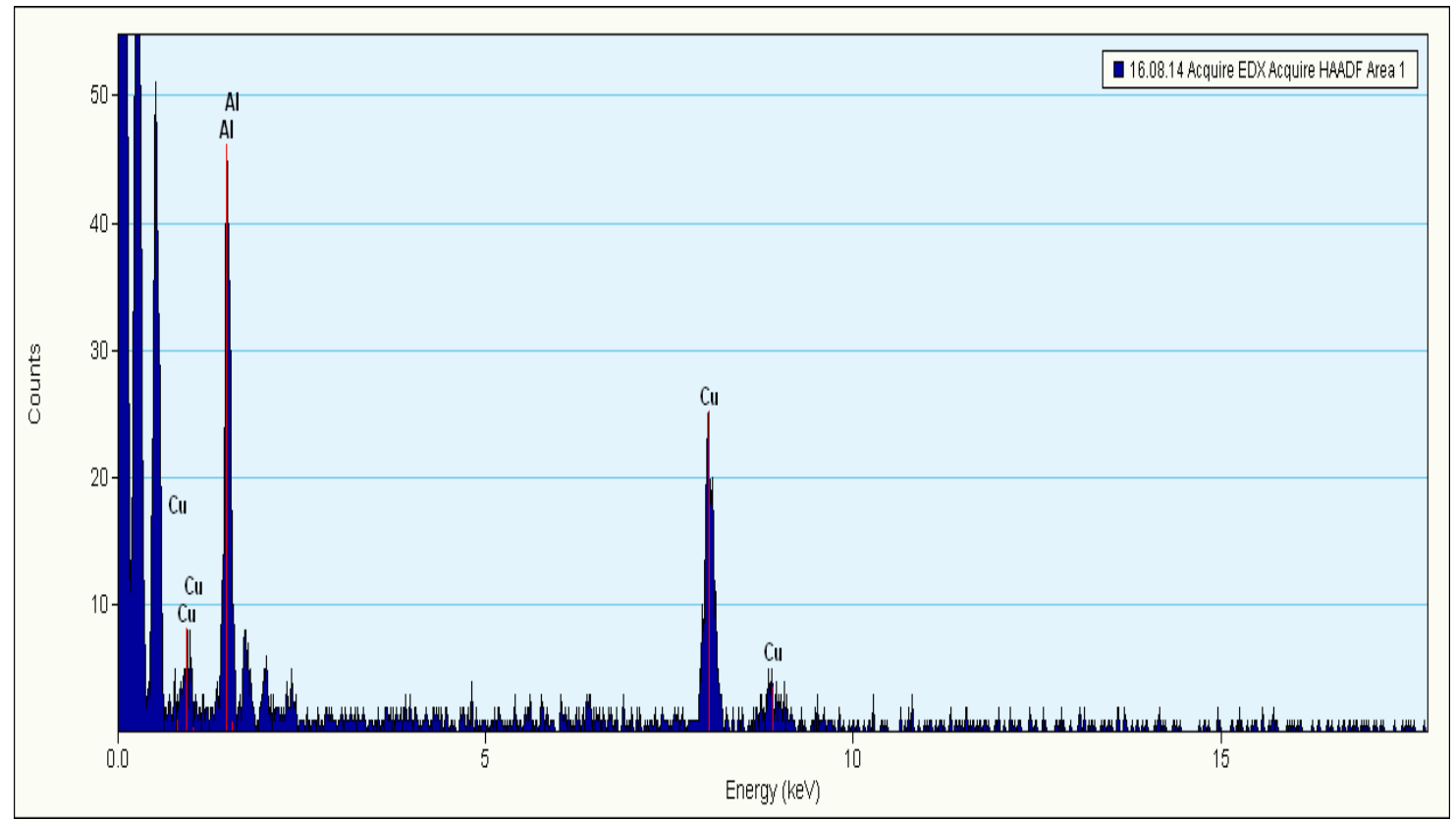

Fig. 10 NF-048 HAADF scan

From HAADF scan, line scan was performed. Figures 11 and 12 show the drift corrected spectrum profile which determines the range for line scan. Figures 13 and 14 show the linescan image. It was found that nanoparticle size in NF-046 was larger than in NF-048. 


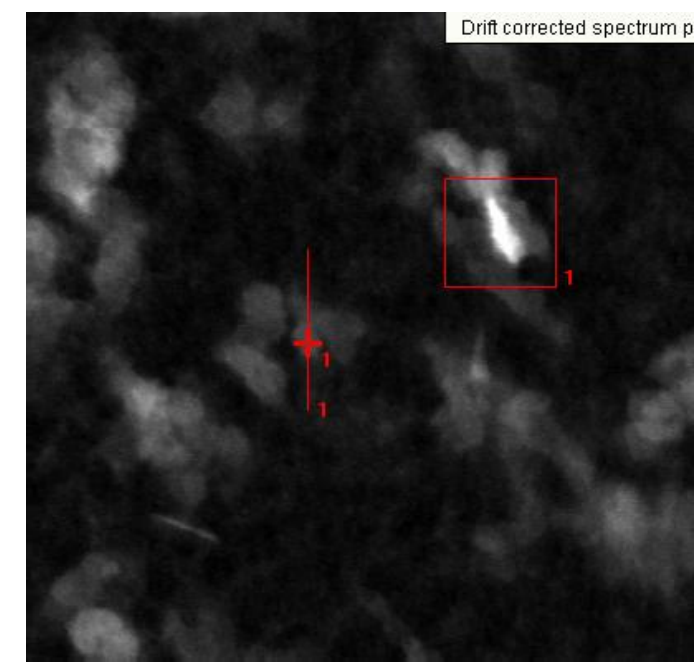

Fig. 11 NF-046 drift corrected spectrum profile

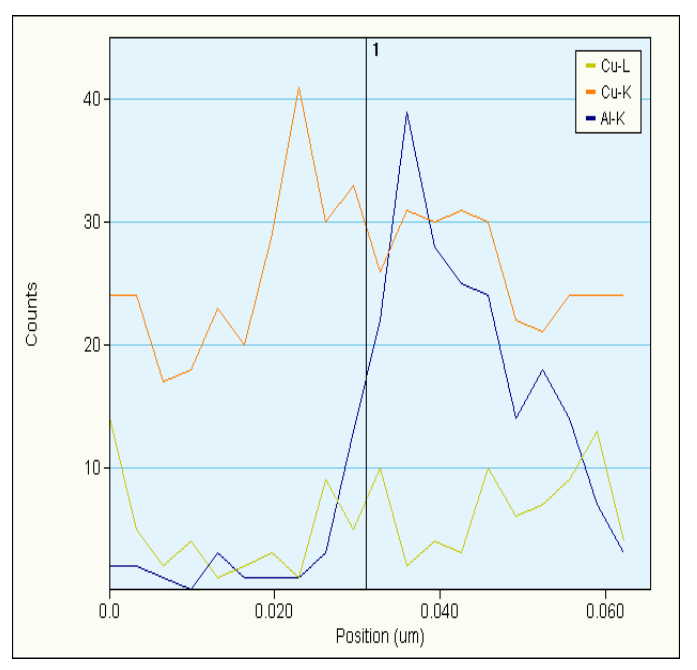

Fig. 13 NF-046 linescan

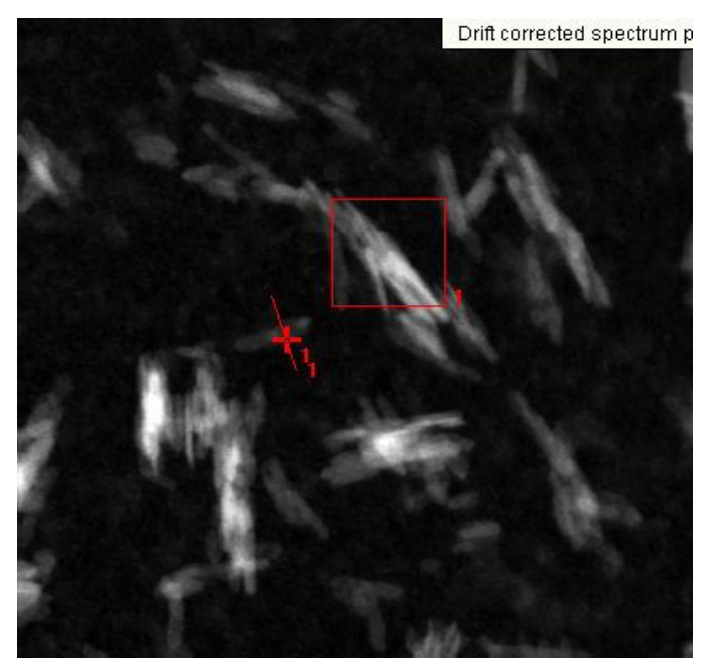

Fig. 12 NF-048 drift corrected spectrum profile

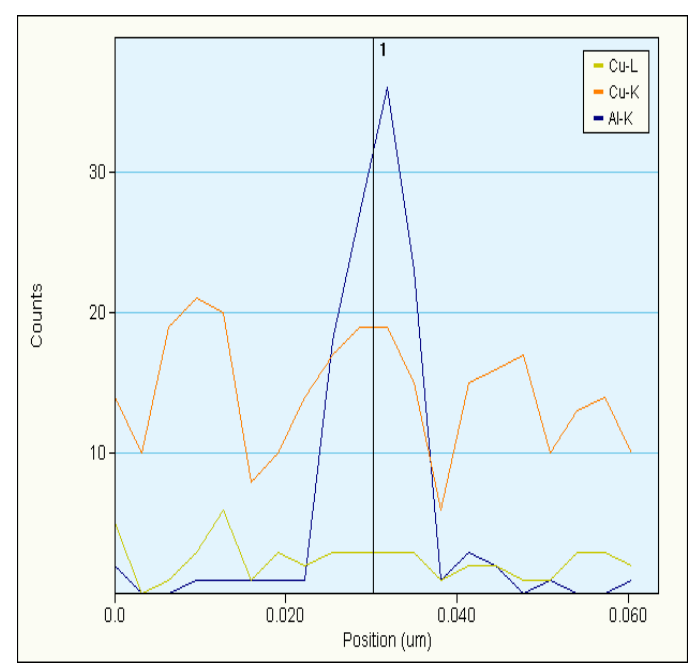

Fig. 14 NF-048 linescan

Figures 15 and 16 show the TEM images taken of each samples at $100 \mathrm{~nm}$ (scale). Figures 17 and 18 show the TEM image of NF-046 and NF-048 samples at 50 nm (scale). 


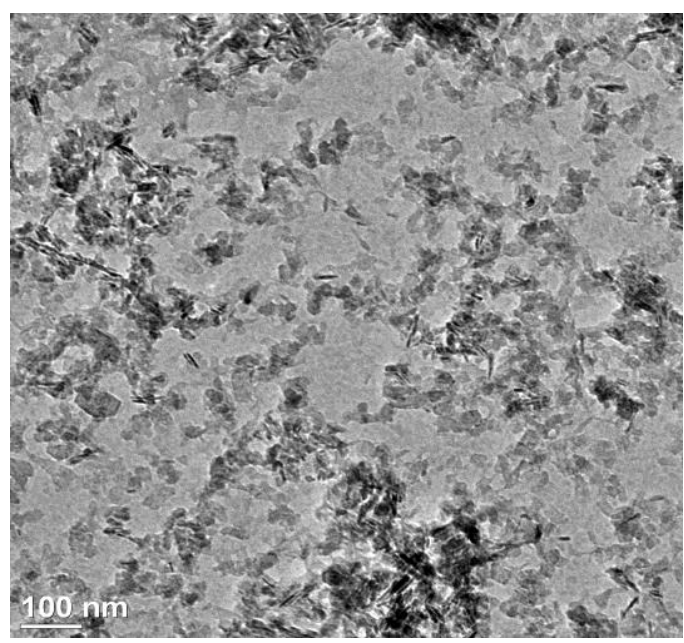

Fig. 15 NF-046 (100nm)

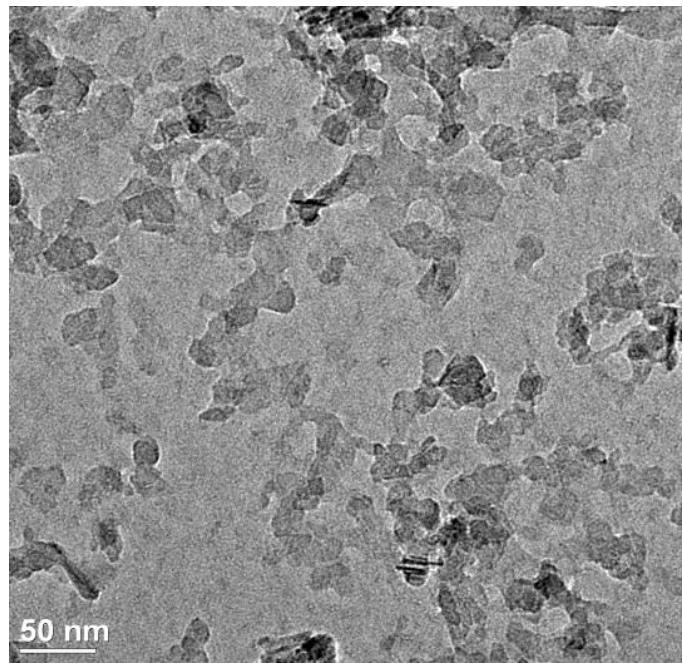

Fig. 17 NF-046 (50nm)

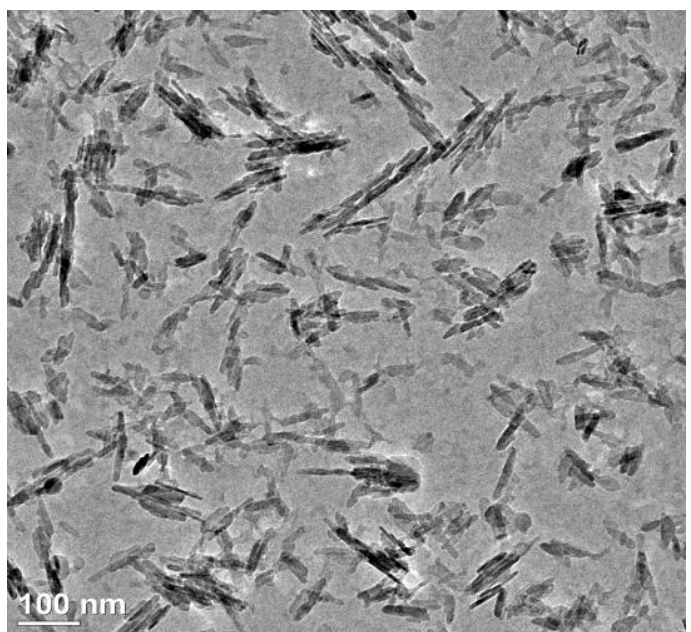

Fig. 16 NF-048 (100nm)

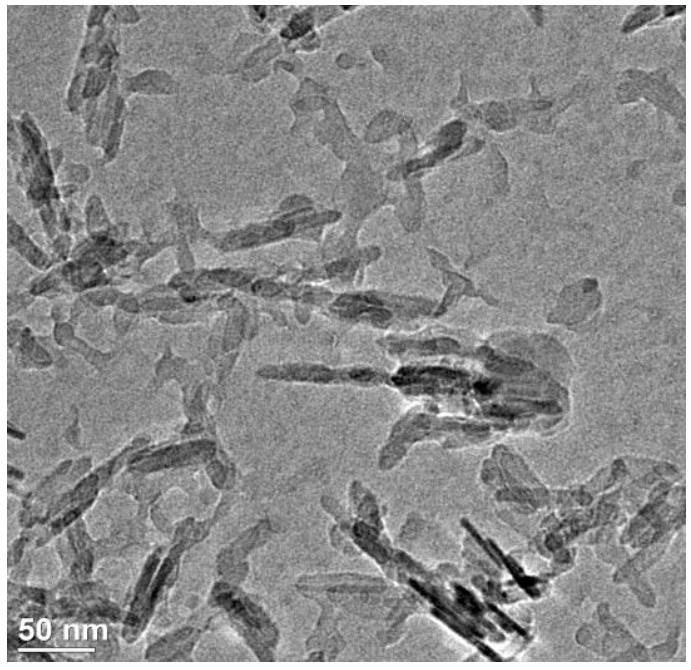

Fig. 18 NF-048 (50nm)

From the TEM images of NF-046 and NF-048, the particle shape information could be found which is spherical and non-spherical, respectively. In addition, an estimate of particle size could be estimated. NF-048 has definite non-spherical morphology while NF-046 has spherical morphology. 


\subsubsection{Dynamic Light Scattering data of NF-007, 013 and 046}

DLS experiments were performed on NF-013 which had $4 \%$ volume fraction. Before running the DLS test, it was diluted to 1 vol. \%. The particle hydrodynamic diameter was calculated from the translational diffusion coefficient using the StokesEinstein equation under the assumption that the particles were spherical and using the measured viscosity. Assuming that the nanoparticles exhibited Brownian motion, the nanoparticle sizes were found using the Stokes-Einstein equation. NF-007, NF-013 and NF-046 were the only samples that contained spherical nanoparticles. The obtained DLS data for NF-007, NF-013 and NF-046 were analyzed using the following data decomposition techniques.

\subsubsection{Particle size information from cumulant fitting}

In DLS analysis [46], the method of cumulants was first proposed for analyzing Polydispersity by fitting light scattering data after interacting with nanoparticles. The method of cumulants is one of the fitting routines that DLS provides. According to [46] the "Poly" (short for polydispersity) is a measure of the width of the decay rate distribution. That is, the "Poly" is the intensity-weighted relative variance of the diffusion coefficient and a measure of the size distribution width [46]. When the 'Poly' equals to zero, the sample is considered to be monodispersed. The cumulant method verified that the higher order terms do not affect significantly so the analysis works best 
if Poly $\leq 0.3$ especially for quadratic fitting. Thus, only quadratic model was used for determining particle size. Also, the 'Poly' value was larger than 0.025 for all cases, thus, the nanofluid samples were considered to be polydispersed. Figures 19-22 show DLS results for NF-007. Table 4 summarizes all the DLS results for NF-007.

$\begin{array}{lcccc} & \text { Diff. Coef. }\left(\mathrm{cm}^{2} \mathrm{~s}^{-1} \text { ) }\right. & \text { Eff. Diam. (nm) } & \text { Poly } & \text { RMS Error } \\ \text { Linear: } & 9.803 \mathrm{e}-09 & 55.5 & & 1.9821 \mathrm{e}-03 \\ \text { Quadratic: } & 1.152 \mathrm{e}-08 & 47.2 & 0.313 & 1.8736 \mathrm{e}-03 \\ \text { Cubic: } & 1.236 \mathrm{e}-08 & 44.0 & 0.532 & 2.5785 \mathrm{e}-04 \\ \text { Quartic: } & 1.274 \mathrm{e}-08 & 42.7 & 0.666 & 1.9588 \mathrm{e}+04\end{array}$
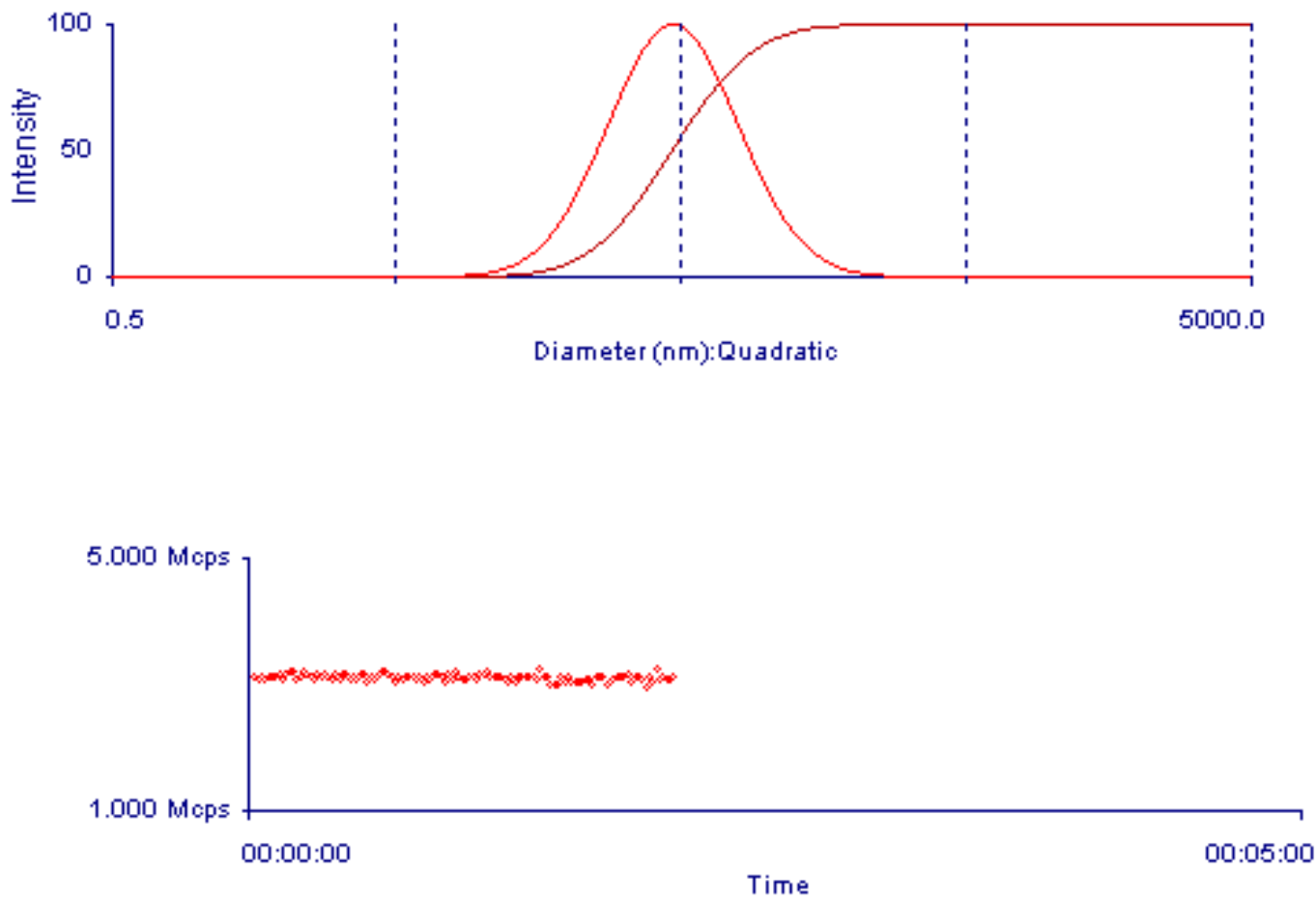

Fig. 19 DLS test 1 results for NF-007 


$\begin{array}{lcccc} & \text { Diff. Coef. }\left(\mathrm{cm}^{2} s^{-1} \text { ) }\right. & \text { Eff. Diam. (nm) } & \text { Poly } & \text { RMS Error } \\ \text { Linear: } & 1.067 \mathrm{e}-08 & 51.0 & & 3.2064 \mathrm{e}-03 \\ \text { Quadratic: } & 1.253 \mathrm{e}-08 & 43.4 & 0.313 & 1.8873 \mathrm{e}-03 \\ \text { Cubic: } & 1.346 \mathrm{e}-08 & 40.4 & 0.546 & 4.5239 \mathrm{e}-04 \\ \text { Quartic: } & 1.382 \mathrm{e}-08 & 39.3 & 0.675 & 6.2438 \mathrm{e}+00\end{array}$
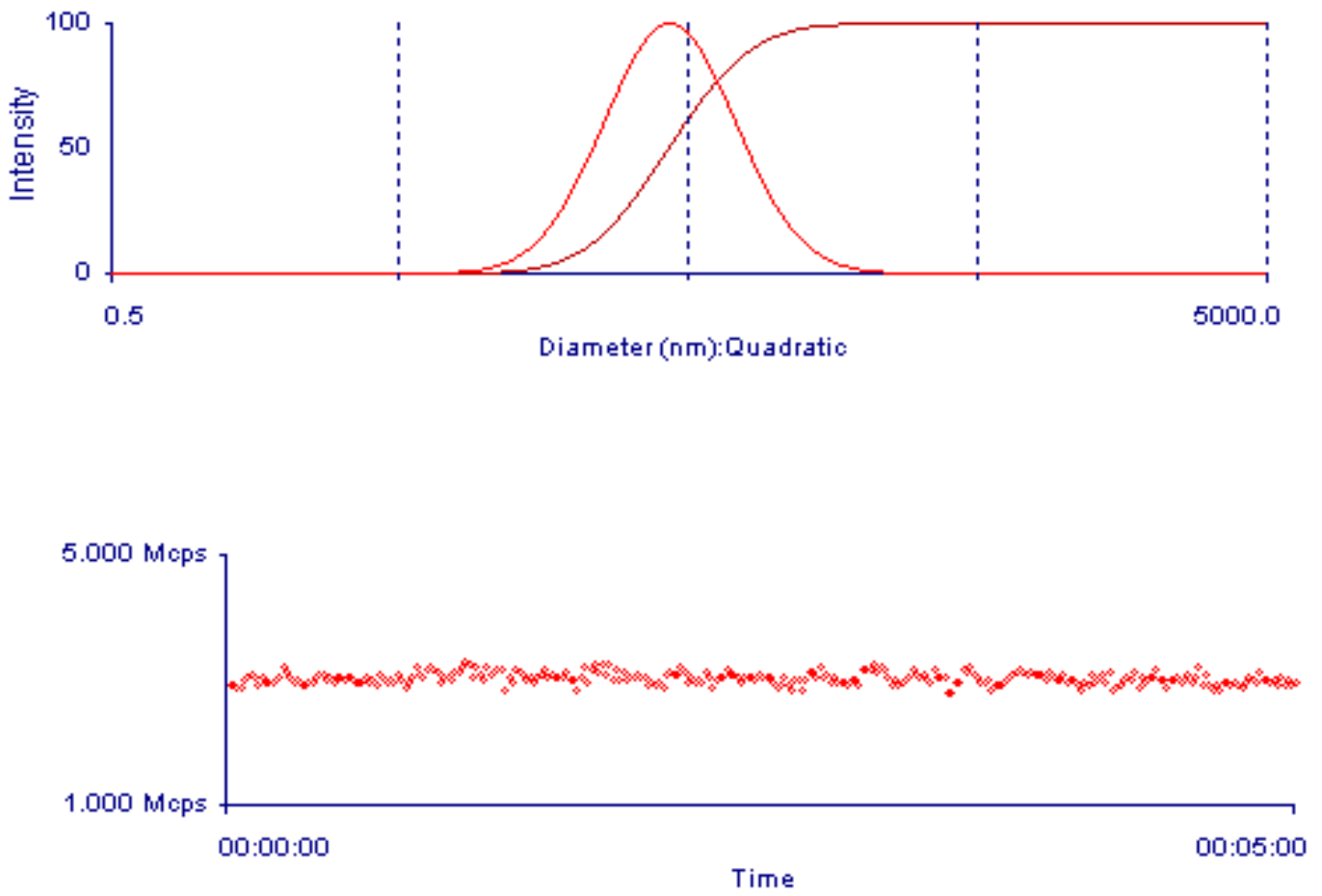

Fig. 20 DLS test 2 results for NF-007 


$\begin{array}{llllll}\text { STOPPED } & & \text { Temp: } & 23.0 \mathrm{deg} \text { C } & \text { MS 0 Chan: } & \text { Undefined } \\ \text { Signal: } & \text { Auto C } & \text { Ref Index: } & 1.331 & \text { Normalization: } & \text { M. Base } \\ \text { First Delay: } & 5.0 \mu \mathrm{sec} & \text { Samples: } & 5.6099 \mathrm{e}+07 & \text { M. Base: } & 1.2480 \mathrm{e}+1 \\ \text { Last Delay: } & 20.0 \mathrm{msec} & \text { Atot: } & 8.3680 \mathrm{e}+08 & \text { C. Base: } & 1.2482 \mathrm{e}+1 \\ \text { Elapsed Time: } & 00: 05: 00 & \text { A.CR [avg.]: } & 3.0 \mathrm{Mcps} & \text { Base diff: } & -0.017 \% \\ \text { Wavelength: } & 660.0 \mathrm{~nm} & \text { Btot: } & 8.3680 \mathrm{e}+08 & \text { Eff Dia: } & 45.7 \mathrm{~nm} \\ \text { Angle: } & 90.0 & \text { B CR (avg.): } & 3.0 \mathrm{Mcps} & \text { Poly: } & 0.250\end{array}$

$\begin{array}{lcccc} & \text { Diff. Coef. }\left[\mathrm{cm}^{2} \mathrm{~s}^{-1} \text { ] }\right. & \text { Eff. Diam. (nm) } & \text { Poly } & \text { RMS Error } \\ \text { Linear: } & 1.030 \mathrm{e}-08 & 52.8 & & 3.6116 \mathrm{e}-03 \\ \text { Quadratic: } & 1.190 \mathrm{e}-08 & 45.7 & 0.250 & 7.8794 \mathrm{e}-03 \\ \text { Cubic: } & 1.284 \mathrm{e}-08 & 42.3 & 0.409 & 1.4279 \mathrm{e}-03 \\ \text { Quartic: } & 1.356 \mathrm{e}-08 & 40.1 & 0.582 & 2.5700 \mathrm{e}+05\end{array}$
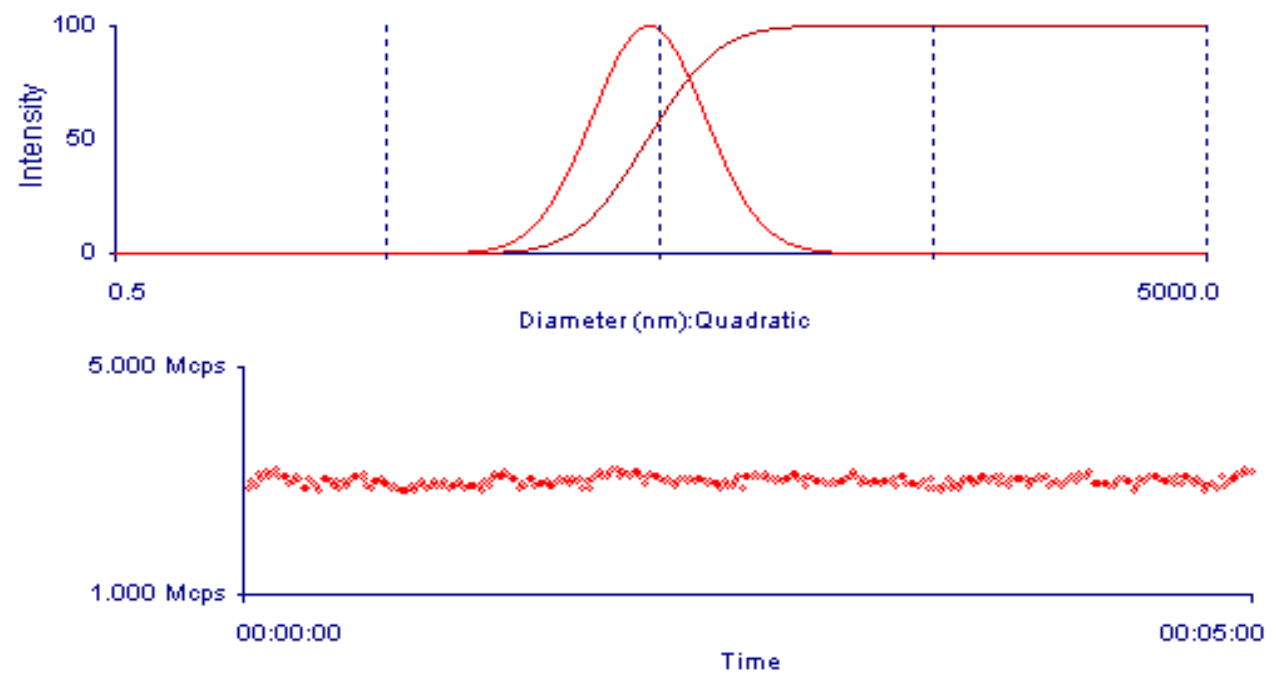

Fig. 21 DLS test 3 results for NF-007 


$\begin{array}{lcccc} & \text { Diff. Coef. }\left(\mathrm{cm}^{2} \mathrm{~s}^{-1} \text { ) }\right. & \text { Eff. Diam. (nm) } & \text { Poly } & \text { RMS Error } \\ \text { Linear: } & 9.751 \mathrm{e}-09 & 55.8 & & 1.9815 \mathrm{e}-03 \\ \text { Quadratic: } & 1.146 \mathrm{e}-08 & 47.4 & 0.309 & 2.4752 \mathrm{e}-03 \\ \text { Cubic: } & 1.234 \mathrm{e}-08 & 44.1 & 0.528 & 3.7787 \mathrm{e}-04 \\ \text { Quartic: } & 1.288 \mathrm{e}-08 & 42.2 & 0.709 & 1.8508 \mathrm{e}+05\end{array}$
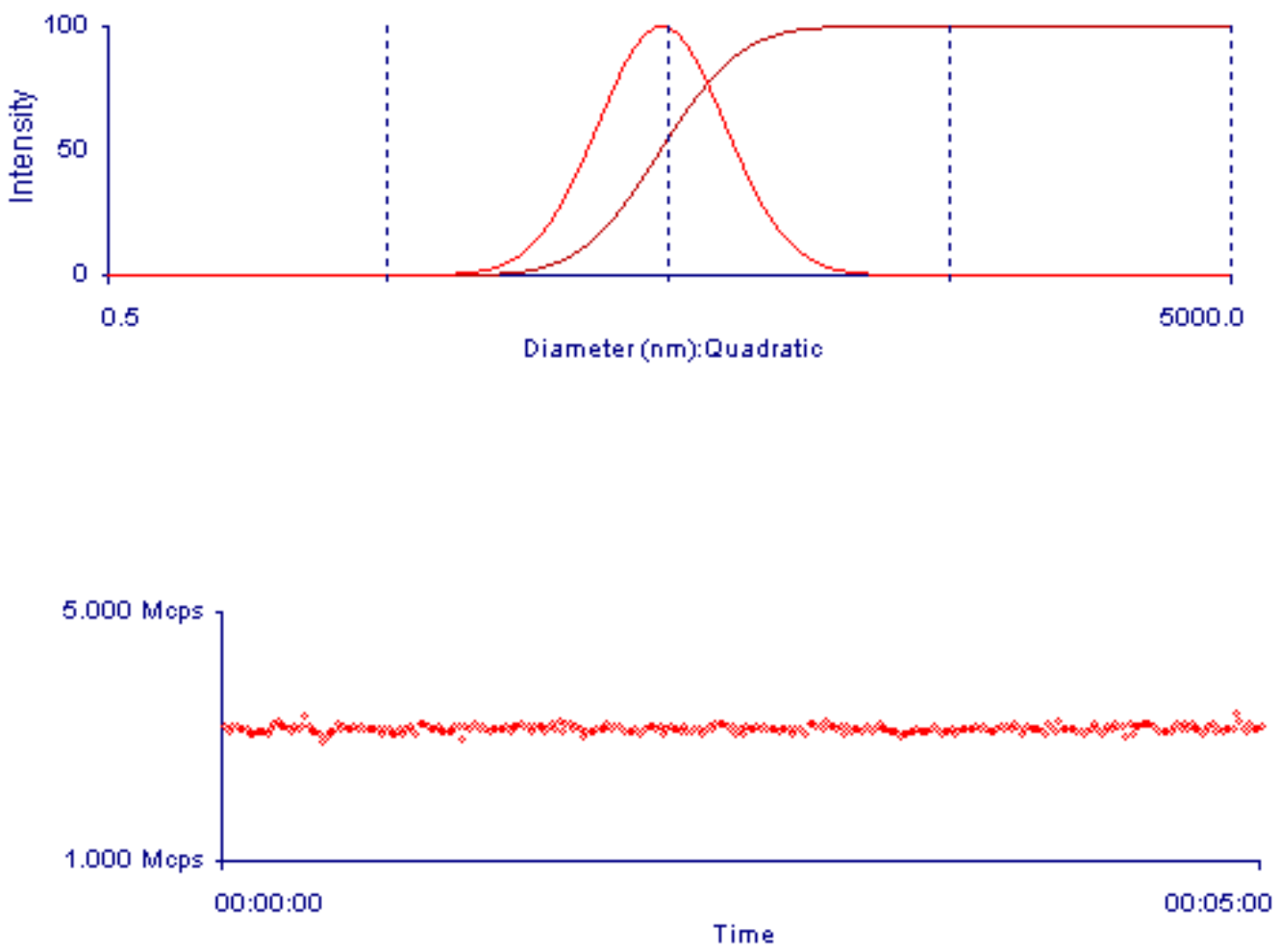

Fig. 22 DLS test 4 results for NF-007 
Table 4. Effective diameter of NF-007

\begin{tabular}{|c|c|c|c|c|}
\hline Type of fit & $\begin{array}{c}\text { Diffusion } \\
\text { Coefficient } \\
\left(\mathrm{cm}^{2} . \mathrm{s}^{-1}\right)\end{array}$ & $\begin{array}{c}\text { Effective } \\
\text { Diameter }(\mathrm{nm})\end{array}$ & Poly & RMS Error \\
\hline Quadratic & $1.152 \mathrm{E}-08$ & 47.2 & 0.313 & $1.8736 \mathrm{E}-03$ \\
\hline Quadratic & $1.253 \mathrm{E}-08$ & 43.4 & 0.313 & $1.8870 \mathrm{E}-03$ \\
\hline Quadratic & $1.190 \mathrm{E}-08$ & 45.7 & 0.250 & $7.8794 \mathrm{E}-03$ \\
\hline $\begin{array}{c}\text { Quadratic } \\
\text { Qune of }\end{array}$ & $1.146 \mathrm{E}-08$ & 47.4 & 0.309 & $2.4752 \mathrm{E}-03$ \\
\hline $\begin{array}{c}\text { Average } \\
\text { all quadratic } \\
\text { fits }\end{array}$ & 45.9 & & \\
\hline
\end{tabular}

Figures 23-25 show DLS results for NF-013. Table 5 summarizes all the DLS results for NF-013. 


$\begin{array}{lcccc} & \text { Diff. Coef. }\left(\mathrm{cm}^{2} \mathrm{~s}^{-1} \text { ) }\right. & \text { Eff. Diam. (nm) } & \text { Poly } & \text { RMS Error } \\ \text { Linear: } & 6.573 \mathrm{e}-09 & 45.7 & & 4.6276 \mathrm{e}-03 \\ \text { Quadratic: } & 8.410 \mathrm{e}-09 & 35.7 & 0.362 & 1.1155 \mathrm{e}-02 \\ \text { Cubic: } & 9.516 \mathrm{e}-09 & 31.5 & 0.621 & 1.1246 \mathrm{e}-03 \\ \text { Quartic: } & 1.026 \mathrm{e}-08 & 29.3 & 0.834 & 2.1699 \mathrm{e}+05\end{array}$
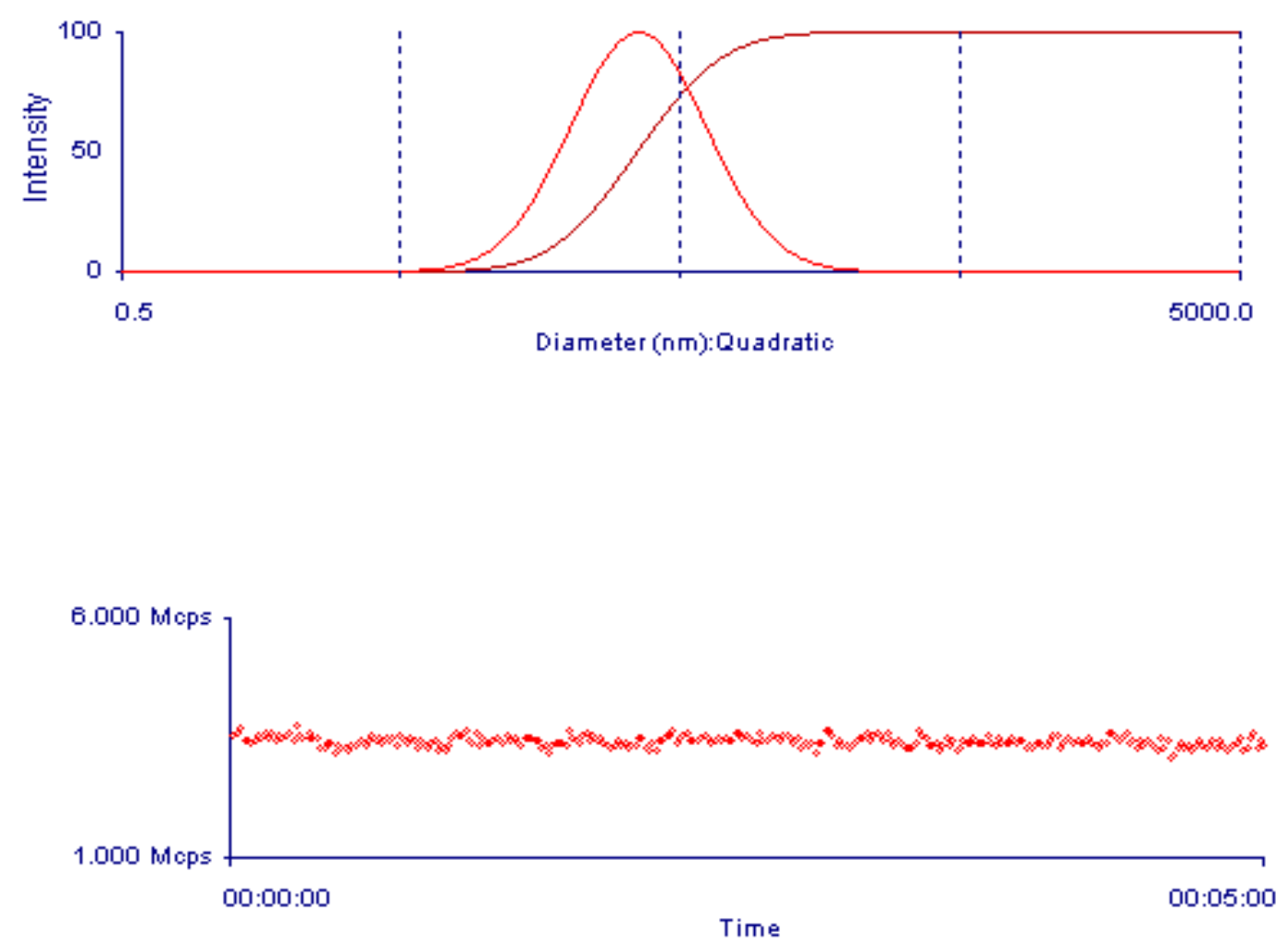

Fig. 23 DLS test 1 results for NF-013 


$\begin{array}{lcccc} & \text { Diff. Coef. }\left(\mathrm{cm}^{2} \mathrm{~s}^{-1} \text { ) }\right. & \text { Eff. Diam. (nm) } & \text { Poly } & \text { RMS Error } \\ \text { Linear: } & 6.729 \mathrm{e}-09 & 44.6 & & 4.5126 \mathrm{e}-03 \\ \text { Quadratic: } & 8.375 \mathrm{e}-09 & 35.9 & 0.351 & 8.8433 \mathrm{e}-03 \\ \text { Cubic: } & 9.349 \mathrm{e}-09 & 32.1 & 0.598 & 1.4372 \mathrm{e}-03 \\ \text { Quartic: } & 1.020 \mathrm{e}-08 & 29.4 & 0.858 & 2.3535 \mathrm{e}+05\end{array}$
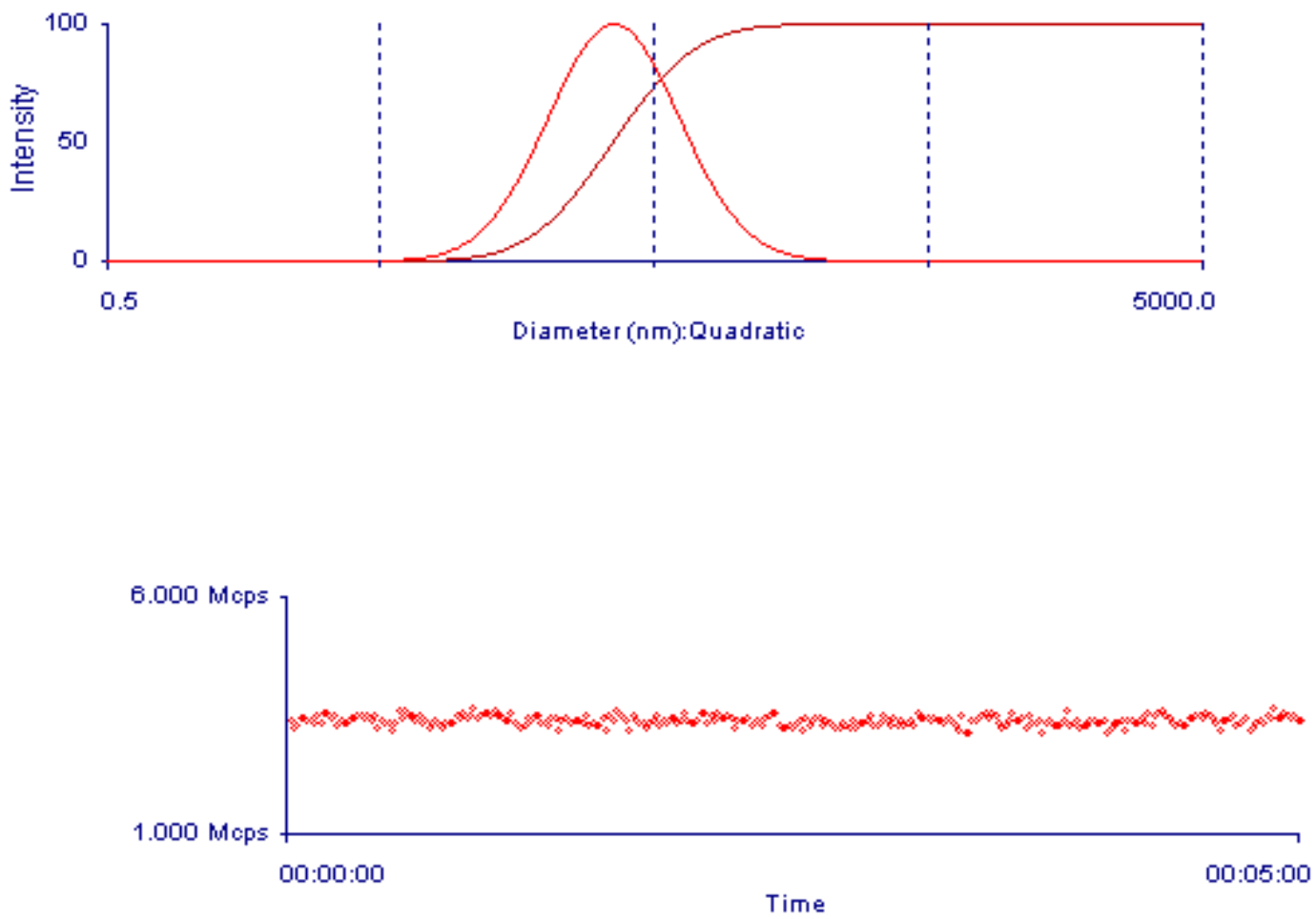

Fig. 24 DLS test 2 results for NF-013 


$\begin{array}{lcccc} & \text { Diff. Coef. }\left(\mathrm{cm}^{2} \mathrm{~s}^{-1}\right) & \text { Eff. Diam. (nm) } & \text { Poly } & \text { RMS Error } \\ \text { Linear: } & 6.769 \mathrm{e}-09 & 44.4 & & 5.0235 \mathrm{e}-03 \\ \text { Quadratic: } & 8.444 \mathrm{e}-09 & 35.6 & 0.358 & 1.2562 \mathrm{e}-02 \\ \text { Cubic: } & 9.531 \mathrm{e}-09 & 31.5 & 0.633 & 1.5102 \mathrm{e}-03 \\ \text { Quartic: } & 1.035 \mathrm{e}-08 & 29.0 & 0.883 & 2.4326 \mathrm{e}+05\end{array}$
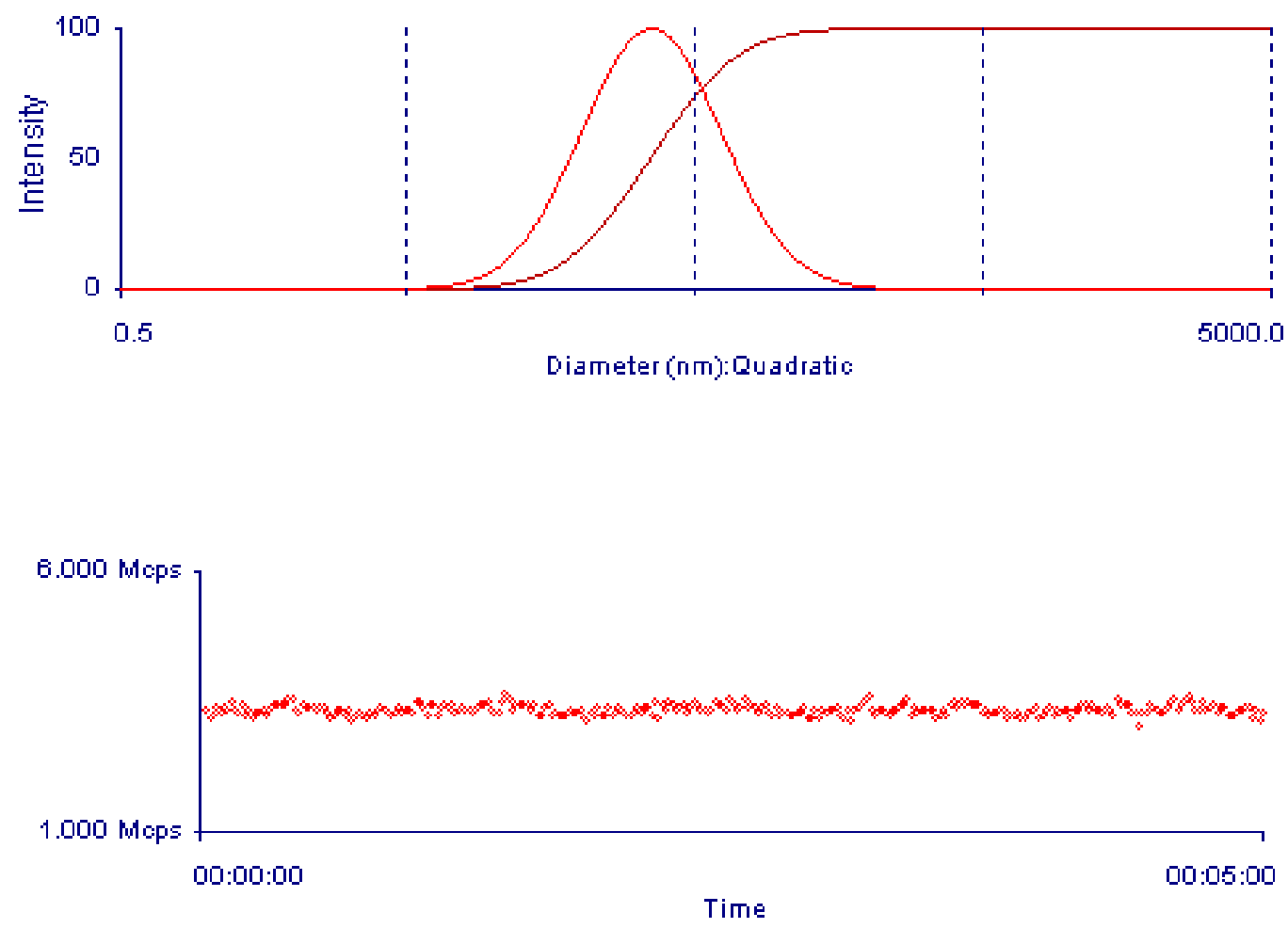

Fig. 25 DLS test 3 results for NF-013 
Table 5. Effective diameter of NF-013

\begin{tabular}{|c|c|c|c|c|}
\hline Type of fit & $\begin{array}{c}\text { Diffusion } \\
\text { Coefficient } \\
\left(\mathrm{cm}^{2} . \mathrm{s}^{-1}\right)\end{array}$ & $\begin{array}{c}\text { Effective } \\
\text { Diameter (nm) }\end{array}$ & Poly & RMS Error \\
\hline Quadratic & $8.410 \mathrm{E}-09$ & 35.7 & 0.362 & $1.1550 \mathrm{E}-02$ \\
\hline Quadratic & $8.375 \mathrm{E}-09$ & 35.9 & 0.351 & $8.8433 \mathrm{E}-03$ \\
\hline Quadratic & $8.444 \mathrm{E}-09$ & 35.6 & 0.358 & $1.2562 \mathrm{E}-02$ \\
\hline $\begin{array}{c}\text { Average of all } \\
\text { quadratic fits }\end{array}$ & & 35.7 & & \\
\hline
\end{tabular}

Figures 26-28 show DLS results for NF-046. Table 6 summarizes all the DLS results for NF-046. 


$\begin{array}{lcccc} & \text { Diff. Coef. }\left(\mathrm{cm}^{2} \mathrm{~s}^{-1} \text { ) }\right. & \text { Eff. Diam. }(\mathrm{nm}) & \text { Poly } & \text { RMS Error } \\ \text { Linear: } & 7.675 \mathrm{e}-09 & 71.8 & & 7.7502 \mathrm{e}-04 \\ \text { Quadratic: } & 8.780 \mathrm{e}-09 & 62.8 & 0.295 & 4.5109 \mathrm{e}-04 \\ \text { Cubic: } & 9.464 \mathrm{e}-09 & 58.2 & 0.571 & 1.6043 \mathrm{e}-04 \\ \text { Quartic: } & 9.840 \mathrm{e}-09 & 56.0 & 0.780 & 6.8831 \mathrm{e}+01\end{array}$
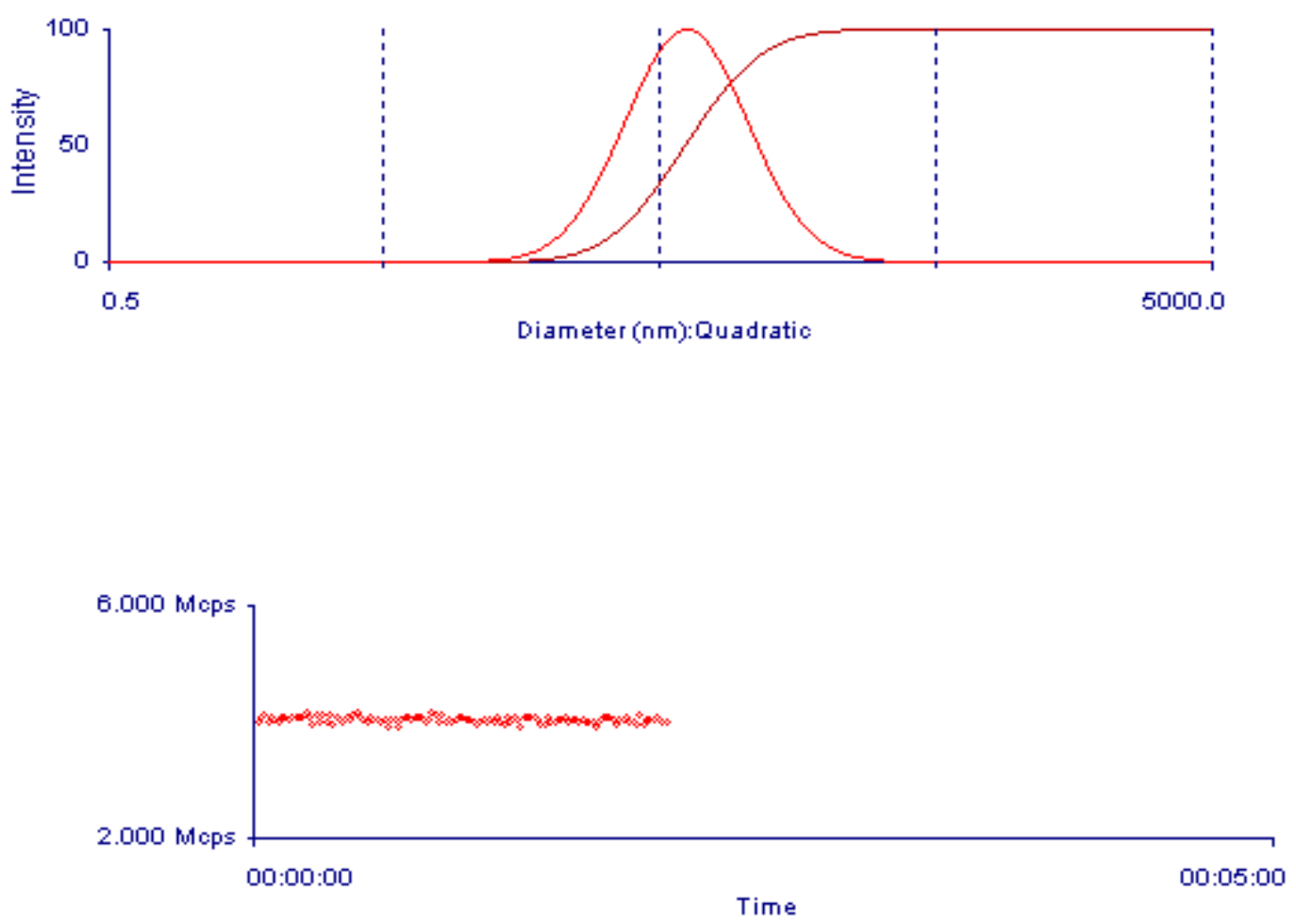

Fig. 26 DLS test 1 results for NF-046 


$\begin{array}{lcccc} & \text { Diff. Coef. }\left(\mathrm{cm}^{2} \mathrm{~s}^{-1}\right) & \text { Eff. Diam. }(\mathrm{nm}) & \text { Poly } & \text { RMS Error } \\ \text { Linear: } & 7.722 \mathrm{e}-09 & 71.4 & & 7.4855 \mathrm{e}-04 \\ \text { Quadratic: } & 8.870 \mathrm{e}-09 & 62.1 & 0.294 & 4.6920 \mathrm{e}-04 \\ \text { Cubic: } & 9.483 \mathrm{e}-09 & 58.1 & 0.529 & 1.5175 \mathrm{e}-04 \\ \text { Quartic: } & 9.822 \mathrm{e}-09 & 56.1 & 0.710 & 3.0473 \mathrm{e}+04\end{array}$
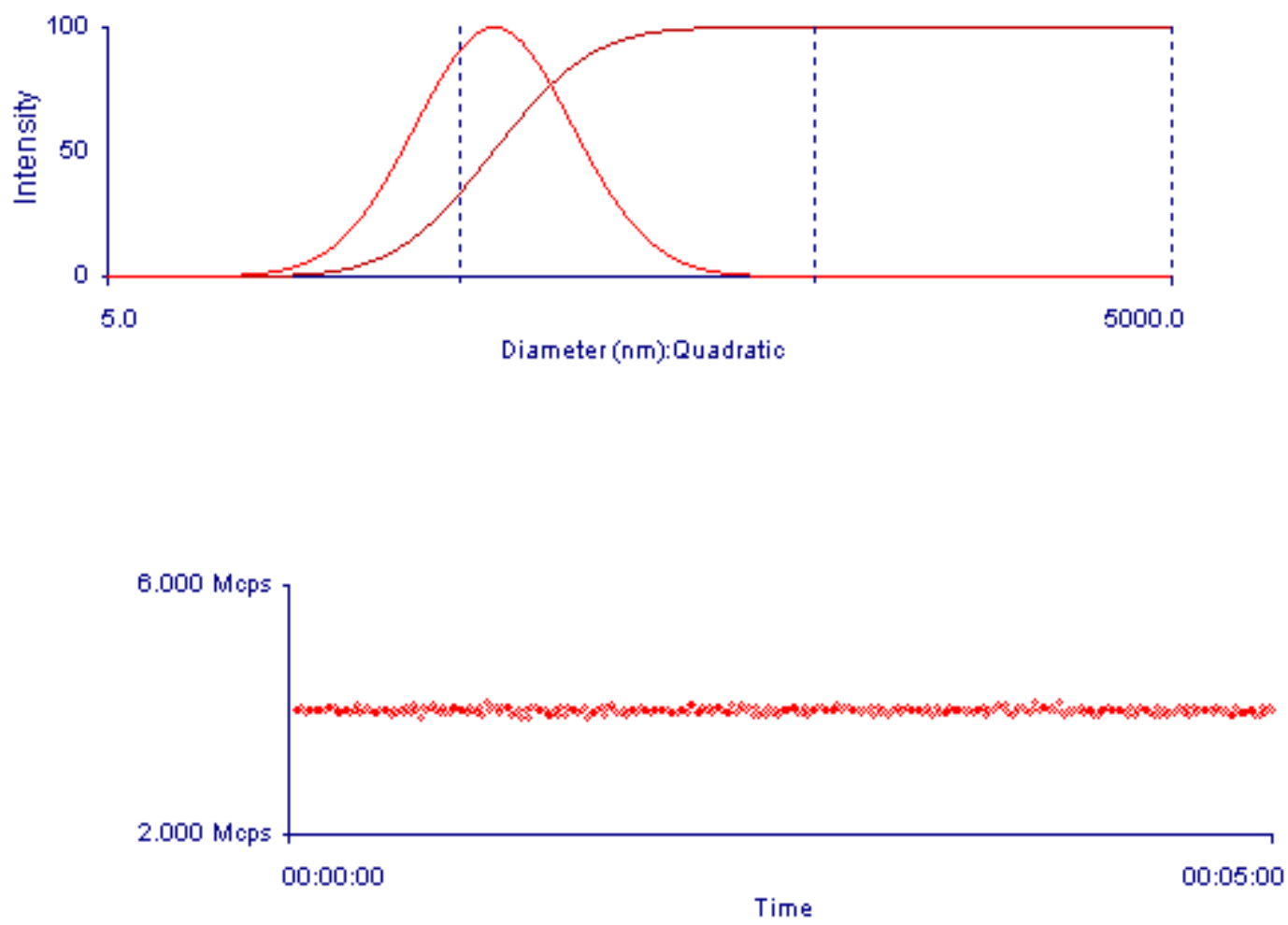

Fig. 27 DLS test 2 results for NF-046 


$\begin{array}{lcccc} & \text { Diff. Coef. }\left(\mathrm{cm}^{2} \mathrm{~s}^{-1}\right) & \text { Eff. Diam. }(\mathrm{nm}) & \text { Poly } & \text { RMS Error } \\ \text { Linear: } & 7.891 \mathrm{e}-09 & 69.9 & & 6.6798 \mathrm{e}-04 \\ \text { Quadratic: } & 8.977 \mathrm{e}-09 & 61.4 & 0.291 & 3.9476 \mathrm{e}-04 \\ \text { Cubic: } & 9.690 \mathrm{e}-09 & 56.9 & 0.588 & 1.1679 \mathrm{e}-04 \\ \text { Quartic: } & 9.996 \mathrm{e}-09 & 55.1 & 0.769 & 6.4323 \mathrm{e}-01\end{array}$
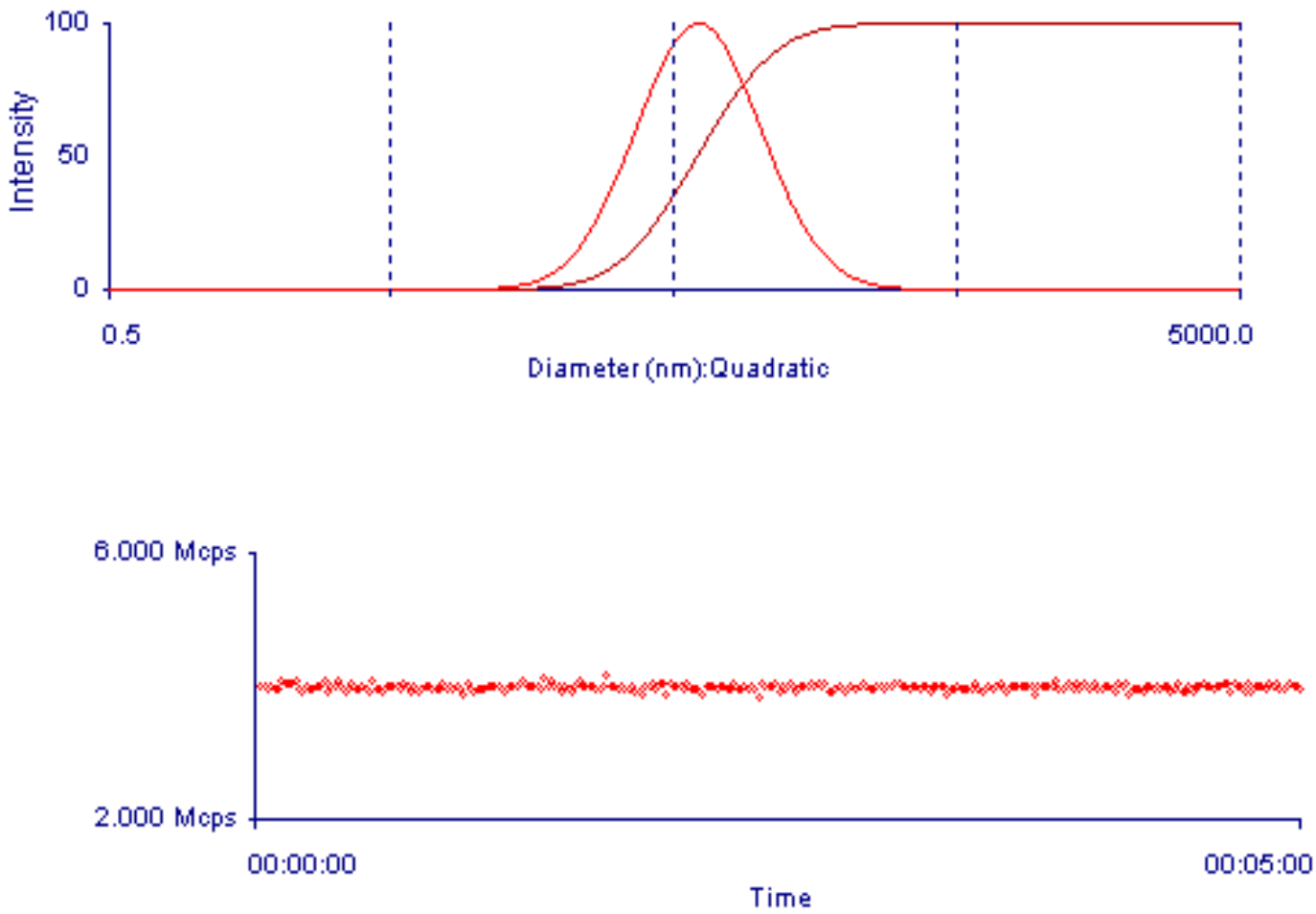

Fig. 28 DLS test 3 results for NF-046 


$\begin{array}{lcccc} & \text { Diff. Coef. }\left(\mathrm{cm}^{2} \mathrm{~s}^{-1} \text { ) }\right. & \text { Eff. Diam. (nm) } & \text { Poly } & \text { RMS Error } \\ \text { Linear: } & 7.781 \mathrm{e}-09 & 70.8 & & 7.7436 \mathrm{e}-04 \\ \text { Quadratic: } & 8.968 \mathrm{e}-09 & 61.5 & 0.304 & 4.9855 \mathrm{e}-04 \\ \text { Cubic: } & 9.669 \mathrm{e}-09 & 57.0 & 0.572 & 1.2541 \mathrm{e}-04 \\ \text { Quartic: } & 9.985 \mathrm{e}-09 & 55.2 & 0.737 & 5.2630 \mathrm{e}+01\end{array}$
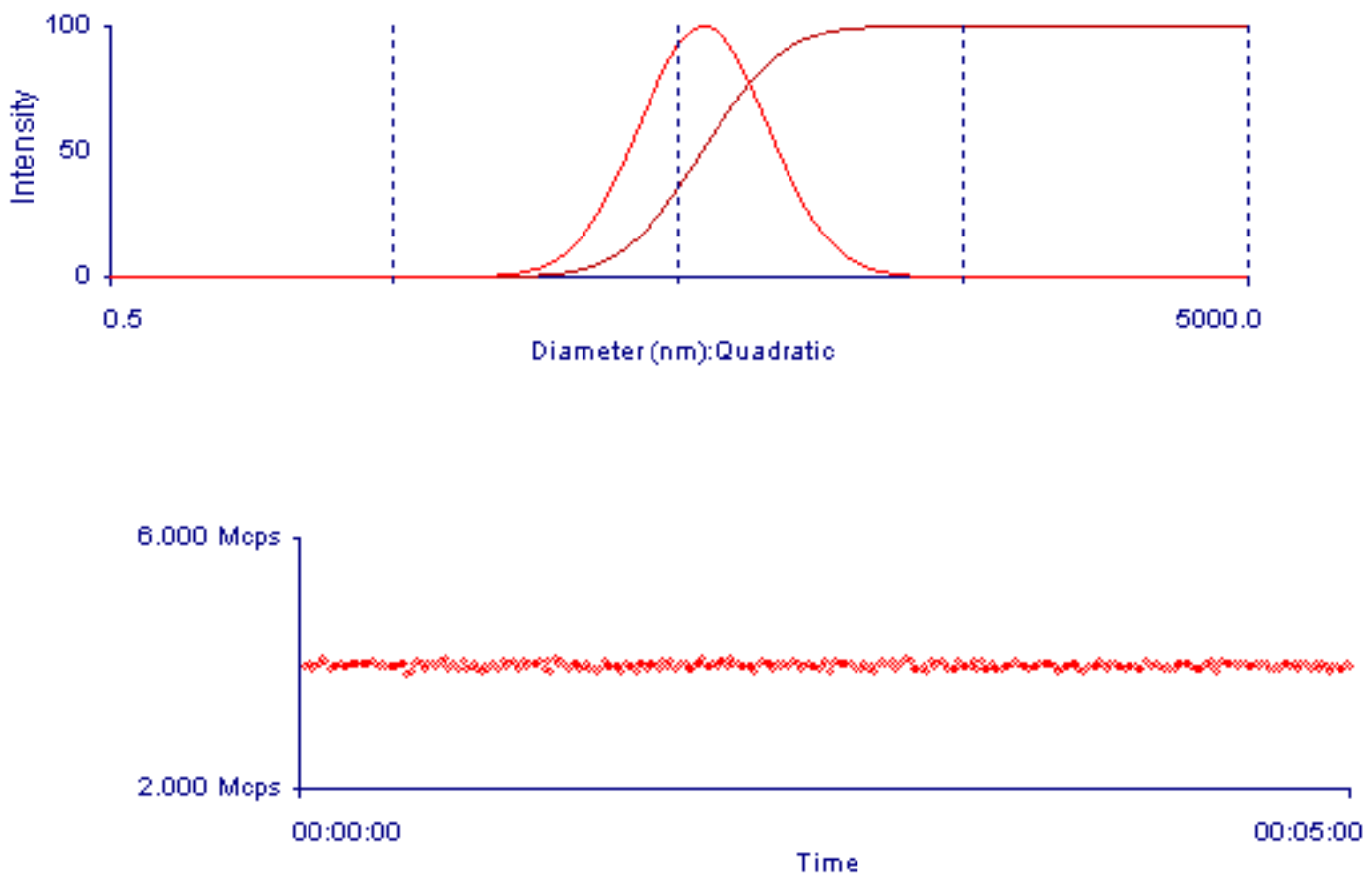

Fig. 29 DLS test 4 results for NF-046 
Table 6. Effective diameter of NF-046

\begin{tabular}{|c|c|c|c|c|}
\hline Type of fit & $\begin{array}{c}\text { Diffusion } \\
\text { Coefficient } \\
\left(\mathrm{cm}^{2} . \mathrm{s}^{-1}\right)\end{array}$ & $\begin{array}{c}\text { Effective } \\
\text { Diameter }(\mathrm{nm})\end{array}$ & Poly & RMS Error \\
\hline Quadratic & $8.780 \mathrm{E}-09$ & 62.8 & 0.295 & $4.5109 \mathrm{E}-04$ \\
\hline Quadratic & $8.870 \mathrm{E}-09$ & 62.1 & 0.294 & $4.6920 \mathrm{E}-04$ \\
\hline Quadratic & $8.977 \mathrm{E}-09$ & 61.4 & 0.291 & $3.9476 \mathrm{E}-04$ \\
\hline $\begin{array}{c}\text { Quadratic } \\
\text { Quverage of } \\
\text { all quadratic } \\
\text { fits }\end{array}$ & $8.968 \mathrm{E}-09$ & 61.5 & 0.304 & $4.9855 \mathrm{E}-04$ \\
\hline
\end{tabular}

Based on the result from polynomial fitting, the data of intensity vs. delay time was obtained. From the data above, the average intensity value depending on delay time was calculated and plotted as shown in Figure 30. 


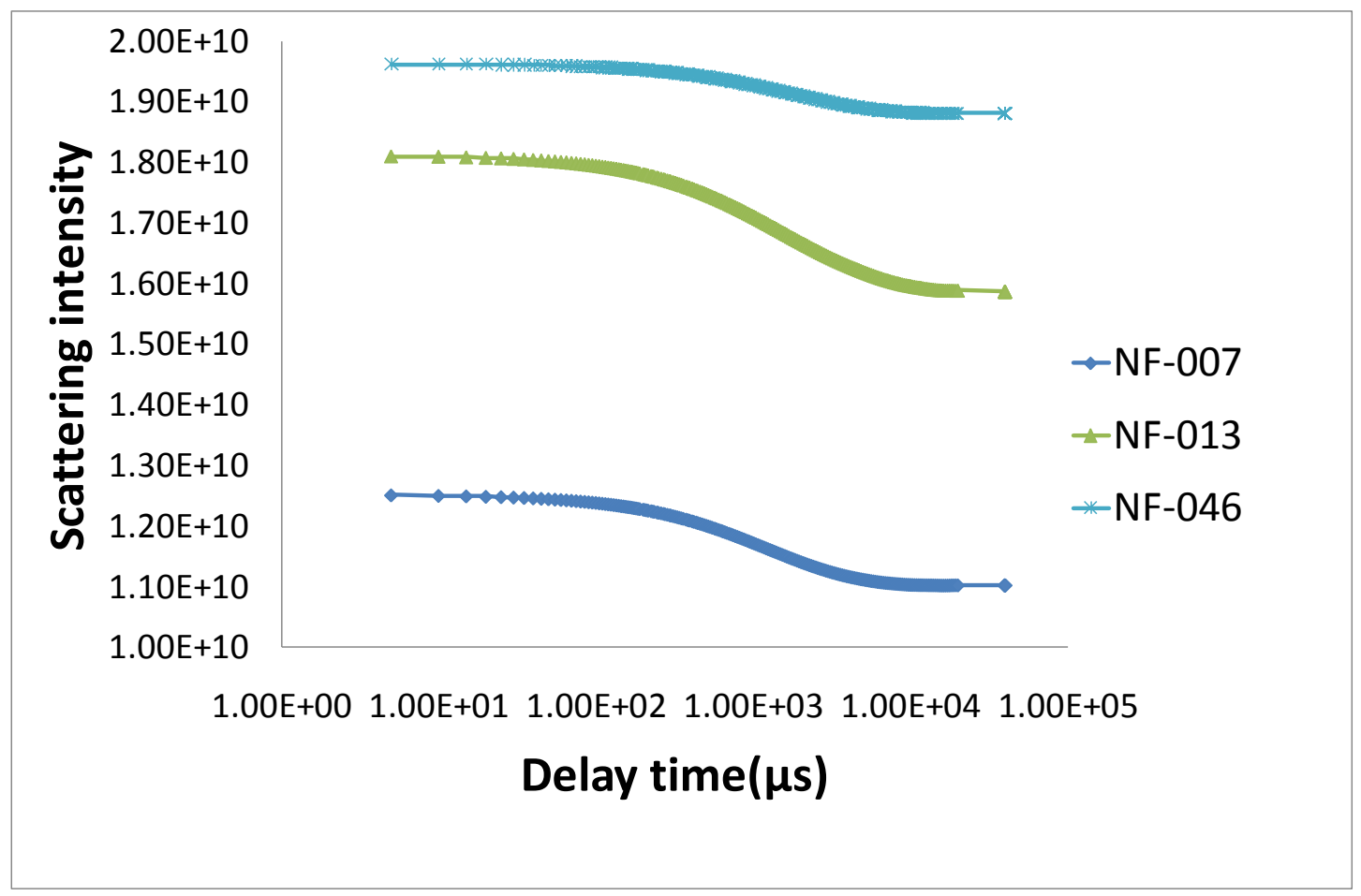

Fig. 30 Scattering intensity vs delay time

It was found that NF-013 decays most rapidly than NF-046 or NF-007. The results are consistent with the particle size data obtained with HAADF STEM. NF-013 has smallest particle size so it decays fastest, and then NF-007 and NF-046.

\subsubsection{Particle size distribution from NNLS}

NNLS (Non Negative Least Squares) was used to obtain particle size distribution [47] of each sample. The particle size distribution can be analyzed based on intensity or volume. In this case, intensity based analysis was performed. For each sample, data from 20 tests were recorded and the average of the data was plotted as shown below. It was 
found that those three samples were more or less polydisperse.

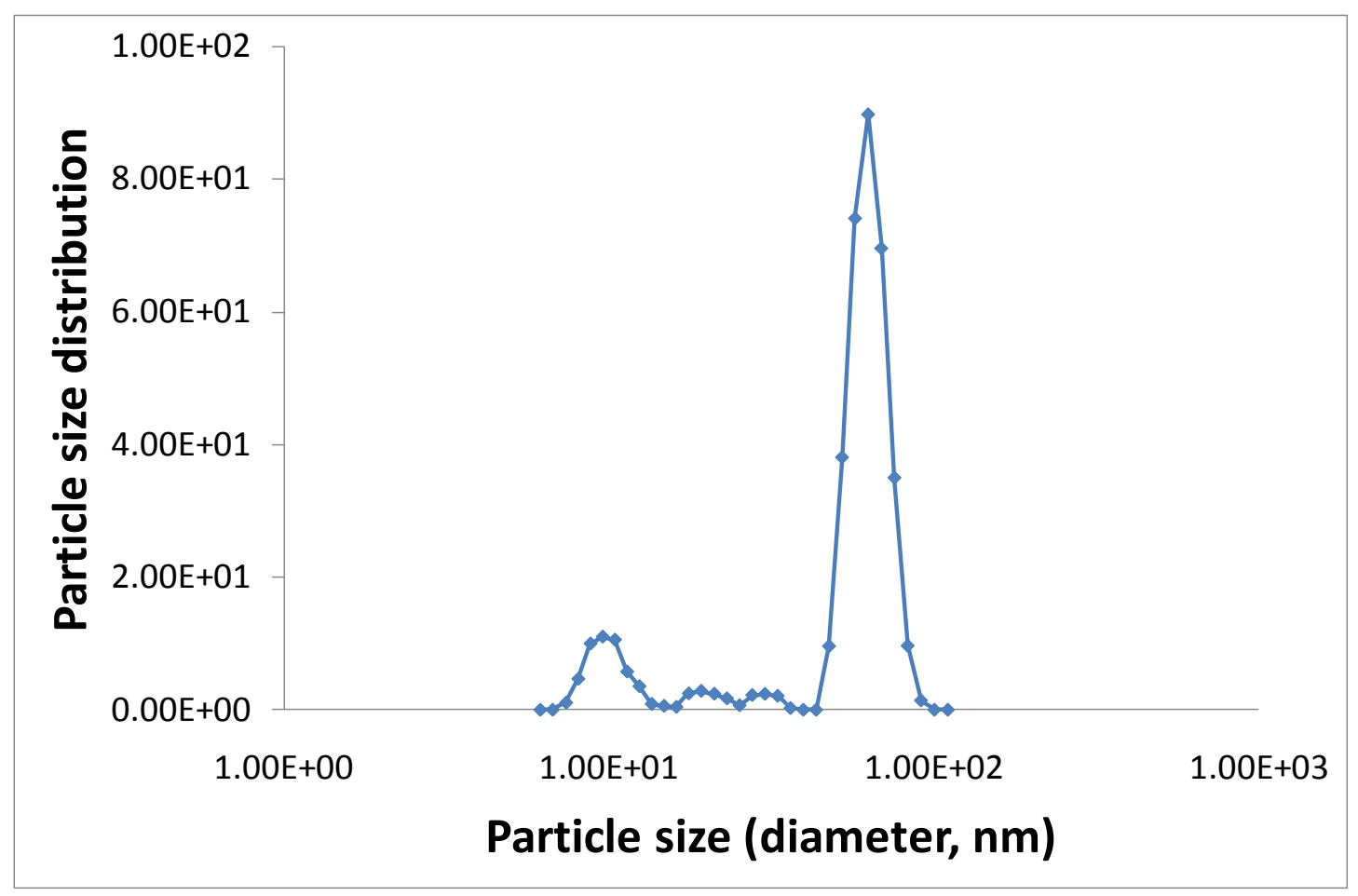

Fig. 31 Particle distribution of NF-007 


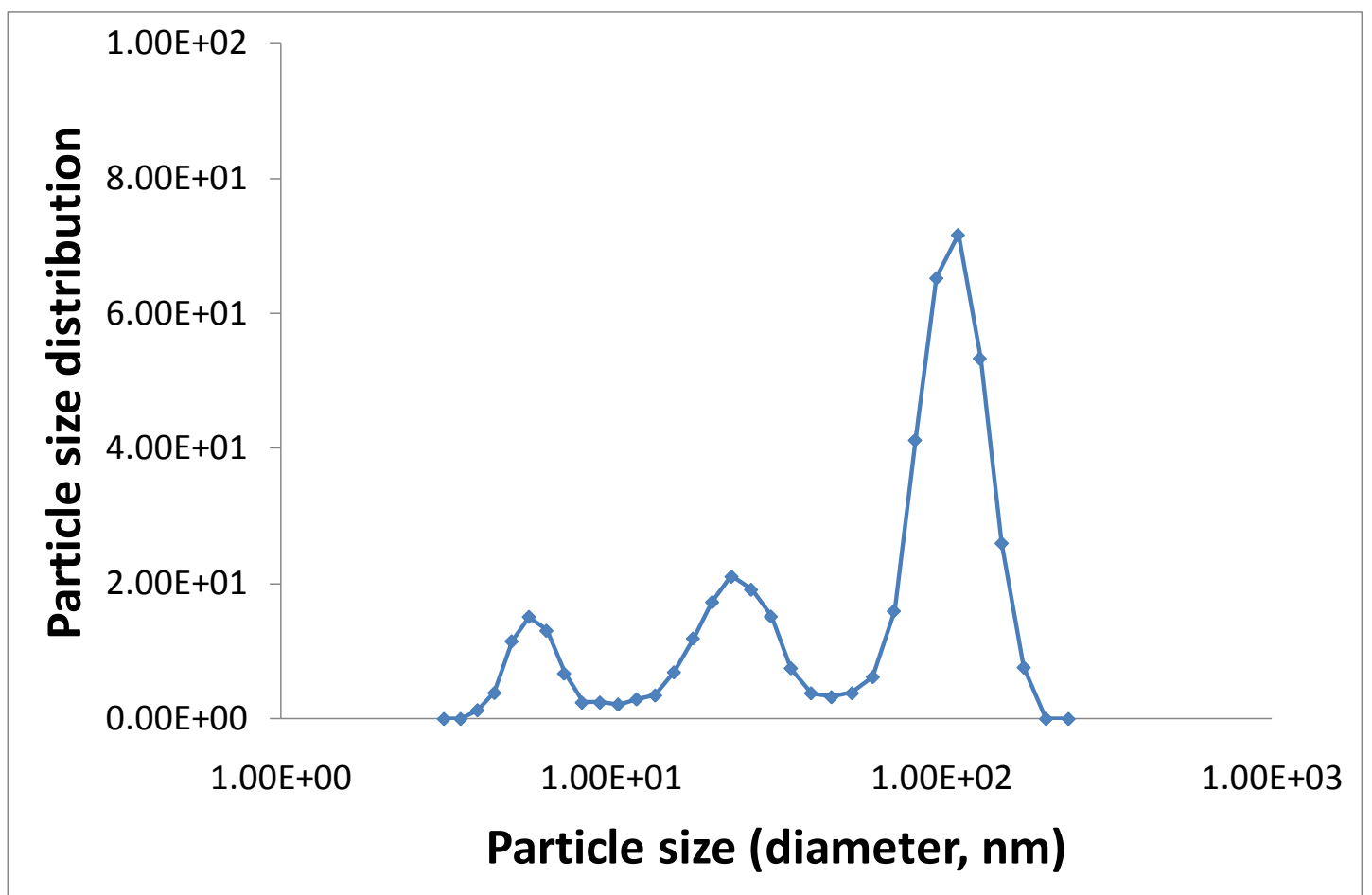

Fig. 32 Particle distribution of NF-013

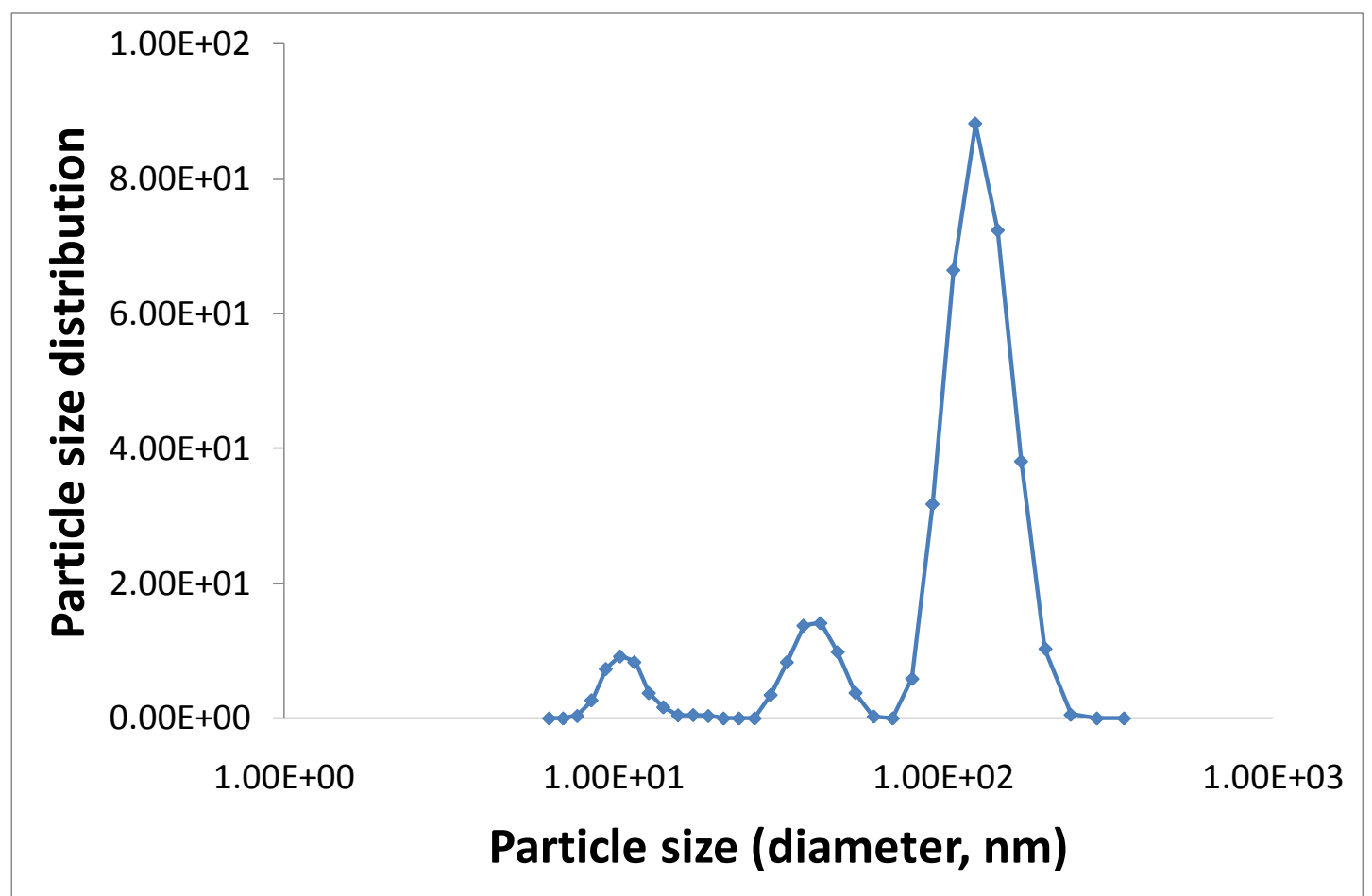

Fig. 33 Particle distribution of NF-046 
As seen from Figures 31-33, NF-007 is least polydispersed sample. The volume fraction of NF-046 is $4 \%$ which is four times greater than those of NF-007 and NF-046 which is $1 \%$. Therefore NF-046 might have a higher possibility to have more polydispersed nanoparticles.

\subsection{Viscosity data}

The viscosity was measured using the rotating type viscometer. The rotational speed, $\mathrm{N}(\mathrm{rpm})$ was converted to shear rate, $\dot{\gamma}\left(\mathrm{sec}^{-1}\right)$ for viscosity comparison. The conversion is described in Appendix A. Figures 34 and 35 show the viscosity data as a function of shear rate for all nanofluids and its base fluid. It was found that all nanofluid samples showed almost Newtonian behavior since the dynamic viscosity does not fluctuate much with shear rate. NF-013 sample only showed higher viscosity due to larger volume concentration but it did exhibit a shear thinning behavior either. Shear rates seem not to affect the viscosity. Figures 36 and 37 show the viscosity trend of pure PAO (Royco 602) and other nanofluids since only Royco 602 was used for comparison. 


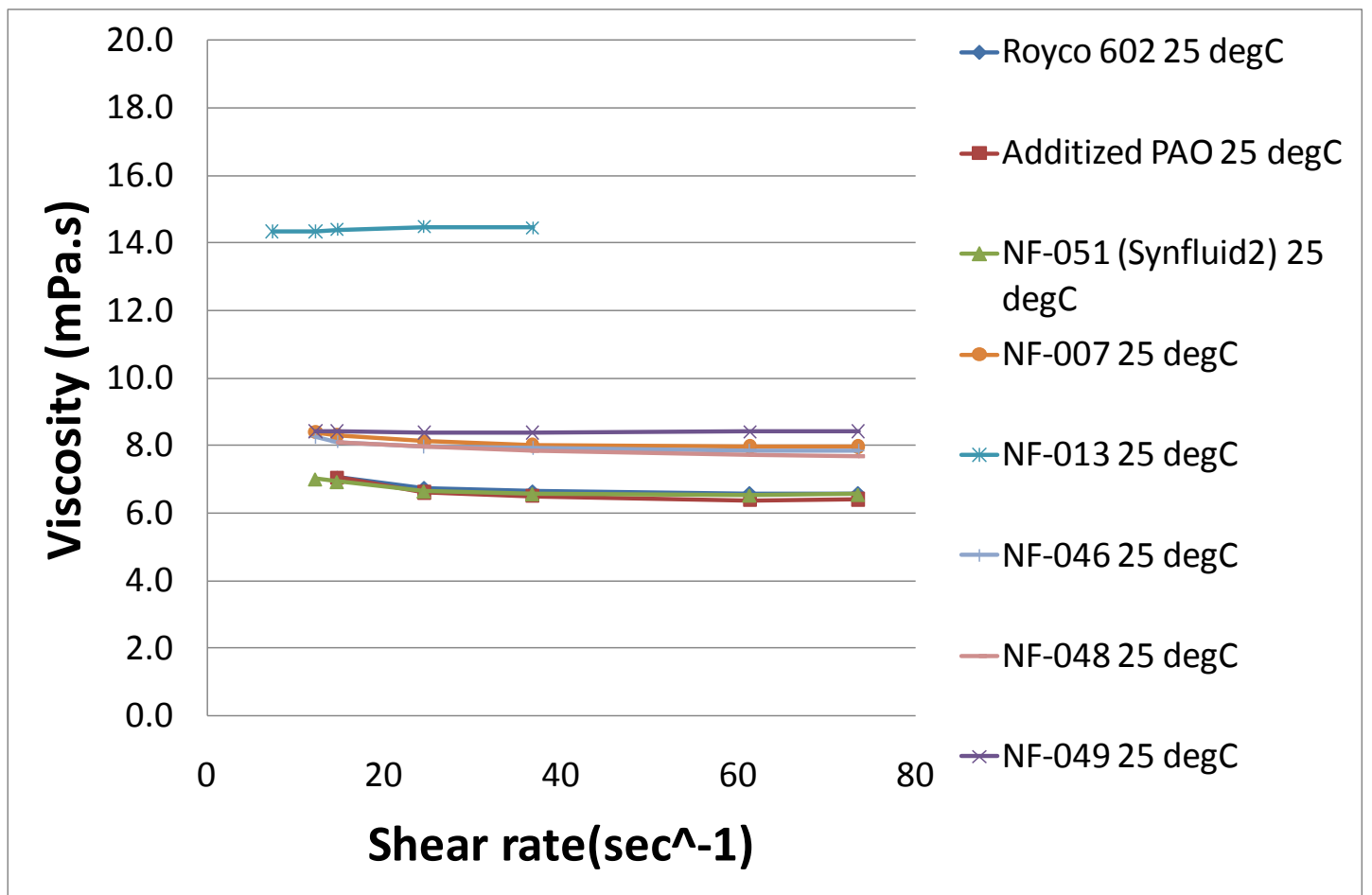

Fig. 34 Dynamic viscosity with shear rate for all fluids at $25^{\circ} \mathrm{C}$

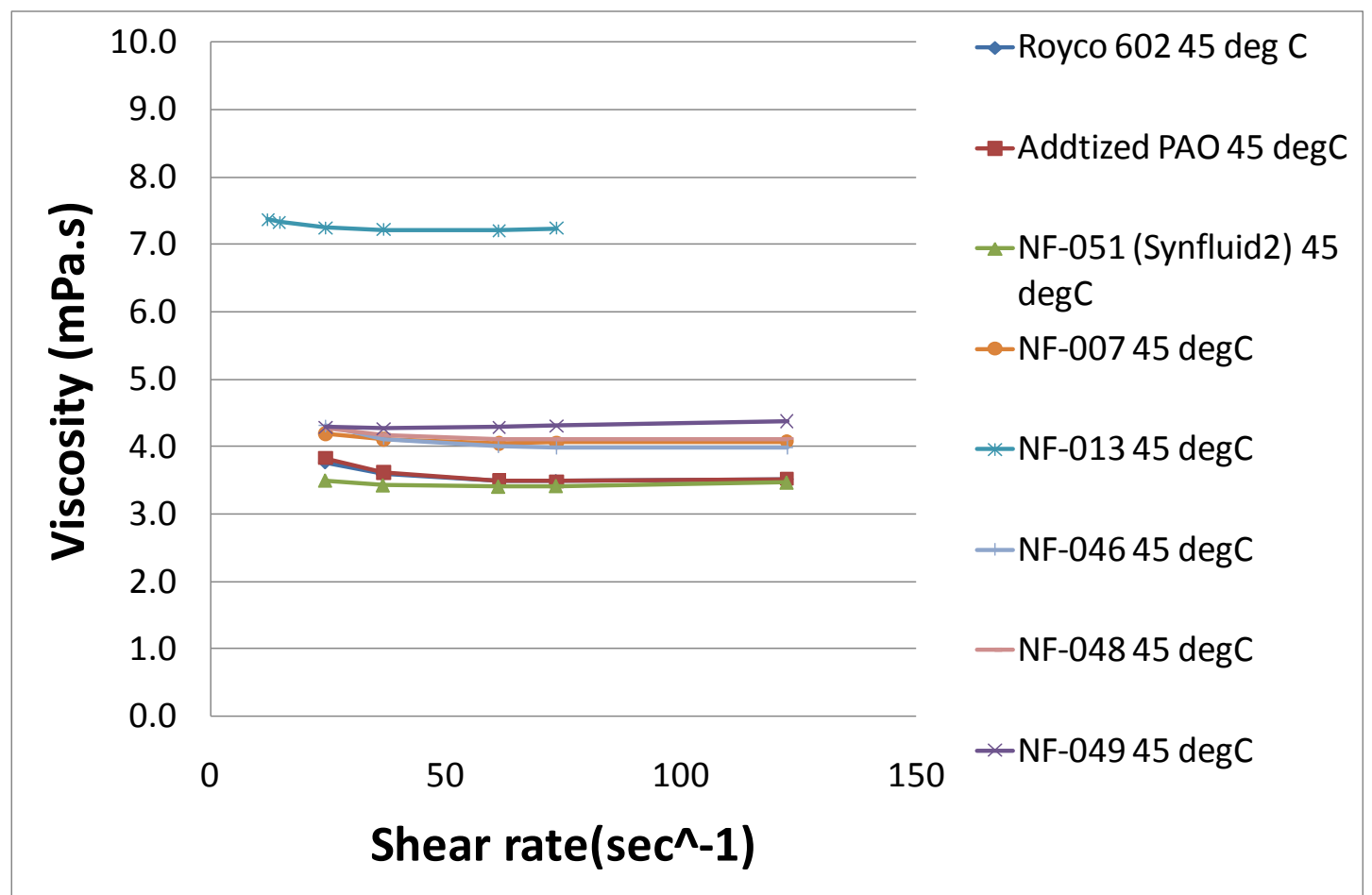

Fig. 35 Dynamic viscosity with shear rate for all fluids at $45^{\circ} \mathrm{C}$ 


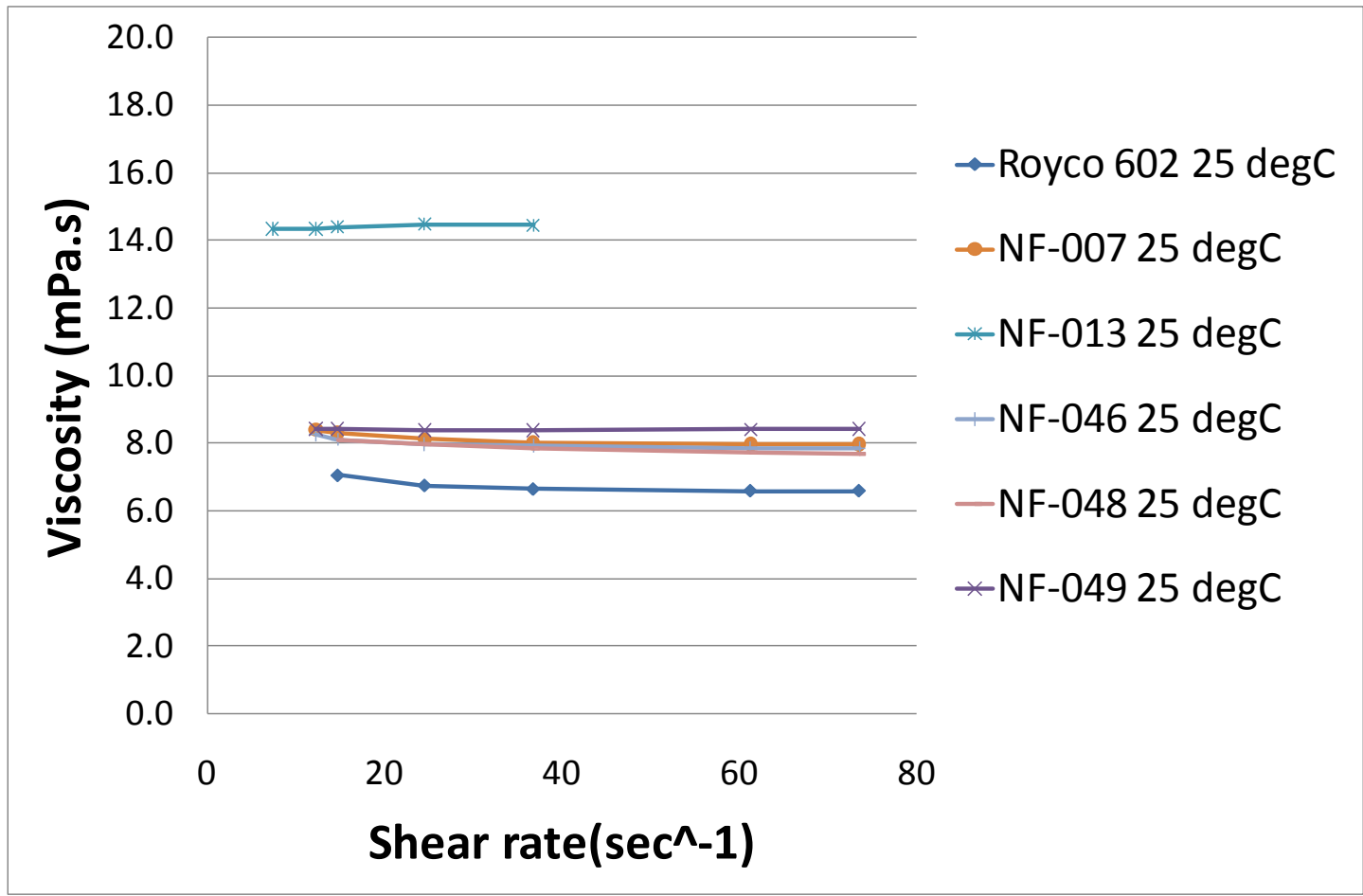

Fig. 36 Dynamic viscosity of nanofluids and Royco 602 at $25^{\circ} \mathrm{C}$

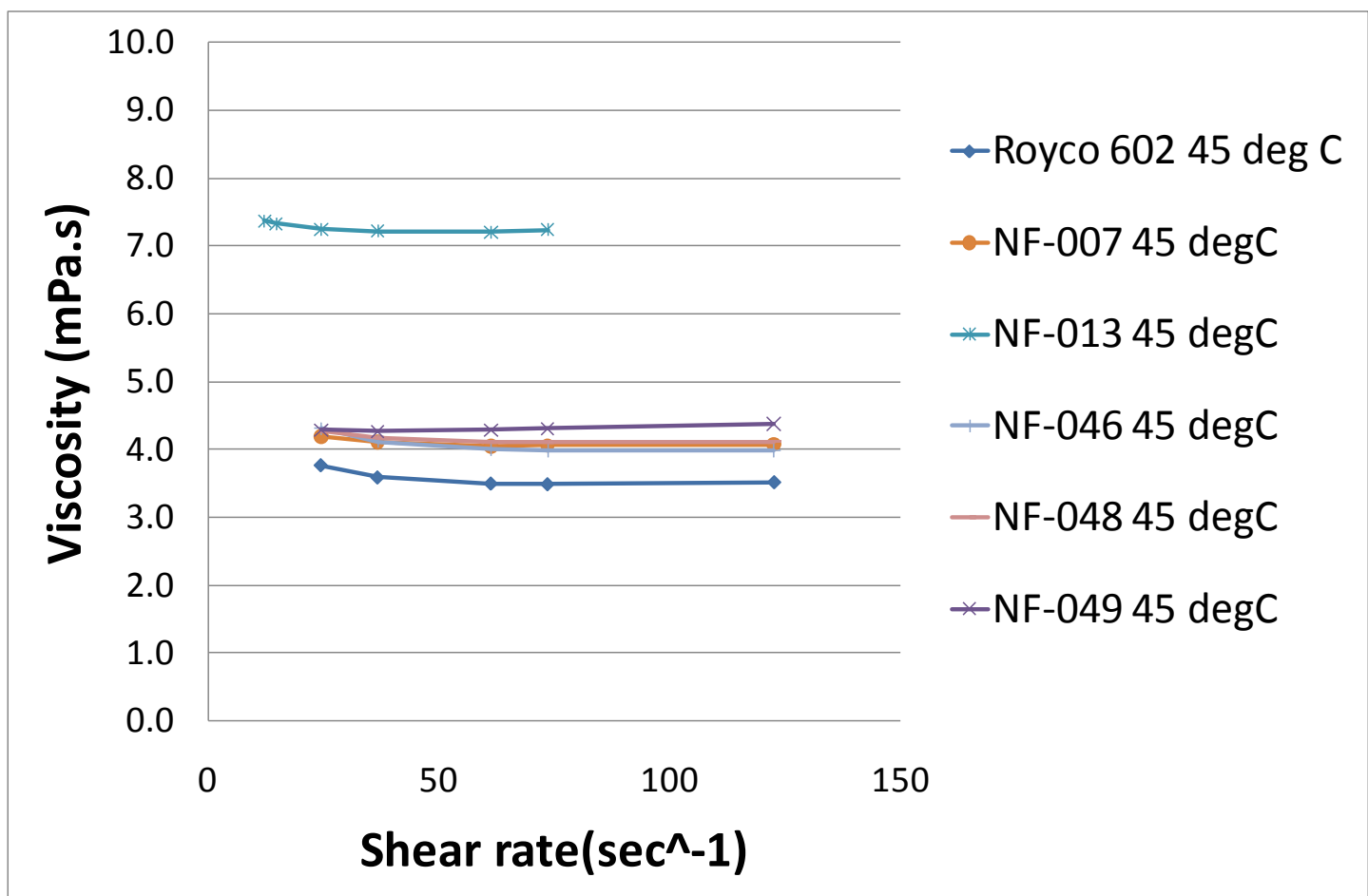

Fig. 37 Dynamic viscosity of nanofluids and Royco 602 at $45^{\circ} \mathrm{C}$ 
As seen above, the viscosity decreased to about half as the temperature increased from $25^{\circ} \mathrm{C}$ to $45^{\circ} \mathrm{C}$. The viscosity of nanofluid samples all showed the similar behavior to that of base fluids such as Royco 602, additized PAO and NF-051 (Synfluid2). Three base fluids showed almost similar viscosity trend even though additized PAO was made with a dispersant, and NF-051 is a slightly different kind of pure PAO. It can be concluded that all nanofluids samples are homogeneous and did not exhibit deagglomerization or realignment in any direction during the viscosity tests. As seen in Table 2, NF-048 and NF-049 exhibit a needle morphology ; however, it has a little effect on viscosity. It might be due to smaller volume concentration compared to other nanofluid samples with spherical/platelet morphology nanoparticles. For NF-013, the volume concentration was $4 \%$ which is about at least 4 times greater than that of other nanofluid samples. Approximately, as the volume fraction increases by 4 , the viscosity increases by a factor of 2 . Pure PAO was used as base fluid for of viscosity, thermal conductivity and heat transfer behavior comparisons.

The measured viscosity data of nanofluids were also compared to the Einstein model (Eq. 2.1). For comparing the measured viscosity values, the following equation (Einstein model) with a $\mathrm{x}$ of 2.5 was used.

$$
\mu_{n f}=(1+x \phi) \mu_{b}
$$

For comparison purposes, the $\mathrm{x}$ value was found for all 5 nanofluids using the viscosity values at only one shear rate. 


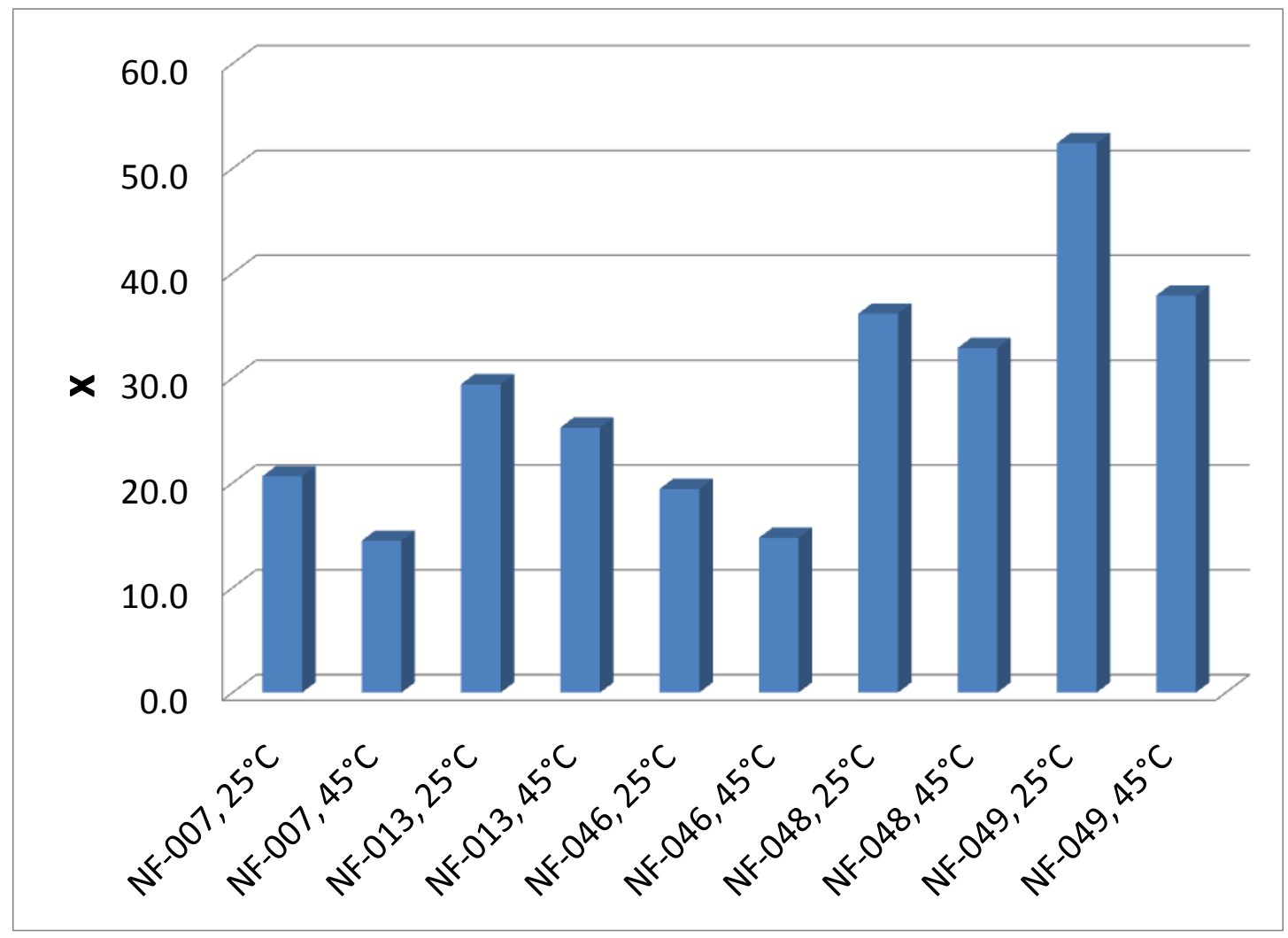

Fig. 38 The comparison of viscosity with Einstein model

Einstein model can be applied to nanofluids, which contain spherical nanoparticles and the volume fraction is less than $2 \%$ [23]. For comparison, only the viscosity values at shear rate of $36.77 \mathrm{sec}^{-1}(30 \mathrm{rpm})$ were used. At higher shear rate, there was no available data for NF-013 at $25{ }^{\circ} \mathrm{C}$ so the viscosity at $30 \mathrm{rpm}$ was chosen for comparison. The volume fraction of all nanofluids was less than $2 \%$ except for NF013 with 4 vol. $\%$ but all $x$ values were way more than 2.5 . It can be concluded that particle interaction in the nanofluids is relevant since Einstein model is based on the assumption that particle drag is not influenced by the flow field around the neighboring particles at low particle concentrations [23]. Especially, only NF-007, NF-013 and NF- 
046 have spherical nanoparticles but have $\mathrm{x}$ values in the range of 10 to 30 . Previous studies have revealed that suspensions with relatively higher concentration deviate from the Einstein model [48].

NF-048 and NF-49 showed the greatest deviation from the Einstein model. The corresponding average $\mathrm{x}$ values were 35 and 45 to 55 , respectively. The change in $\mathrm{x}$ is caused by differences in particle-solvent interactions which result in small density changes in the critical interfacial regions [48]. If solvent-particle interactions were different from particle-particle interactions, $x$ value would deviate from 2.5 [48]. In other words, when particle and solvent have different solubility parameters, the microscopic viscosity of the solvent differs from the viscosity of the pure solvent and $\mathrm{x}$ deviates from Einstein model considerably.

\subsection{Thermal conductivity data}

Thermal conductivity was measured using the transient hot wire (THW) method under different temperature conditions. Each thermal conductivity value of nanofluid sample was compared to the base fluid, which was pure PAO (Royco 602). It was found that the measured thermal conductivity of Royco 602 did not change significantly with temperature. The thermal conductivity of the nanofluid samples was determined using the THW procedure described above. The maximum enhancement in thermal conductivity at $25^{\circ} \mathrm{C}$ was found in NF-048 which was $40 \%$. However, the enhancement at $45{ }^{\circ} \mathrm{C}$ showed a smaller enhancement, $13.3 \%$. Nonetheless, NF-048 was chosen for 
heat transfer test because of the highest enhancement in overall thermal conductivity.

The enhancement in thermal conductivity as a function of temperature is shown in Table 7.

Table 7. The enhancement in thermal conductivity of nanofluids

\begin{tabular}{|c|c|c|c|c|}
\hline Nanofluid & $\begin{array}{c}\text { Temperature } \\
\left({ }^{\circ} \mathrm{C}\right)\end{array}$ & $\begin{array}{c}\text { Thermal } \\
\text { conductivity } \\
\text { (W/mk) of Royco } \\
602\end{array}$ & $\begin{array}{c}\text { Thermal } \\
\text { conductivity } \\
\text { (W/mk) of } \\
\text { nanofluid }\end{array}$ & $\begin{array}{c}\text { Enhancement } \\
\qquad(\%)\end{array}$ \\
\hline \multirow{2}{*}{$\begin{array}{c}\text { NF-007 at } 1 \\
\text { vol. } \% \text { and } 5 \\
\text { wt. } \%\end{array}$} & $25^{\circ} \mathrm{C}$ & 0.15 & 0.15 & 0 \\
\hline & $45^{\circ} \mathrm{C}$ & 0.15 & 0.15 & 0 \\
\hline \multirow{2}{*}{$\begin{array}{c}\mathrm{NF}-013 \text { at } 4 \\
\text { vol. } \% \text { and } 20 \\
\text { wt. } \%\end{array}$} & $25^{\circ} \mathrm{C}$ & 0.15 & 0.19 & 26.7 \\
\hline & $45^{\circ} \mathrm{C}$ & 0.15 & 0.18 & 20 \\
\hline \multirow{2}{*}{$\begin{array}{l}\text { NF-046 at } 1 \\
\text { vol. } \% \text { and } 5 \\
\text { wt. } \%\end{array}$} & $25^{\circ} \mathrm{C}$ & 0.15 & 0.18 & 20 \\
\hline & $45^{\circ} \mathrm{C}$ & 0.15 & 0.18 & 20 \\
\hline \multirow{2}{*}{$\begin{array}{c}\mathrm{NF}-048 \text { at } 0.5 \\
\text { vol. } \% \text { and } 2.5 \\
\text { wt. } \%\end{array}$} & $25^{\circ} \mathrm{C}$ & 0.15 & 0.21 & 40 \\
\hline & $45^{\circ} \mathrm{C}$ & 0.15 & 0.17 & 13.3 \\
\hline \multirow{2}{*}{$\begin{array}{c}\mathrm{NF}-049 \text { at } 0.5 \\
\text { vol. } \% \text { and } 5 \\
\text { wt. } \%\end{array}$} & $25^{\circ} \mathrm{C}$ & 0.15 & 0.17 & 13.3 \\
\hline & $45^{\circ} \mathrm{C}$ & 0.15 & 0.17 & 13.3 \\
\hline
\end{tabular}

It was found that NF-007, NF-046 and NF-049 have constant percentage enhancement with temperature. According to the specification, the difference between NF-007 and NF-046 is the different kind of dispersant or additive. The difference 
between NF-007 and NF-049 is the slight different volume concentration and morphology. The needle morphology of NF-049 was shown to affect more thermal conductivity enhancement even though NF-049 had smaller volume fraction. The percentage enhancement of NF-049 was about 10\% more than NF-007. For NF-007 and NF-013, NF-013 had a higher concentration, which included another dispersant. Results revealed that higher concentration yielded increased thermal conductivity.

The difference between NF-046 and NF-048 is that NF-048 has half the concentration of NF-046. It was seen that the needle morphology was affected more by temperature changes than when using spherical nanoparticles. The agglomeration behavior of nanoparticles might vary more in non-spherical nanoparticles as well. Different dispersant and additives were used for making NF-048 and NF-049. It was found that even though those two fluids consisted of nanoparticles with needle morphology, the effect of dispersant or additives should not be disregarded completely. The thermal conductivity of NF-048 was measured again after six months to check the stability of NF-048. Table 8 shows thermal conductivity data for NF-048 after the second experiment. 
Table 8. The comparison of enhancement in thermal conductivity of NF-048 measured at different time period

\begin{tabular}{|c|c|c|c|c|}
\hline Temperature & $\begin{array}{c}\text { Date the } \\
\text { data was } \\
\text { obtained }\end{array}$ & $\begin{array}{c}\text { Thermal } \\
\text { conductivity } \\
\text { of Royco } 602 \\
(\mathrm{~W} / \mathrm{mk})\end{array}$ & $\begin{array}{c}\text { Thermal } \\
\text { conductivity } \\
\text { of Royco 602 } \\
(\mathrm{W} / \mathrm{mk})\end{array}$ & $\begin{array}{c}\text { Enhanceme } \\
\mathrm{nt} \\
(\%)\end{array}$ \\
\hline $25^{\circ} \mathrm{C}$ & $\begin{array}{l}04 / 04 \\
/ 2010\end{array}$ & 0.15 & 0.21 & 40 \\
\hline $45^{\circ} \mathrm{C}$ & $\begin{array}{l}04 / 27 \\
/ 2010\end{array}$ & 0.15 & 0.17 & 13.3 \\
\hline $25^{\circ} \mathrm{C}$ & $\begin{array}{l}09 / 22 \\
/ 2010\end{array}$ & 0.15 & 0.17 & 26.7 \\
\hline $45^{\circ} \mathrm{C}$ & $\begin{array}{c}09 / 23 \\
/ 2010\end{array}$ & 0.15 & 0.19 & 2 \\
\hline
\end{tabular}

It was found that the values differed especially when temperature was increased.

The recent result seems more reasonable according to the result of other research groups.

It is hypothesized that a small fraction of nanoparicles might have settled down or agglomerated resulting in lower thermal conductivity enhancement. Nevertheless, NF048 was used for heat transfer testing to determine the effect of nanoparticle morphology on convection.

\subsection{Convective heat transfer data}

A heat transfer section with coiled nichrome wire has been used for measuring convective heat transfer behavior under laminar and constant heat flux condition as described in Chapter III. The calibration procedure is explained in the Appendix B. 
After the set-up was calibrated both for isothermal condition and operating conditions, temperature measurements were taken for two samples, Royco 602 pure PAO base fluid and NF-048 nanofluid at same flow rates. The experiments were performed at constant heat flux condition with three different heat flux values. Figure 39 shows the difference between surface and bulk temperatures for both pure PAO and NF-048. For each sample, the temperature difference shows a consistent trend thus it can be said that thermocouples and heat transfer loop are reliable. Figures 40 and 41 show the variation of convective heat transfer coefficient for two samples, pure PAO and NF-048 with respect to the non-dimensionalized axial distance, $x / D_{i}$ from the inlet section of the loop at different voltages $60,62.5$ and $65 \mathrm{~V}$, corresponding to heat flux values of 920.5 , 999 and $1080.4 \mathrm{~W} / \mathrm{m}^{2}$. Correction factors for isothermal condition were applied to all surface thermocouples. Also a correction factor for heat flux ' 0.82 ' based on heat capacity was used. The correction factor for heat flux is nothing but the fraction of DC power transferred to heat flowing fluid. 


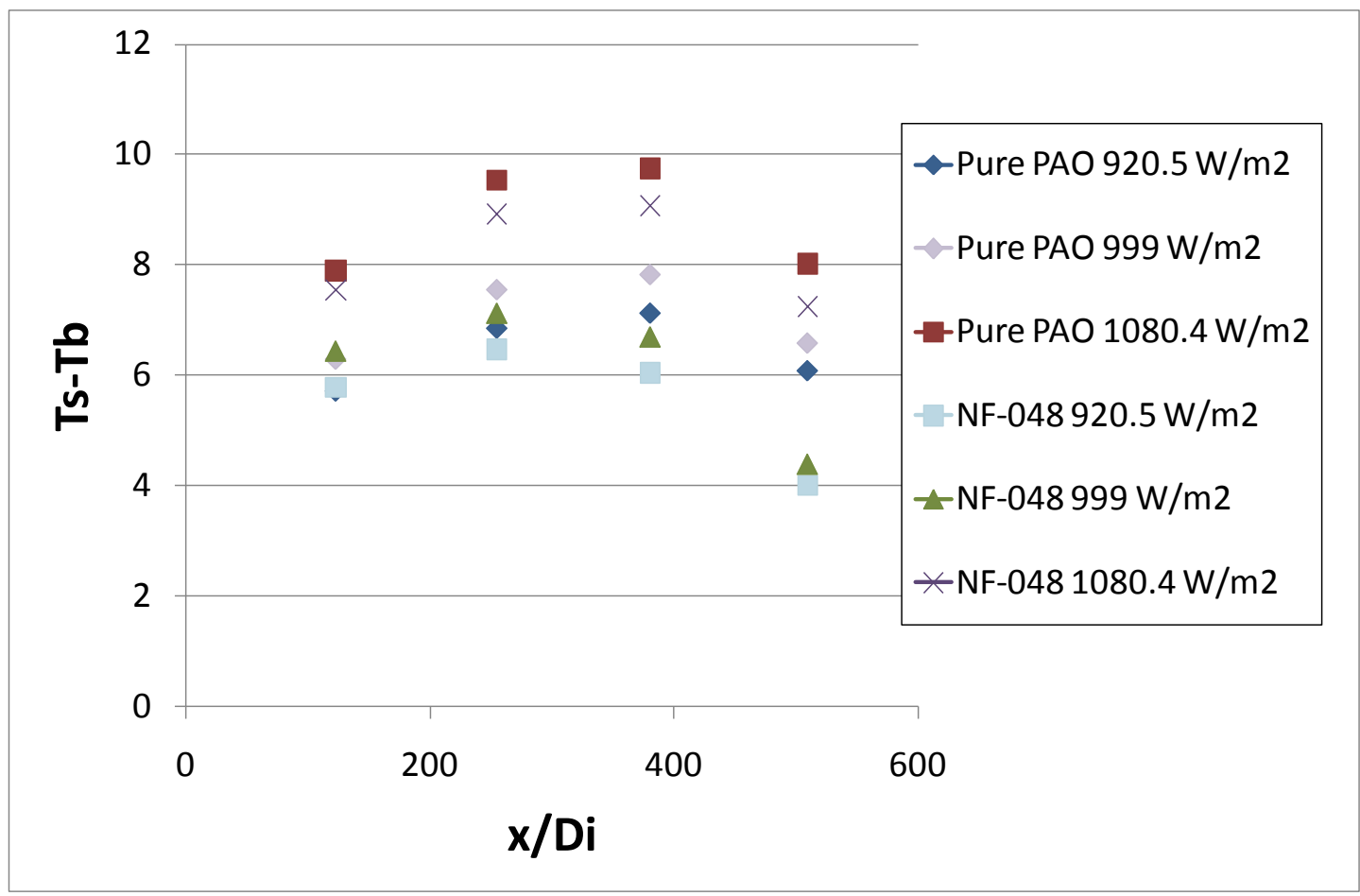

Fig. 39 The surface and bulk temperature difference of pure PAO and NF-048

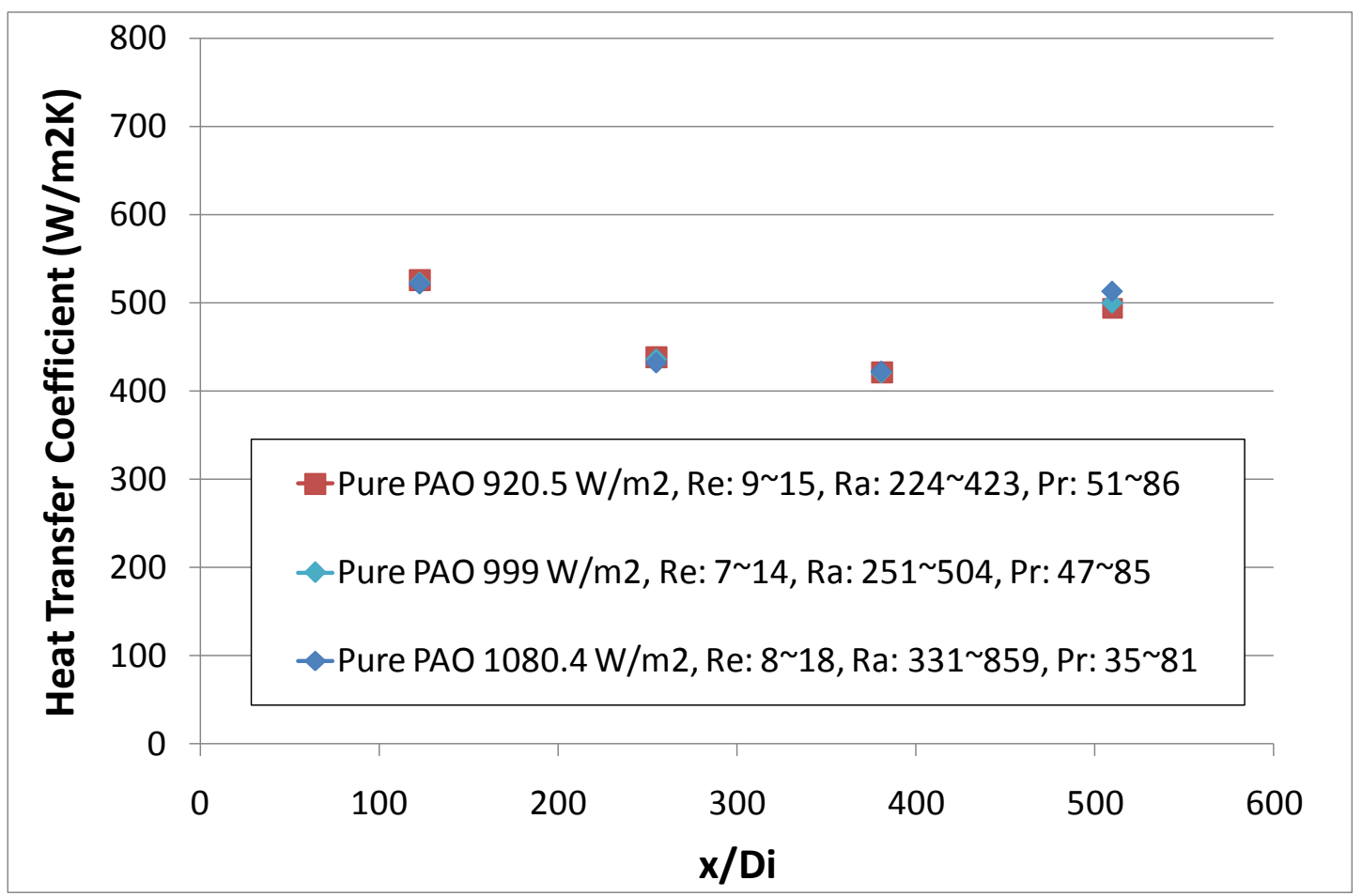

Fig. 40 The variation of heat transfer coefficient of pure PAO 


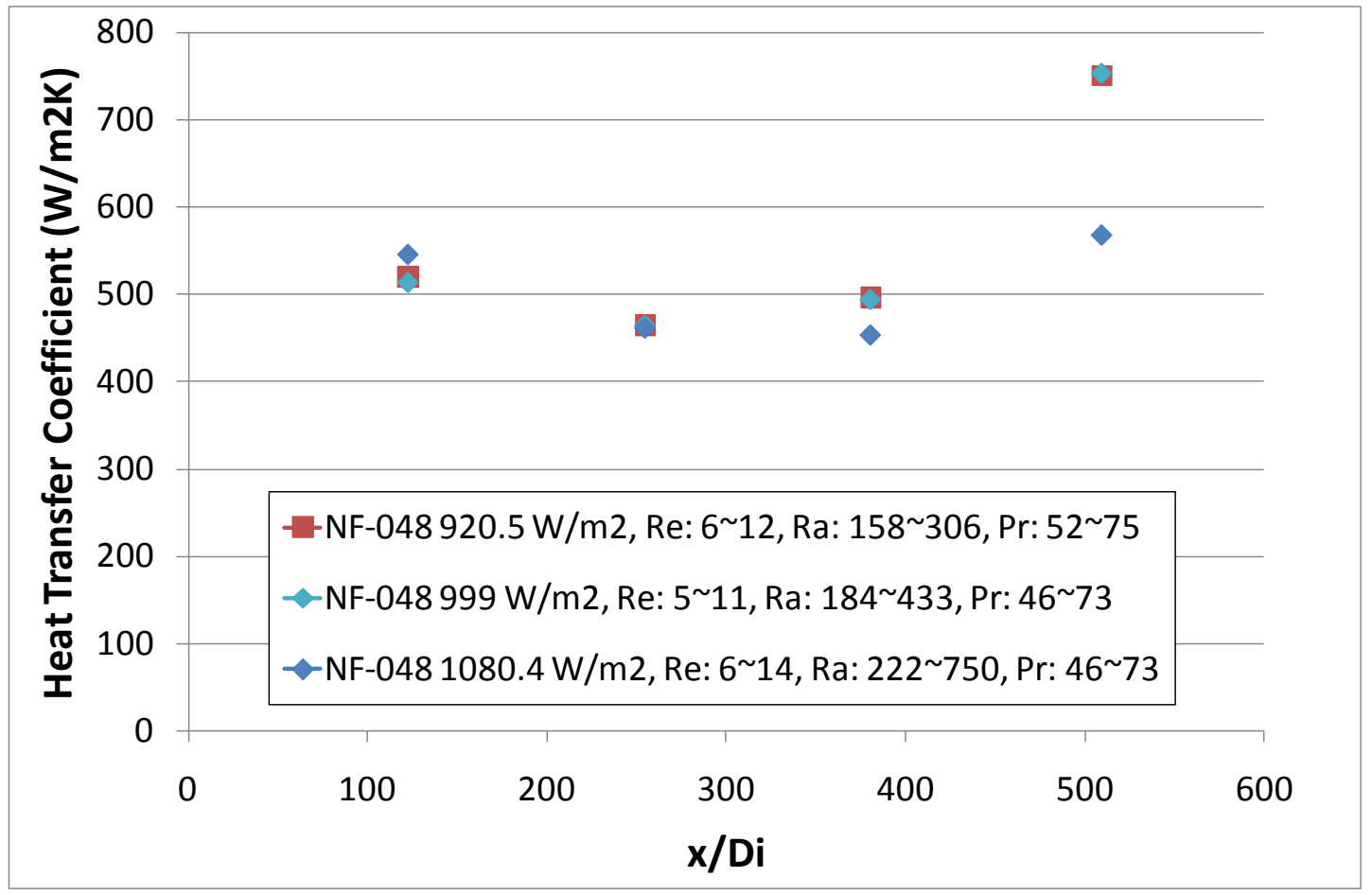

Fig. 41 The variation of heat transfer coefficient of NF-048

Figure 40 shows that for similar mass flow rate, the heat transfer coefficient of pure PAO is same regardless of heat flux. However, pure PAO exhibits an increase in heat transfer coefficient after $\mathrm{x} / \mathrm{D}_{\mathrm{i}}$ of 400 . Similar behavior has been reported for low Reynolds number, high Rayleigh number experiments [49, 50]. For NF-048 exhibits greater heat transfer coefficient values at $x / D_{i}$ of 500 , as shown in Figure 41 . It is evident that the heat transfer coefficient is higher for NF-048 than for pure PAO as the axial distance increases. Heat transfer coefficient in laminar flow is supposed to reach a steady value as the axial distance increases for both pure PAO and NF-048; however, the experimental data reveal that Rayleigh and Reynolds number have an effect on the flow structure which results in greater convection. The Grashof number might also have an 
effect on the heat transfer coefficient. With increase in axial distance, both surface and bulk temperatures increase considerably. It might cause the greater convection. The same data including bulk fluid temperature are plotted for comparison purposes in Figures 42-44 at different heat flux values.

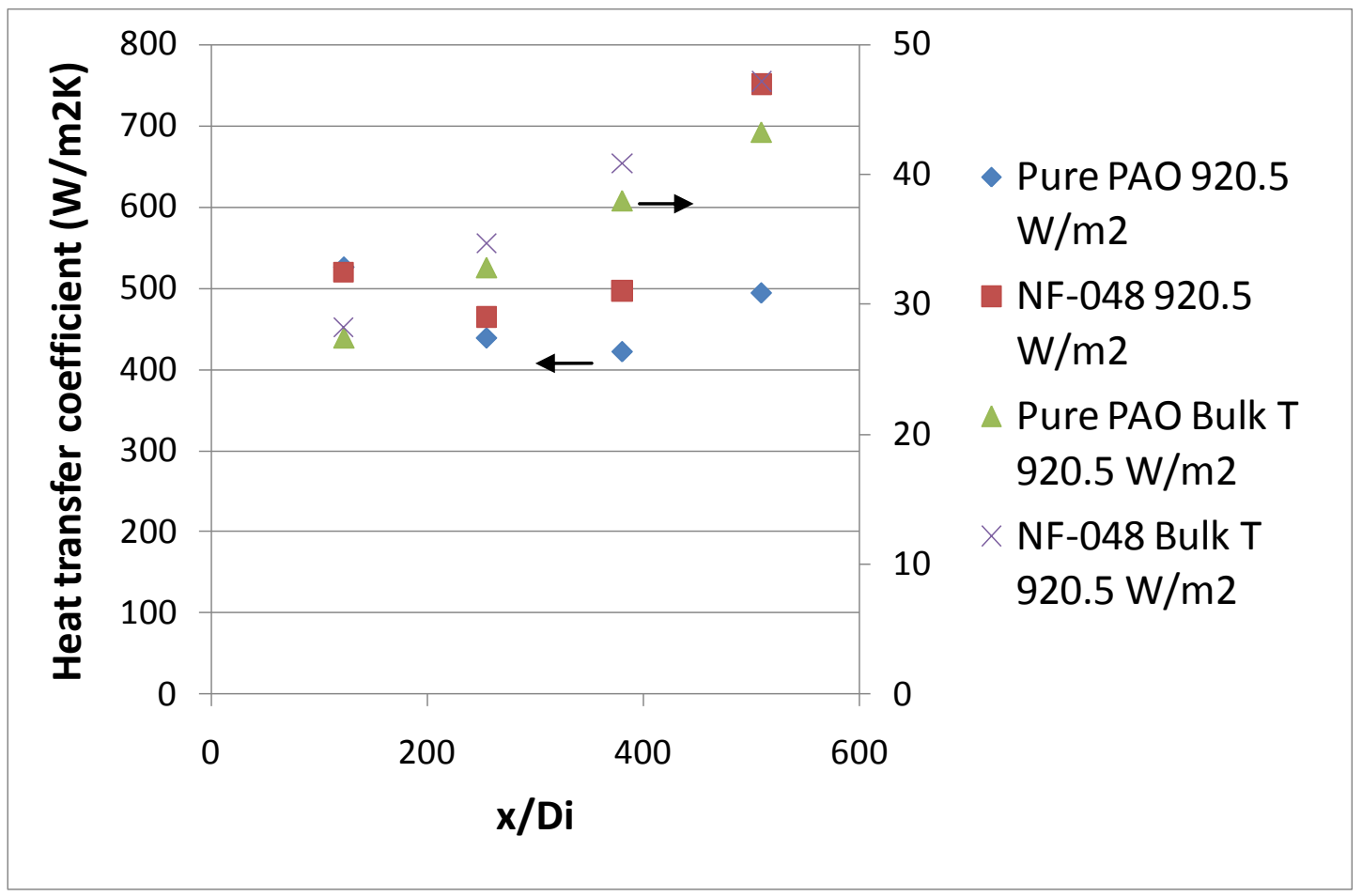

Fig. 42 The comparison of heat transfer coefficient of pure PAO and NF-048 at 60V 


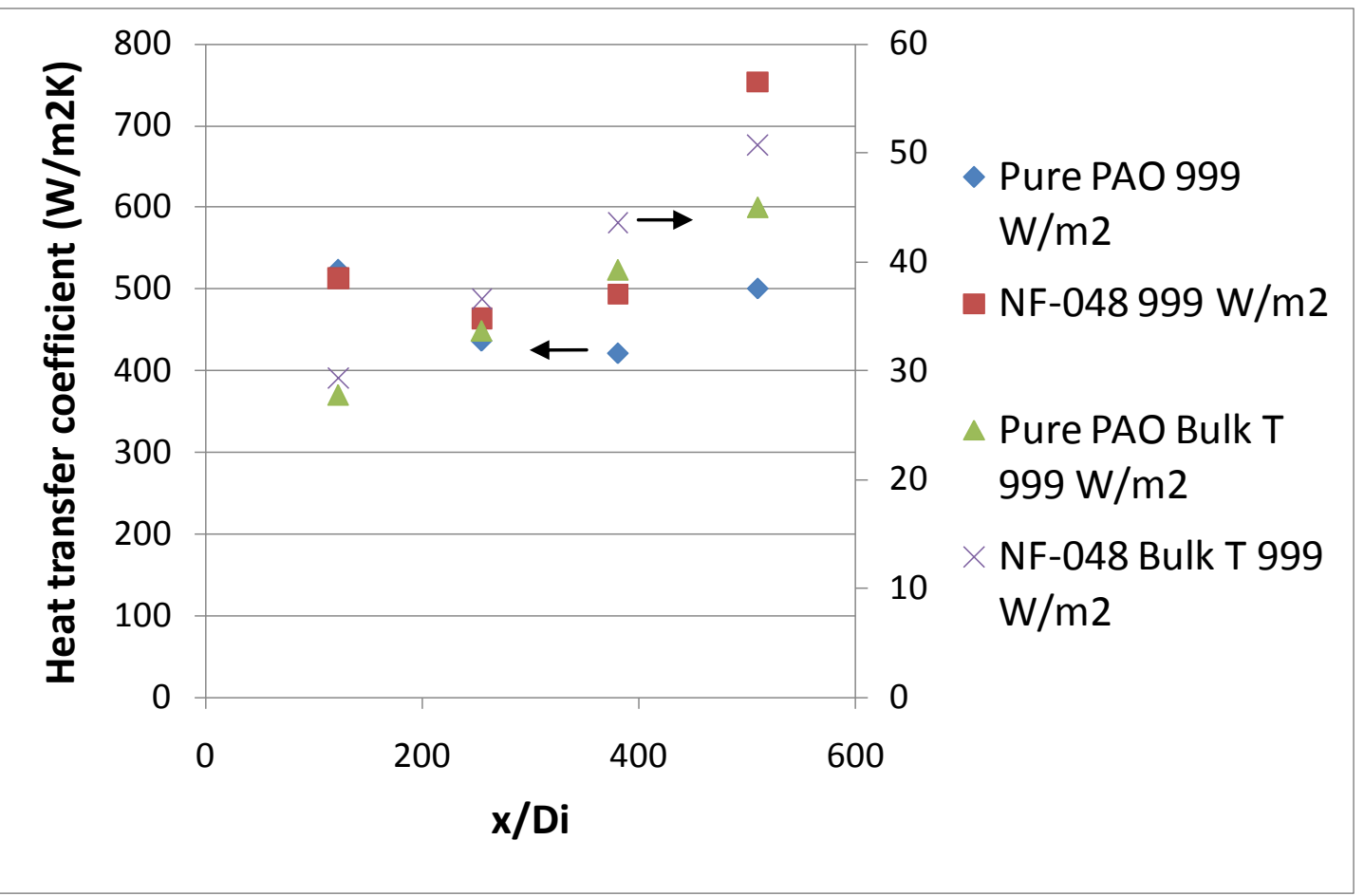

Fig. 43 The comparison of heat transfer coefficient of pure PAO and NF-048 at $62.5 \mathrm{~V}$

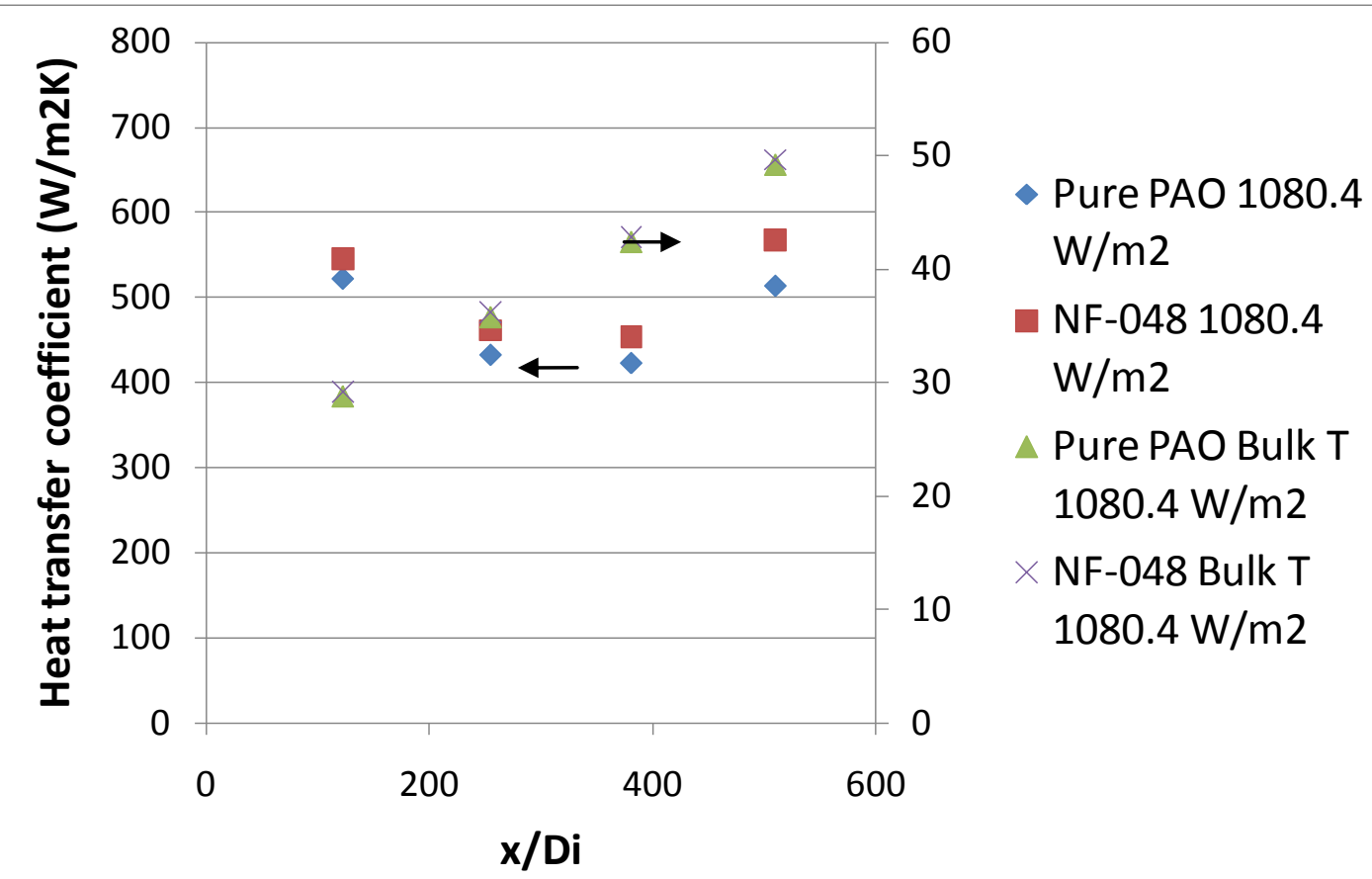

Fig. 44 The comparison of heat transfer coefficient of pure PAO and NF-048 at 65 
Figures 42 and 43 indicate that mass flow rate might not be the important factor in determining heat transfer coefficient as previously discussed. NF-048 especially shows a sharp increase in heat transfer behavior. Pure PAO has the same behavior but it does not increase as much like NF-048. The bulk temperatures linearly increase with increase in the axial distance both for pure PAO and NF-048 indicating adequate energy balance for all the fluids that were tested. Figures 45 and 46 exhibit the percentage enhancement in heat transfer coefficient as function of axial distance and bulk temperature, respectively.

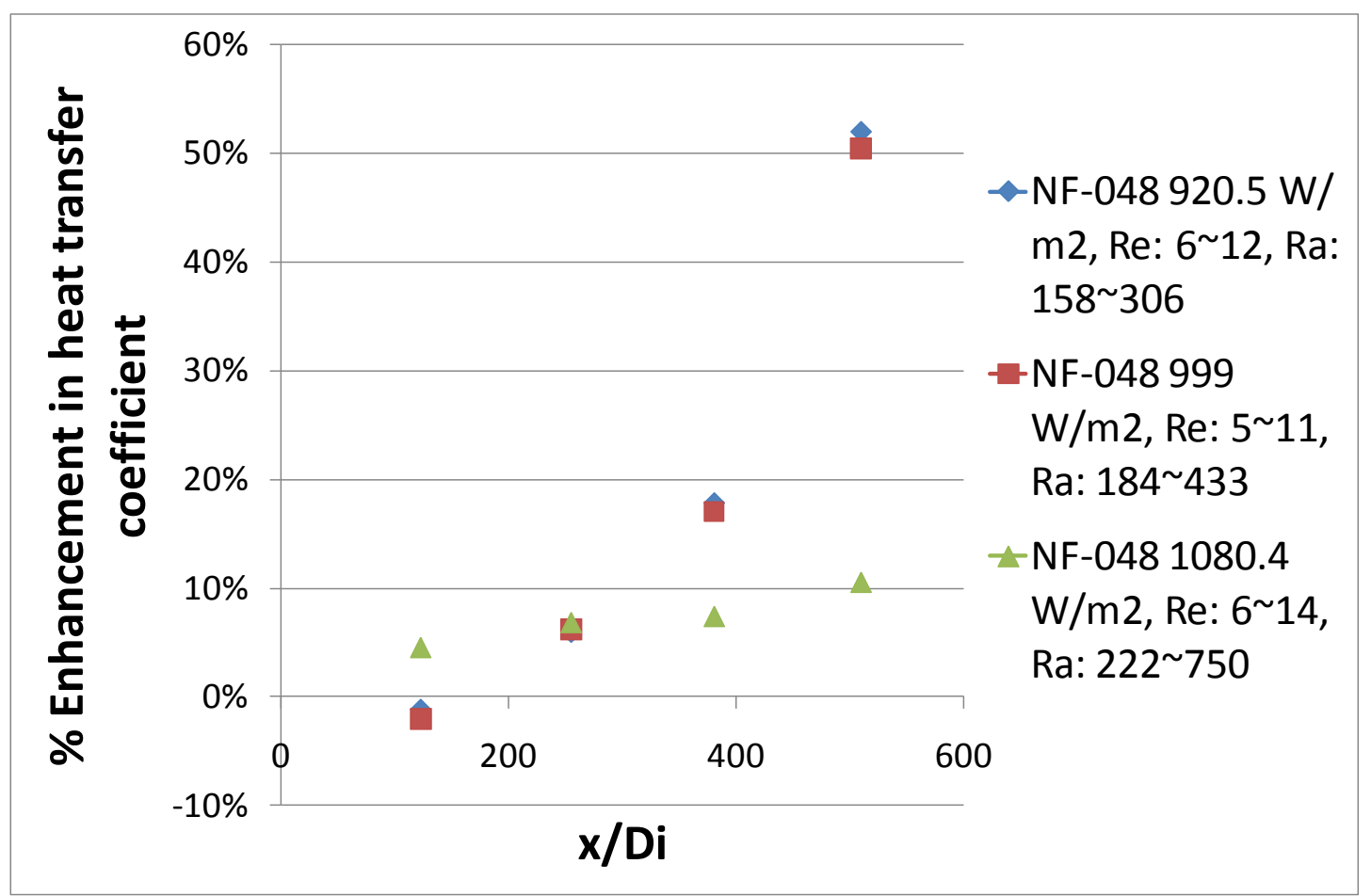

Fig. 45 The percentage enhancement of heat transfer coefficient of NF-048 with axial distance 


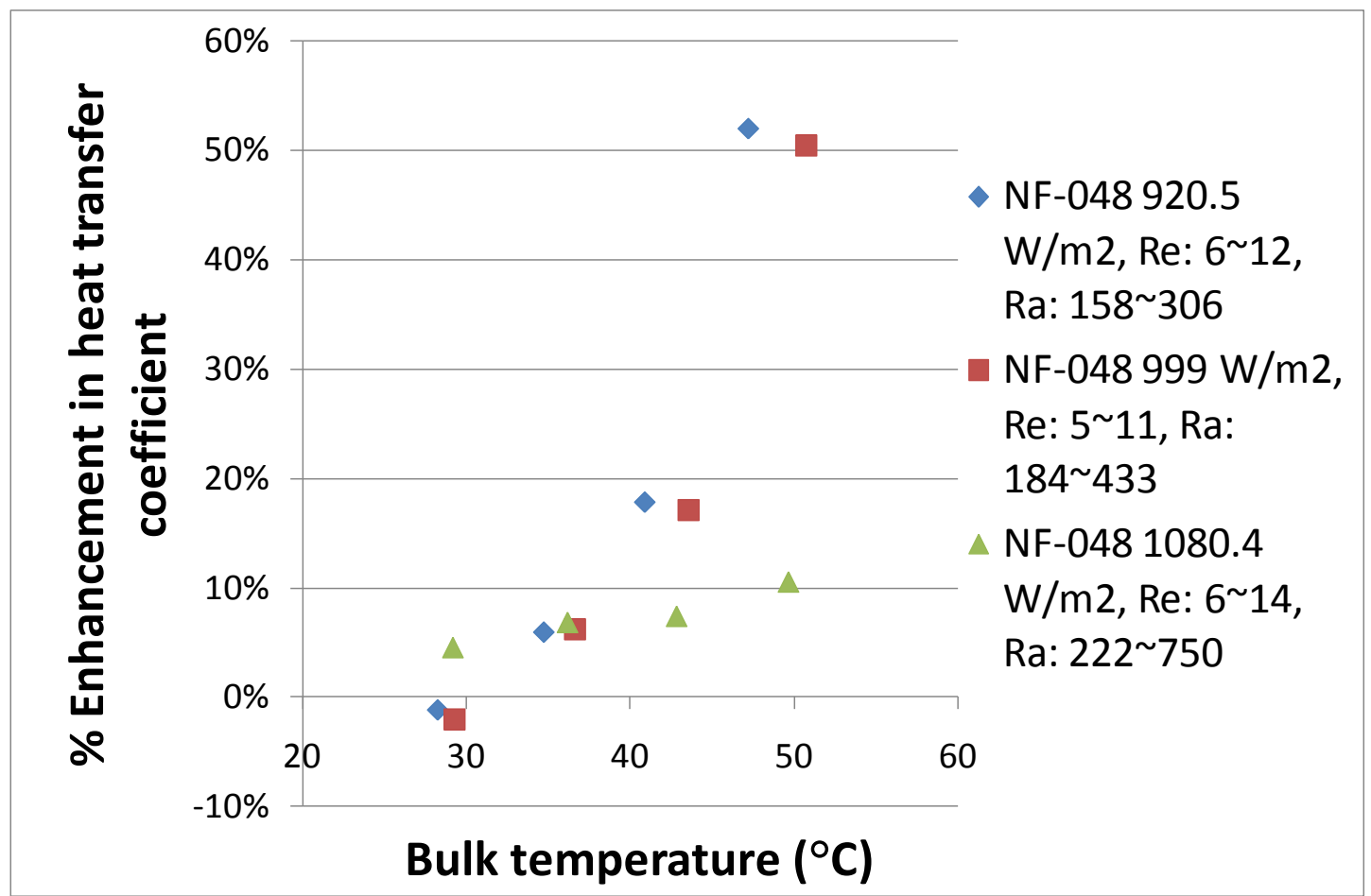

Fig. 46 The percentage enhancement of heat transfer coefficient of NF-048 with bulk temperature

The effect of axial conduction in a flowing fluid with Reynolds number range between 5-20 and Prandtl number range of 50-90 seemed to have contributed to higher heat transfer coefficient values both in pure PAO and NF-048. Normally axial conduction is negligible compared to axial convection. However, axial conduction cannot be disregarded for fluids having a low Prandtl number and low Reynolds number [51]. Moreover, when the Peclet number decreases, the effect of axial conduction became more significant. On the other hand, it was found that NF-048 had lower Peclet number than pure PAO. 
Nevertheless, the heat transfer data suggest that axial heat conduction was not the only mechanism responsible for high heat transfer coefficient when $\mathrm{x} / \mathrm{D}$ was greater than 400 as discussed below.

The relationship between relative Peclet number and the axial distance is shown in Figure 47. From the figure it can be seen that the reduction in Pe of NF-048 is significant when compared to pure PAO. It is said that if the Peclet number increases, the thermal resistance across the flow decreases and it weakens the effect of axial conduction [52]. It was concluded that the increase in heat transfer coefficient for both pure $\mathrm{PAO}$ and $\mathrm{NF}-048$ after $\mathrm{x} / \mathrm{D}=400$ could be attributed in part to axial conduction. However, Nusselt number of NF-048 depends more on Peclet number than pure PAO. Figure 48 shows the relationship between Nusselt number and Peclet number for all cases. NF-048 shows greater sensitivity to Peclet number than that of pure PAO. Therefore, Peclet number alone could not be used to explain the enhancement in heat transfer coefficient. 


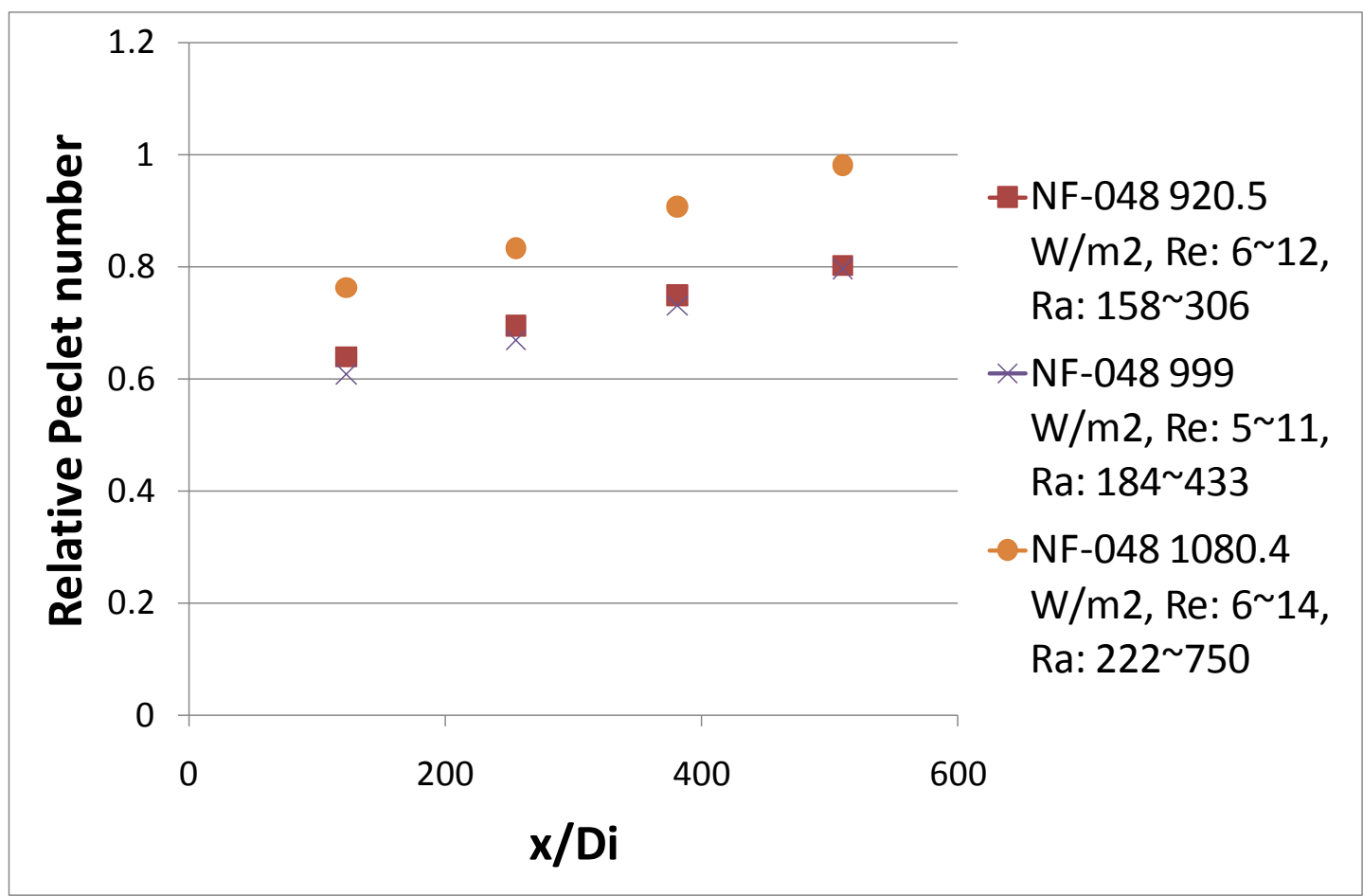

Fig. 47 The variation of relative Peclet number with axial distance 


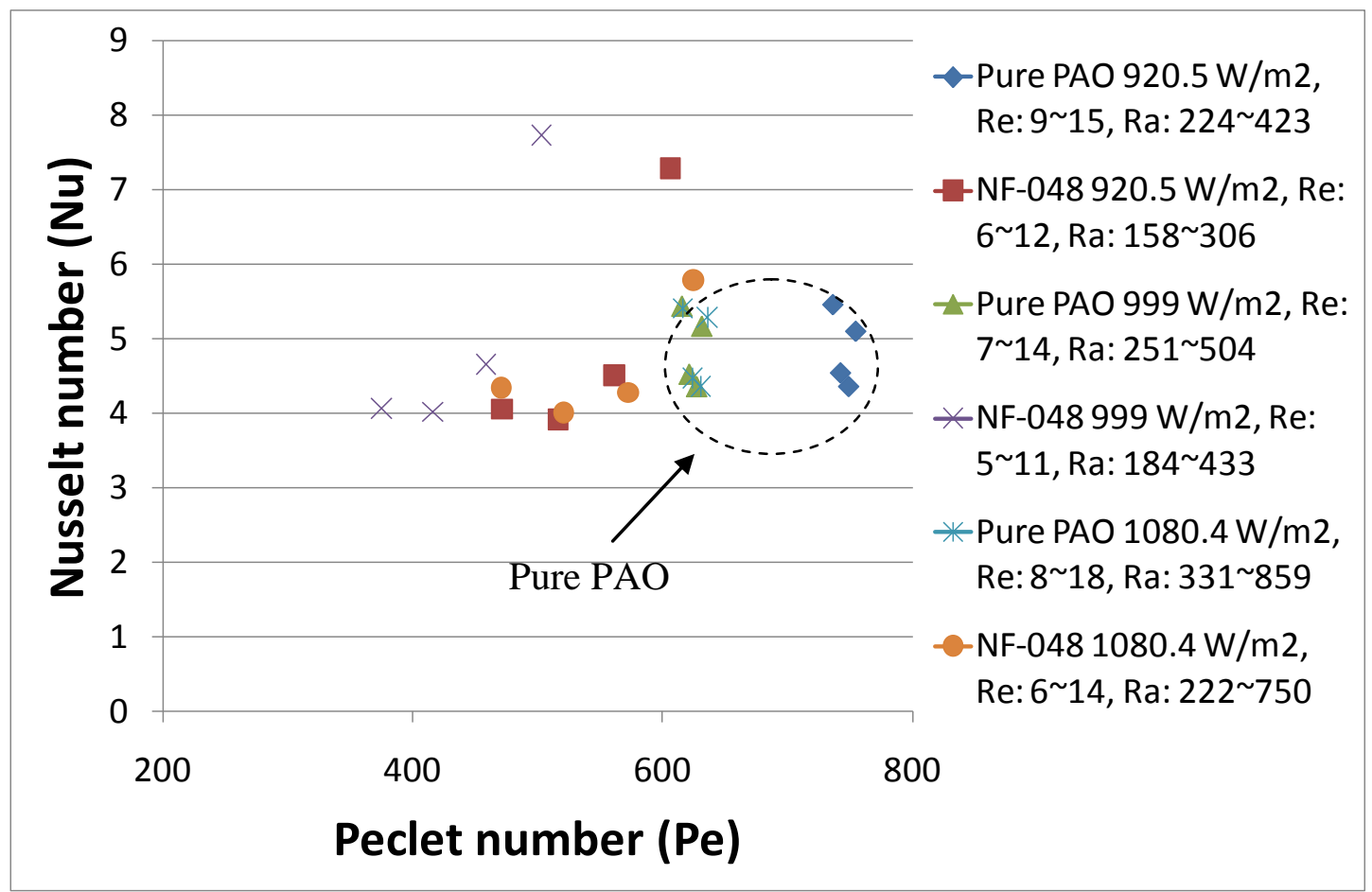

Fig. 48 The variation of Nusselt number depending on Peclet number

Figure 49 exhibits how Nusselt number increases with axial distance after $x / D_{i}$ of 400. Similar behavior has been observed for pure liquids in low Reynolds and high Rayleigh number applications $[49,50]$. 


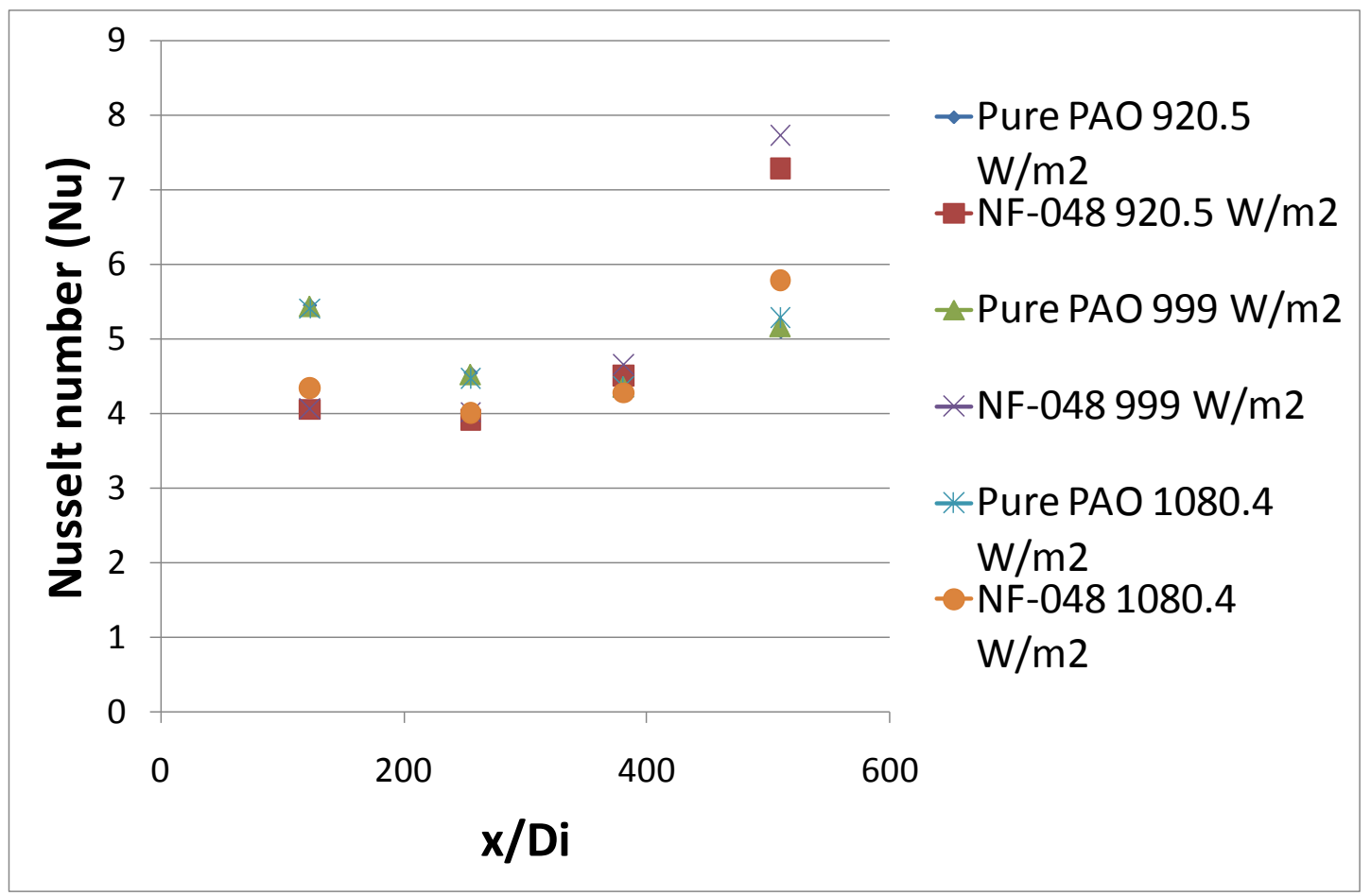

Fig. 49 The variation of Nusselt number depending on axial distance

Past studies have also revealed that at high Prandtl and low Reynolds number could induce formation of secondary flows resulting in higher heat transfer within the heat transfer section $[49,50]$. Secondary flows appear when natural convection becomes more significant.

Another possible enhancement mechanism is the onset of natural convection as a significant mode of heat transfer. With low Reynolds number, natural convection seemed to have a significant effect on the heat transfer performance [49]. As the difference in surface and bulk temperature increases, free convection becomes significant and $\mathrm{Nu}_{\mathrm{x}}$ starts increasing with $\mathrm{Z}^{+}$since the effect of free convection becomes stronger at slower flows [49]. $\mathrm{Z}^{+}$is defined as: 


$$
Z^{+}=\frac{x}{D_{i}(\operatorname{Re} \operatorname{Pr})}
$$

Figure 50 depicts how Nusselt number changes with $\mathrm{Z}^{+}$.

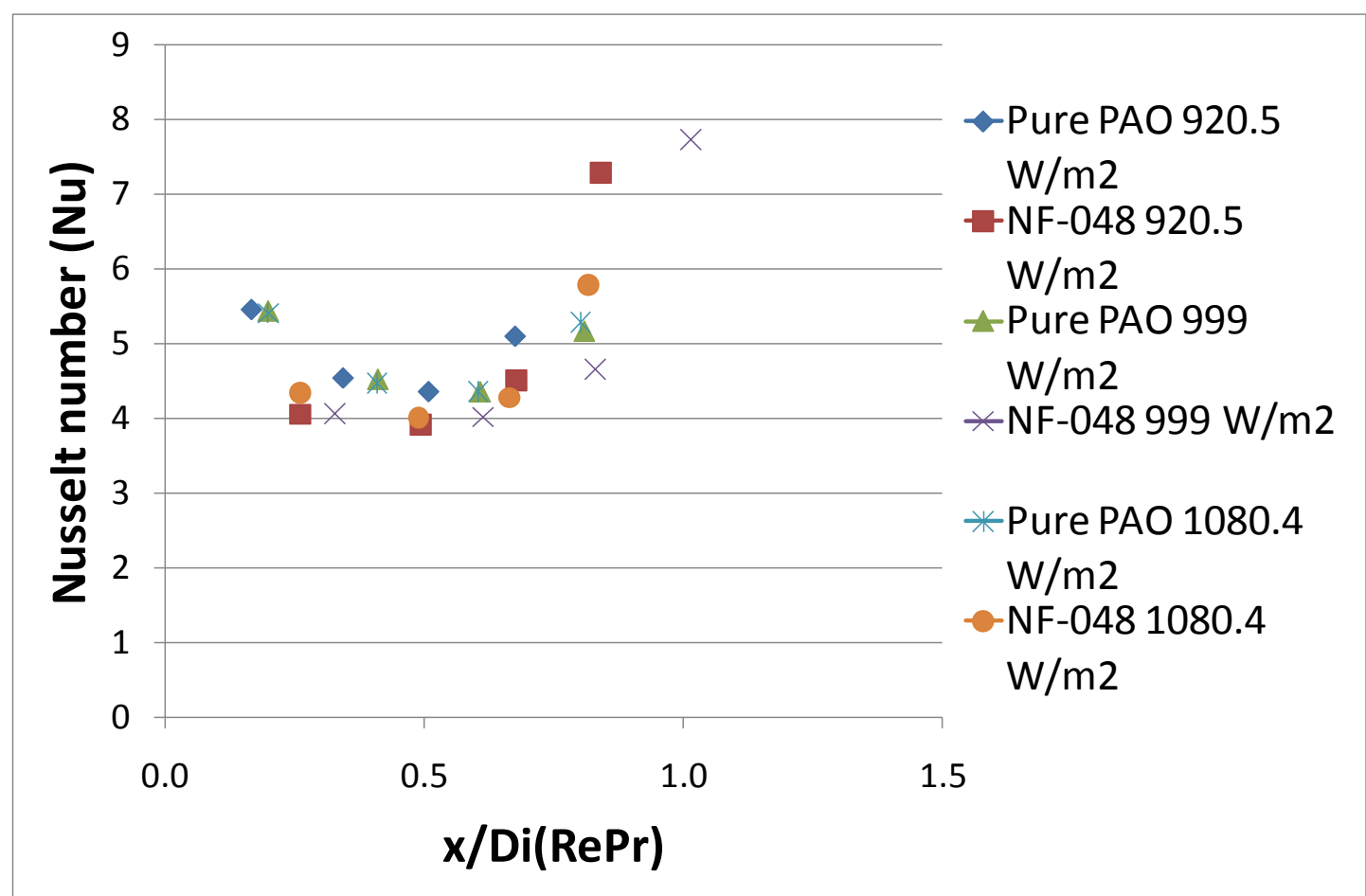

Fig. 50 The variation of Nusselt number along heat transfer section

The effects of the entrance sections lengths and heating on the free and forced convection was investigated in [49]. As seen in Figure 13 of [49], when Reynolds number is about $400, \mathrm{Z}^{+}$is around 0.1 , which corresponds to the point $\left(\mathrm{Z}^{+}{ }_{\min }\right)$ where Nusselt number starts increasing with $\mathrm{Z}^{+}$. Moreover, as Reynolds number increases, $\mathrm{Z}^{+}{ }_{\text {min }}$ decreases. This is consistent with the result shown in Figure 50 where $\mathrm{Z}^{+}$min has a 
value of about 0.5 where Nusselt number reaches a minimum. Even though laminar air flows were used in their study [49], the analysis was useful in that it considered both free and forced convection. Similar trends had been found in another study [50]. At Figure 3 of [50], a $\mathrm{Z}^{+}{ }_{\min }$ value of 0.0112 resulted in a minimum Nusselt number which is consistent with Figure 50. At $\mathrm{Z}^{+}{ }_{\text {min }}, \mathrm{Gr} / \mathrm{Re}^{2}$ was also calculated to see the extent of free convection in [50] and it was about 0.0018. In our study, $\mathrm{Gr} / \mathrm{Re}^{2}$ was in the range of between $0.03 \sim 0.1$ indicating that natural convection is an important heat transfer mechanism affecting both pure PAO and NF-048. A previous study [49] also indicated that at low Reynolds number and high heat flux, the effect of secondary flow could make free convection superior to forced convection. In other words, as heat flux increases, the fluid temperature near the wall becomes warmer and lighter than the bulk fluid in the core and also temperature-induced vortices helped transfer more heat from the surface resulting in lower surface temperature [49]. Nonetheless, Kupper et al. [50] found that as Grashof number increases, Nusselt number increases for constant Reynolds and Prandtl numbers. However, in the current, Grashof number of NF-048 was less than that of pure PAO. Therefore, the high heat transfer enhancement seen NF-048 cannot be explained by natural convection alone. Kupper et al. [50] also formulated that Nusselt number is directly proportional $\mathrm{Re}^{*} \mathrm{Ra}$ term in laminar flow under uniform heat flux conditions. In the current study, pure PAO exhibited greater Re*Ra values than in NF-048 as seen in Figure 51. Therefore, the only plausible explanation for the heat transfer enhancement seen when $x / D_{i}$ is greater than 400 , can be attributed to the combined effect of natural convection and thermal conductivity enhancement that comes from the non-spherical 
alumina nanoparticles. Moreover, the heat transfer behavior (Nusselt number) of NF048, which consists of non-spherical nanoparticles, is very sensitive to Peclet number. This also suggests that the particles could be interacting with the fluid in a way to enhance convection.

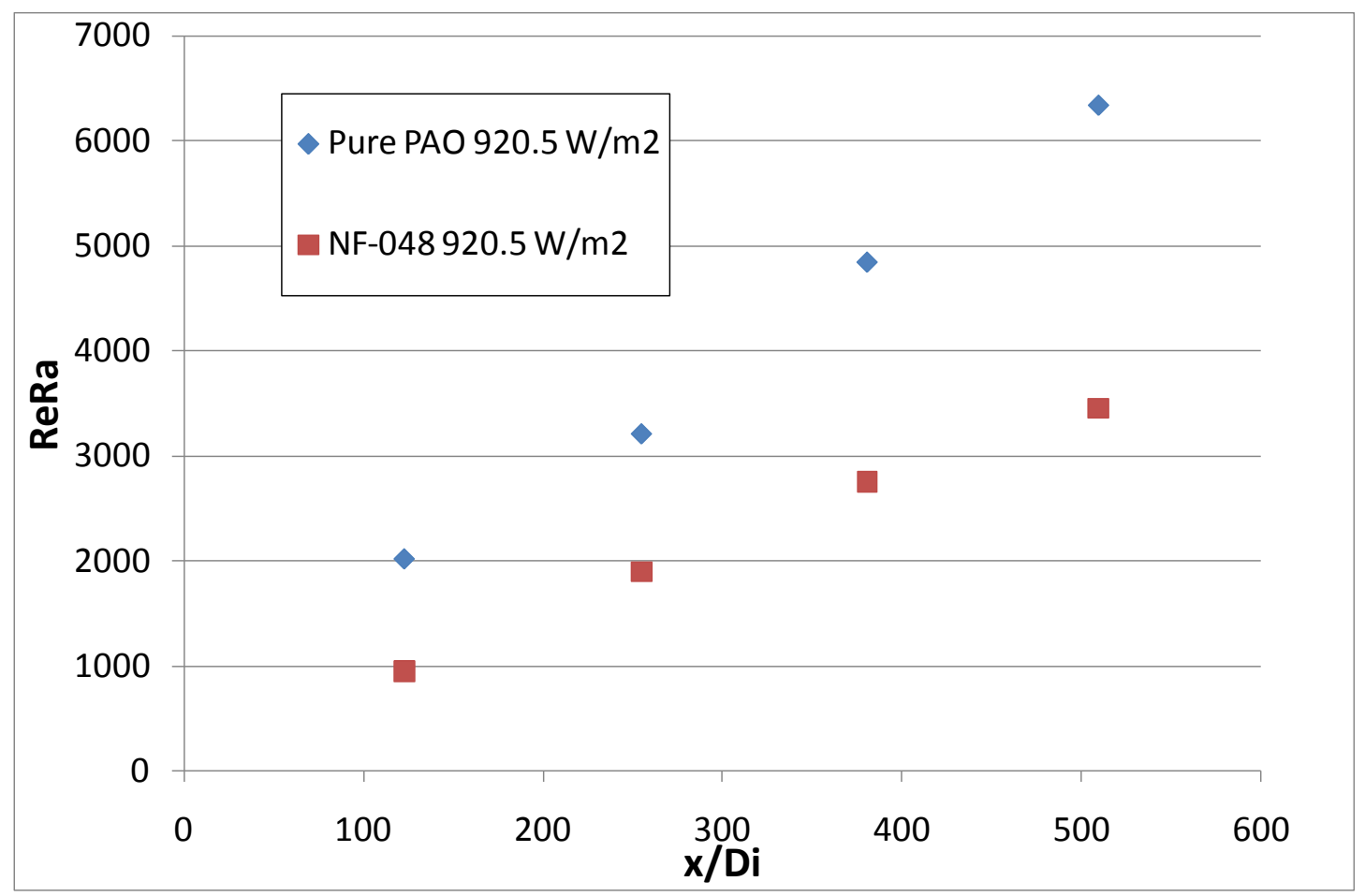

Fig. 51 The variation of ReRa with axial distance for pure PAO and NF-048 


\section{CHAPTER V}

CONCLUSIONS

In this study, the possibility of using Alumina-PAO nanofluids for heat transfer application has been examined and it was found that it is promising for the purpose. This chapter demonstrates the results obtained from imaging, viscosity, thermal conductivity, and convective heat transfer coefficient measurements. In addition, recommendations for future work are presented.

\subsection{Imaging conclusions}

From the TEM image of NF-046 and NF-048, it can be said that:

1. NF-046 and NF-048 have spherical/platelet and needle nanoparticle morphology, respectively.

2. NF-046 has smaller aspect ratio than that of NF-048.

From the Dynamic light scattering data of NF-007, NF-013 and NF-048, all nanoparticles were found to be polydispersed.

\subsection{Viscosity conclusions}

From the viscosity measurements, it can be said that: 
1. All nanofluids and base fluids show Newtonian behavior even at $4 \%$ volume fraction.

2. Shear thinning was not found to be a factor.

3. The viscosity of all nanofluids and base fluids was temperaturedependent. As temperature increases from 25 to $45^{\circ} \mathrm{C}$, the viscosity decreases by a factor of two.

4. The measured viscosity does not follow the Einstein model (Eq. 2.1) even though the volume concentration was relatively small. Particle-toparticle and particle-to-fluid interactions could be playing a significant role in viscosity.

5. Morphology also plays a role in viscosity. Greater viscosity was observed when rod-like nanoparticles were used compared to platelet type, even though the volume fraction was half of NF-046 (platelet type).

\subsection{Thermal conductivity conclusions}

From the thermal conductivity measurements, it can be said that:

1. The percentage enhancement in thermal conductivity of NF-048 is larger at $25{ }^{\circ} \mathrm{C}$ compared to that measured at $45{ }^{\circ} \mathrm{C}$ when it was measured first time. However, the trend was different when it was measured six months later. 
2. NF-048 (rod type nanoparticles) at $0.5 \%$ volume, or $2.5 \%$ by weight has a maximum thermal conductivity enhancement of $42 \%$ and $11 \%$ at 25 and $45{ }^{\circ} \mathrm{C}$, respectively. Enhancement was greater for NF-048 (rod type) than for platelet-type nanoparticles (NF-046) even when the volume fraction of NF-048 was only $0.5 \%$ (compared to $1 \%$ for NF-046, platelet)

3. The enhancement can be directly attributed to the needle nanoparticle morphology.

\subsection{Convective heat transfer conclusions}

From the convective heat transfer measurements, it can be said that:

1. As the axial distance increases from the inlet of the section, the heat transfer coefficient of nanofluids decreases first then increase again anomalously in the case of NF-048.

2. The maximum percentage enhancement in heat transfer coefficient was $52.1 \%$ and was found when using NF-048.

3. Convection and axial conduction might explain the increase in Nusselt number when $\mathrm{x} / \mathrm{D}_{\mathrm{i}}$ is greater than 400 .

4. The percentage enhancement in heat transfer coefficient (i.e. 52.1\%) was shown to be higher than the maximum enhancement in thermal conductivity (i.e. $42 \%$ ). The non-spherical nanoparticles under laminar 
flow conditions might have caused convection effects in the fluid since they exhibited a strong dependence on Peclet number. Furthermore, radial movement of nanoparticles within the fluid could have enhanced convection due to changes in viscosity and the effect of buoyancy at lower Reynolds number.

\subsection{Recommendations for future work}

In this study, the possibility of using Alumina-PAO nanofluid for heat transfer performance has been investigated. It was found that NF-048 could enhance heat transfer compared to the base fluid. However, some results still need to be studied in more depth. The thermal conductivity enhancement varies with temperature but does not follow the conventional model accurately. It is still not understood what nanoscale mechanisms are involved and how much the effect of those mechanisms play in thermal conductivity enhancement.

A real time computer simulation would help analyzing the heat transfer behavior of nanofluids. The different flow conditions including laminar, transition, and turbulent flow cases should be also considered for better understanding of Alumina-PAO nanofluid as heat transfer fluids.

Finally, there are still some discrepancies among the result published by a variety of nanofluid research groups. The standardization in manufacturing and testing of nanofluids should improve the reliability of any nanofluid study. The optimization of 
procedures through the interaction between industry and academy makes it possible to manufacture more practical and cost effective nanofluids. 


\section{REFERENCES}

[1] Buongiorno, J., Venerus, D. C., Prabhat, N., McKrell, T., and Townsend, J., 2009, "A Benchmark Study on the Thermal Conductivity of Nanofluids," J. Appl. Phys., 106, pp. 094312-1 14.

[2] Schmidt, A. J., Chiesa, M., Torchinsky, D. H., Johnson, J. A., and Boustani, A., 2008, "Experimental Investigation of Nanofluid Shear and Longitudinal Viscosities," Appl. Phys. Lett., 92, pp. 244107-1 3.

[3] Schmidt, A. J., Chiesa, M., Torchinsky, D. H., Johnson, J. A., and Nelson, K. A., 2008, "Thermal Conductivity of Nanoparticle Suspensions in Insulating Media Measured with a Transient Optical Grating and a Hotwire," J. Appl. Phys., 103, pp. 083529-1 5.

[4] Hamilton, R. L., and Crosser, O. K., 1962, "Thermal Conductivity of Heterogeneous Two-Component Systems," Industrial \& Engineering Chemistry Fundamentals, 1, pp. 187-191.

[5] Chiesa, M., and Das, S. K., 2009, "Experimental Investigation of the Dielectric and Cooling Performance of Colloidal Suspensions in Insulating Media," Colloids and Surfaces A: Physicochem. Eng. Aspects, 335, pp. 88-97.

[6] Zhou, S. Q., Ni, R., and Funfschilling, D., 2010, "Effects of Shear Rate and Temperature on Viscosity of Alumina Polyalphaolefins Nanofluids," J. Appl. Phys., 107, pp. 054317-1 6.

[7] Heris, S. Z., Esfahany, M. N., and Etemad, S. Gh., 2007, "Experimental 
Investigation of Convective Heat Transfer of $\mathrm{Al}_{2} \mathrm{O}_{3} /$ water Nanofluid in Circular

Tube," Int. J. Heat Fluid Flow, 28, pp. 203-210.

[8] Fischer, M., Juric, D., and Poulikakos, D., 2010, "Large Convective Heat Transfer Enhancement in Microchannels with a Train of Coflowing Immiscible or Colloidal Droplets," ASME J. Heat Transfer, 132, pp. 112402-1 10.

[9] Li, C. H., and Peterson, G. P., 2006, "Experimental Investigation of Temperature and Volume Fraction Variations on the Effective Thermal Conductivity of Nanoparticle Suspensions (nanofluids)," J. Appl. Phys., 99, pp. 084314-1 8.

[10] Zhang, X., Gu, H., and Fujii, M., 2007, "Effective Thermal Conductivity and Thermal Diffusivity of Nanofluids Containing Spherical and Cylindrical Nanoparticles," Experimental Thermal and Fluid Science, 31, pp. 593-599.

[11] Nguyen, C. T., Desgranges, F., Galanis, N., Roy, G., and Mare, T., 2008, "Viscosity Data for $\mathrm{Al}_{2} \mathrm{O}_{3}$-water Nanofluid--hysteresis: Is Heat Transfer Enhancement Using Nanofluids Reliable?," Int. J. Thermal Sciences, 47, pp. 103111.

[12] Tavman, I.and Turgut, A., 2010, "An Investigation on Thermal Conductivity and Viscosity of Water Based Nanofluids," in Microfluidics Based Microsystems, 0, S. Kakaç, et al., eds.,: Springer, Netherlands, pp. 139-162.

[13] Chandrasekar, M., Suresh, S., and Bose, A. C., 2010, "Experimental Investigations and Theoretical Determination of Thermal Conductivity and Viscosity of $\mathrm{Al}_{2} \mathrm{O}_{3}$ /water Nanofluid," Experimental Thermal and Fluid Science, 34, pp. 210-216. 
[14] Beck, M. P., Yuan, Y., Warrier, P., and Teja, A. S., 2009, "The Effect of Particle Size on the Thermal Conductivity of Alumina Nanofluids," J. Nanopart Res., 11, pp. 1129-1136.

[15] Yu, W., and Choi, S. U. S., 2003, "The Role of Interfacial Layers in the Enhanced Thermal Conductivity of Nanofluids: A Renovated Maxwell Model," J. Nanopart Res., 5, pp. 167-171.

[16] Timofeeva, E. V., Gavrilov, A. N., McCloskey, J. M., and Tolmachev, Y. V., 2007, "Thermal Conductivity and Particle Agglomeration in Alumina Nanofluids: Experiment and Theory," Phys. Rev. E, 76, p. 061203-1 16.

[17] Kumar, D. H., Patel, H. E., Kumar, V. R. R., Sundararajan, T., and Pradeep, T., 2004, "Model for Heat Conduction in Nanofluids," Phys. Rev. Lett., 93, p. 144301-1 4.

[18] Chon, C. H., Kihm, K. D., Lee, S. P., and Choi, S. U. S., 2005, "Empirical Correlation Finding the Role of Temperature and Particle Size for Nanofluid $\left(\mathrm{Al}_{2} \mathrm{O}_{3}\right)$ Thermal Conductivity Enhancement," Appl. Phys. Lett., 87, p. 1531071 3.

[19] Prasher, R., Bhattacharya, P., and Phelan, P. E., 2005, "Thermal Conductivity of Nanoscale Colloidal Solutions (Nanofluids)," Phys. Rev. Lett., 94, p. 025901$1 \sim 4$.

[20] Xie, H., Fujii, M., and Zhang, X., 2005, "Effect of Interfacial Nanolayer on the Effective Thermal Conductivity of Nanoparticle-Fluid Mixture," Int. J. Heat Mass Transfer , 48, pp. 2926-2932. 
[21] Xue, L., Keblinski, P., Phillpot, S. R., Choi, S. U. S., and Eastman, J. A., 2004, "Effect of Liquid Layering at the Liquid-Solid Interface on Thermal Transport," Int. J. Heat Mass Transfer, 47, pp. 4277-4284.

[22] Das, S. K., Putra, N., Thiesen, P., and Wilfried, R., 2003, "Temperature Dependence of Thermal Conductivity Enhancement for Nanofluids," ASME J. Heat Transfer, 125, pp. 567-574.

[23] Wen, D., and Ding, Y., 2004, "Experimental Investigation into Convective Heat Transfer of Nanofluids at the Entrance Region under Laminar Flow Conditions," Int. J. Heat Mass Transfer, 47, pp. 5181-5188.

[24] Shaikh, S., Lafdi, K., and Ponnappan, R., 2007, "Thermal Conductivity Improvement in Carbon Nanoparticle Doped PAO Oil: An Experimental Study," J. Appl. Phys., 101, p. 064302-1 7.

[25] Hong, H., Thomas, D., Waynick, A., Yu, W., and Smith, P., 2010, "Carbon Nanotube Grease with Enhanced Thermal and Electrical Conductivities," J. Nanopart Res., 12, pp. 529-535.

[26] Hwang, Y., Park, H. S., Lee, J. K., and Jung, W. H., 2006, "Thermal Conductivity and Lubrication Characteristics of Nanofluids," Current Applied Physics, 6, pp. e67-e71.

[27] Choi, S. U. S., Zhang, Z. G., Yu, W., Lockwood, F. E., and Grulke, E. A., 2001, "Anomalous Thermal Conductivity Enhancement in Nanotube Suspensions," Appl. Phys. Lett., 79, pp. 2252-2254.

[28] Yang, Y., Grulke, E. A., Zhang, Z. G., and Wu, G., 2006, "Thermal and 
Rheological Properties of Carbon Nanotube-in-Oil Dispersions," J. Appl. Phys., 99, p. 114307-1 8.

[29] Singh, A. K., 2008, "Thermal Conductivity of Nanofluids," Defence Science Journal, 58, pp. 600-607.

[30] Xue, Q.-Z., 2003, "Model for Effective Thermal Conductivity of Nanofluids," Phys. Lett. A, 307, pp. 313-317.

[31] Nan, C. W., Birringer, R., Clarke, D.R., and Gleiter, H., 1997, "Effective Thermal Conductivity of Particulate Composites with Interfacial Thermal Resistance," J. Appl. Phys., 81(10), pp. 6692-6699.

[32] Keblinski, P., Phillpot, S. R., Choi, S. U. S., and Eastman, J. A., 2002, "Mechanisms of Heat Flow in Suspensions of Nano-sized Particles (Nanofluids)," Int. J. Heat Mass Transfer, 45, pp. 855-863.

[33] Özerinç, S., Kakaç, S., and Yazicioğlu, A. G., 2010, "Enhanced Thermal Conductivity of Nanofluids: A State-of-the-Art Review," Microfluid. Nanofluid., 8, pp. $145-170$.

[34] Prasher, R., Phelan, P. E., and Bhattacharya, P., 2006, "Effect of Aggregation Kinetics on the Thermal Conductivity of Nanoscale Colloidal Solutions (Nanofluid)," Nano Letters, 6, pp. 1529-1534.

[35] Sommers, A. D., and Yerkes, K. L., 2010, "Experimental Investigation into the Convective Heat Transfer and System-Level Effects of $\mathrm{Al}_{2} \mathrm{O}_{3}$-propanol Nanofluid," J. Nanopart Res., 12, pp. 1003-1014.

[36] Bhattacharya, D. K., and Bhakat, P., 1997, "Dark-Field Contrast of Elements in 
High-Voltage Electron Microscopy," Japanese J. Appl. Phys., 36, pp. 2918-2921.

McNeil-Watson, F., Tscharnuter, W., and Miller, J., 1998, "A New Instrument

for the Measurement of Very Small Electrophoretic Mobilities using Phase Analysis Light Scattering (PALS)," Colloids and Surfaces A: Physicochemical and Engineering Aspects, 140, pp. 53-57.

[38] Haskell, K. H., and Hanson, R. J., 1981, "An Algorithm for Linear Least Squares Problems with Equality and Nonnegativity Constraints," Mathematical Programming, 21, pp. 98-118.

[39] Edward, J. T., 1970, "Molecular Volumes and the Stokes-Einstein Equation," Journal of Chemical Education, 47, pp. 261-270.

[40] Nagasaka, Y. and Nagashima, A., 1981, "Absolute Measurement of the Thermal Conductivity of Electrically Conducting Liquids by the Transient Hot-Wire Method" J. Phys. E: Sci. Instrum., 14, pp. 1435-1440.

[41] Lee, S., Choi, S. U. S., Li, S., and Eastman, J. A., 1999, "Measuring Thermal Conductivity of Fluids Containing Oxide Nanoparticles," ASME J. Heat Transfer, 121, pp. 280-289.

[42] Buongiorno, J., 2006, "Convective Transport in Nanofluids," ASME J. Heat Transfer, 128, pp. 240-250.

[43] Zhou, S. Q., and Ni, R., 2008, "Measurement of the Specific Heat Capacity of Water-based $\mathrm{Al}_{2} \mathrm{O}_{3}$ Nanofluid," Appl. Phys. Lett., 92, p. 093123-1 3.

[44] Sleiti, A. K., and Kapat, J. S., 2006, "An Experimental Investigation of Liquid Jet Impingement and Single-phase Spray Cooling using Polyalphaolefin," Exp. Heat 
Transfer, 19, p. 149.

[45] Herrera, M., Ramasse, Q. M., Morgan, D. G., Gonzalez, D., and Pizarro, J., 2009, "Atomic Scale High-angle Annular Dark Field STEM Analysis of the N Configuration in Dilute Nitrides of GaAs," Physical Review B, 80, p. 125211$1 \sim 11$

[46] Koppel, D. E., 1972, "Analysis of Macromolecular Polydispersity in Intensity Correlation Spectroscopy: The Method of Cumulants," J. Chem. Phys., 57, pp. 4814-4820.

[47] Zhu, X., Shen, J., Liu, W., Sun, X., and Wang, Y., 2010, "Nonnegative Leastsquares Truncated Singular Value Decomposition to Particle Size Distribution Inversion from Dynamic Light Scattering Data," Appl. Opt. 49, pp. 6591-6596.

[48] Merker, R. L., and Scott, M. J., 1964, "The Einstein Viscosity-Concentration Relationship-Application to True Solutions of the Large Spherical Molecule Tetrakis (Trimethylsilyl) Methane," Journal of Colloid Science, 19, pp. 245-251.

[49] Mohammed, H. A., and Salman, Y. K., 2007, "The Effects of Different Entrance Sections Lengths and Heating on Free and Forced Convective Heat Transfer inside a Horizontal Circular Tube," International Communications in Heat and Mass Transfer, 34, pp. 769-784.

[50] Kupper, A., Hauptmann, E. G., and Iqbal, M., 1969, "Combined Free and Forced Convection in a Horizontal Tube under Uniform Heat Flux," Solar Energy, 12, pp. 439-446.

[51] Vick, B., Özişik, M. N., and Ullrich, D. F., 1983, "Effects of Axial Conduction in 
Laminar Tube Flow with Convective Boundaries," Journal of the Franklin Institute, 316, pp. 159-173.

[52] Davis, E. J., and Gill, W. N., 1970, "The Effects of Axial Conduction in the Wall on Heat Transfer with Laminar Flow," Int. J. Heat Mass Transfer, 13, pp. 459470.

[53] Abu-Nada, E., 2009, "Effects of Variable Viscosity and Thermal Conductivity of $\mathrm{Al}_{2} \mathrm{O}_{3}$-water Nanofluid on Heat Transfer Enhancement in Natural Convection," Int. J. Heat Fluid Flow, 30, pp. 679-690.

[54] Choi, S. U. S., 2009, "Nanofluids: From Vision to Reality Through Research," ASME J. Heat Transfer, 131, p. 033106-1 9.

[55] Beck, M. P., Yuan, Y., Warrier, P., and Teja, A. S., 2010, "The Thermal Conductivity of Alumina Nanofluids in Water, Ethylene Glycol, and Ethylene Glycol + Water Mixtures," J. Nanopart Res., 12, pp. 1469-1477.

[56] Murshed, S. M. S., Leong, K. C., and Yang, C., 2008, "Investigations of Thermal Conductivity and Viscosity of Nanofluids," Int. J. Thermal Sciences, 47, pp. 560568.

[57] Tillman, P., and Hill, J. M., 2007, "Modelling the Thermal Conductivity of Nanofluids," in IUTAM Symposium on Mechanical Behavior and MicroMechanics of Nanostructured Materials, 144, Y. L. Bai, et al., eds.,: Springer, Netherlands, pp. 105-118.

[58] Yu, W., and Choi, S. U. S., 2004, "The Role of Interfacial Layers in the Enhanced Thermal Conductivity of Nanofluids: A Renovated Hamilton-Crosser 
Model," J. Nanopart Res., 6, pp. 355-361.

[59] Xuan, Y., Li, Q., and Hu, W., 2003, "Aggregation Structure and Thermal

Conductivity of Nanofluids," AIChE Journal, 49, pp. 1038-1043.

[60] Kays, W.M. and Crawford, M.E., 1980, Convective Heat and Mass Transfer, McGraw-Hill Book Company, New York.

[61] Choy, T.C., 1999, Effective Medium Theory, Oxford University Press, UK.

[62] Campo, A., and Auguste, J.-C., 1978, "Axial Conduction in Laminar Pipe Flows with Nonlinear Wall Heat Fluxes," Int. J. Heat Mass Transfer, 21, pp. 1597-1607.

[63] Jaluria, Y., 1980, Natural Convection : Heat and Mass Transfer, Pergamon Press, New York.

[64] Mori, Y., Futagami, K., Tokuda, S., and Nakamura, M., 1966, "Forced Convective Heat Transfer in Uniformly Heated Horizontal Tubes 1st ReportExperimental Study on the Effect of Buoyancy," Int. J. Heat Mass Transfer, 9, pp. 453-463.

[65] Faris, G. N., and Viskanta, R., 1969, "An Analysis of Laminar Combined Forced and Free Convection Heat Transfer in a Horizontal Tube," Int. J. Heat Mass Transfer, 12, pp. 1295-1309.

[66] Li, X. and Shantz, D. F., 2010, "PFG NMR Investigations of Heated Tetrapropylammonium-Silica Mixtures," The Journal of Physical Chemistry C, 114, pp. 14561-14570.

[67] Bergles, A. E., and Simonds, R. R., 1971, "Combined Forced and Free Convection for Laminar Flow in Horizontal Tubes with Uniform Heat Flux," Int. 
J. Heat Mass Transfer, 14, pp. 1989-2000. 


\section{APPENDIX A}

\section{SPEED AND SHEAR RATE VALUE}

At each rotational speed, $N(\mathrm{rpm})$ of the spindle, corresponding shear rates using Eq. 3.1 have been obtained. The radius of the UL adapter, $R_{c}=13.81 \mathrm{~mm}$ and the radius of the spindle used, $R_{s p}=12.575 \mathrm{~mm}$. The values obtained have been tabulated in Table A.1.

Table A.1. Rotational speed and corresponding shear for UL Adapter and Spindle

\begin{tabular}{|c|c|}
\hline $\mathbf{N},(\mathbf{r p m})$ & Shear rate, $\left(\mathbf{s e c}^{-\mathbf{1}}\right)$ \\
\hline 10 & 12.26 \\
\hline 12 & 14.71 \\
\hline 20 & 24.52 \\
\hline 30 & 36.77 \\
\hline 50 & 61.29 \\
\hline 60 & 73.55 \\
\hline 100 & 122.58 \\
\hline
\end{tabular}




\section{APPENDIX B}

\section{CALIBRATION OF HEAT TRANSFER SECTION}

This chapter mentions about the calibration procedure for the experimental measurements of thermocouples with the theoretical temperature values. The calibrated thermocouples include two bulk temperature thermocouples $\left(\mathrm{T}_{\mathrm{b}, \mathrm{i}}\right.$ and $\left.\mathrm{T}_{\mathrm{b}, \mathrm{o}}\right)$ and four surface temperature thermocouples $\left(\mathrm{T}_{\mathrm{s}, 1}, \mathrm{~T}_{\mathrm{s}, 2}, \mathrm{~T}_{\mathrm{s}, 3}\right.$ and $\left.\mathrm{T}_{\mathrm{s}, 4}\right)$. The test fluid used for this process was pure PAO (Royco 602). The thermal properties like specific heat, thermal conductivity and viscosity of pure PAO were taken at the arithmetic mean of inlet and outlet bulk temperature. The specific heat of pure PAO was taken from paper[47] and the thermal conductivity was taken from measured value using THW method and the viscosity was also taken from measured value using viscometer.

The calibration was performed both under isothermal condition without supplied heat and under operating condition with supplied heat. At both conditions, the heat transfer section was filled with the test fluid.

\section{B.1. Calibration under isothermal conditions}

The temperature of each section of heat transfer loop has been measured under steady state conditions. Due to inherent error in the accuracy of the thermocouples, there are some discrepancies in the temperature in each thermocouple. Therefore, to guarantee that all the thermocouples have the same base value before running the heat transfer 
experiments, temperature data were calibrated under isothermal conditions. The heat transfer loop has been filled with the test fluid and has been checked to make sure there is no air inside of the loop. No heat was supplied for isothermal conditions. Then, each thermocouple data has been recorded.

Measurements were obtained for all the six thermocouples under equilibrium isothermal conditions for 3 days. At each day, ten times of test has been running. Each test included 50 scans. Therefore, the average temperature of 30 tests, total 1500 scans has been taken as:

$$
T_{\text {average }, i}=\frac{\sum_{n=1}^{30} T_{\text {measured }, i}}{30}
$$

where $i=1,2,3,4,5$ and 6 is designated to each of the six thermocouples. Based on the above values, a total mean was calculated for each of the average values of thermocouples, expressed as:

$$
T_{\text {averagetotal }}=\frac{\sum_{i=1}^{6} T_{\text {average } i}}{6}
$$

Finally, isothermal correction factors $\left(C F_{i s o}\right)$ were obtained for each of the corresponding thermocouple based on deviation from the total average, expressed as:

$$
C F_{\text {iso,i }}=T_{\text {averagetotal }}-T_{\text {average }, i}
$$


The correction factors are shown in Table B.1.

Table B.1 Isothermal correction factors for thermocouples

\begin{tabular}{|c|c|c|c|c|c|}
\hline \multicolumn{7}{|c|}{$\mathrm{CF}_{\text {iso }}$} \\
\hline $\mathrm{T}_{\mathrm{b}, \mathrm{i}}$ & $\mathrm{T}_{\mathrm{s}, 1}$ & $\mathrm{~T}_{\mathrm{s}, 2}$ & $\mathrm{~T}_{\mathrm{s}, 3}$ & $\mathrm{~T}_{\mathrm{s}, 4}$ & $\mathrm{~T}_{\mathrm{b}, \mathrm{o}}$ \\
\hline 0.33 & 0.01 & -0.05 & -0.14 & -0.13 & -0.01 \\
\hline
\end{tabular}

\section{B.2. Calibration under operating conditions}

The experimental set-up was designed by the assumption that the temperatures recorded by the surface thermocouples are same for both outside surface and inside surface of the copper tubing. However, the temperature cannot be perfectly same due to the limited thermal conductivity of thermally conductive epoxy adhesive used to mount the thermocouples on the copper tubing, imperfect insulation from the nichrome wire connection. In addition, there is a thermal resistance between the fluid and the copper tubing. The measured temperature value is supposed to be little different from the theoretical value. This difference was taken off using the correction factor under operating conditions. The heat transfer section was filled with PAO and some amount of heat was supplied to the loop and the correction factor was obtained. First, the isothermal correction factors had been applied to each thermocouple, then a series of 
calculation has been performed and the heat transfer coefficient and Nusselt number were calculated then another correction factor for heat transfer coefficient was found. Then the correction factor was applied to NF-048 as well. The steps involved are as follows:

1. The isothermally corrected temperature is defined as :

$$
T_{\text {iso }, i}=T_{\text {measured }, i}+C F_{\text {iso }, i}
$$

2. The correction factor for heat flux was already found to be 0.82 so it was applied to the original heat flux. Then the heat transfer coefficient was found for each different heat flux using the difference between isothermally corrected surface temperature and bulk temperature.

$$
h_{\text {corrected }}=\frac{q_{\text {corrected }}^{\prime \prime}}{T_{i s o, i}-T_{b, x}}
$$

3. Under the laminar forced convection flow based on the constant heat flux condition, values of local Nusselt number for each $x_{i} / D$ value were found. The method is described in [59] and uses separation of variables and Sturm-Liouville theory to obtain an eigenvalue solution in terms of an infinite series function which gives local Nusselt number. Nusselt number was almost same as 4.36 . corresponding local convective heat transfer coefficient, $h(x)$ were also found using (Eq. B.6). 


$$
h(x)=\frac{N u(x) \cdot k}{D_{i}}
$$

However, there was a siginificant difference in calculated $\mathrm{h}(\mathrm{x})$ and experimental $\mathrm{h}_{\text {corrected, }}$, so the correction factor for heat transfer coefficient was found.

4. For four surface sections, heat transfer coefficients were obtained and the value at the lowest point was assumed that it corresponds to Nusselt number of 4.36 . Backwards, the corrected heat transfer coefficient was found as well as the correction factor, $\mathrm{CF}_{\mathrm{h}}$. The lowest heat transfer coefficient values were found for each heat flux.

5. The correction factor, $\mathrm{CF}_{\mathrm{h}}$ was applied to all points and the heat transfer coefficient and Nusselt number at each section were found. Then, it was also applied to NF-048.

Table B.2 The correction factor for heat transfer coefficient at each heat flux

\begin{tabular}{|c|c|c|}
\hline \multicolumn{3}{|c|}{$\mathrm{CF}_{\mathrm{h}}$} \\
\hline $920 \mathrm{~W} / \mathrm{m}^{2}$ & $999 \mathrm{~W} / \mathrm{m}^{2}$ & $1080.4 \mathrm{~W} / \mathrm{m}^{2}$ \\
\hline 3.27 & 3.31 & 3.81 \\
\hline
\end{tabular}

Using correction factors above, the final value of heat transfer coefficient was obtained. 
$h=C F_{h}\left(h_{\text {corrected }}\right)$ 


\section{VITA}

Chan Hyun Park received his Bachelor of Science degree in mechanical engineering from Hanyang University, Korea in 2008. He entered the Mechanical Engineering Program at Texas A\&M University in September 2008 and received his Master of Science degree in mechanical engineering in May 2011. His research interests include microscale heat transfer and energy conversion.

Mr. Park can be contacted at Dept. of Mechanical Engineering MS 3123 Texas A\&M University, College Station, TX 77843-3123. His email is chpark2712@naver.com. 